\title{
Advancing public health surveillance in Europe
}

Citation for published version (APA):

Rosenkötter, N. (2017). Advancing public health surveillance in Europe. [Doctoral Thesis, Maastricht University]. Maastricht University. https://doi.org/10.26481/dis.20170212nr

Document status and date:

Published: 01/01/2017

DOI:

10.26481/dis.20170212nr

Document Version:

Publisher's PDF, also known as Version of record

Document license:

Unspecified

\section{Please check the document version of this publication:}

- A submitted manuscript is the version of the article upon submission and before peer-review. There can be important differences between the submitted version and the official published version of record.

People interested in the research are advised to contact the author for the final version of the publication, or visit the DOI to the publisher's website.

- The final author version and the galley proof are versions of the publication after peer review.

- The final published version features the final layout of the paper including the volume, issue and page numbers.

Link to publication

\footnotetext{
General rights rights.

- You may freely distribute the URL identifying the publication in the public portal. please follow below link for the End User Agreement:

www.umlib.nl/taverne-license

Take down policy

If you believe that this document breaches copyright please contact us at:

repository@maastrichtuniversity.nl

providing details and we will investigate your claim.
}

Copyright and moral rights for the publications made accessible in the public portal are retained by the authors and/or other copyright owners and it is a condition of accessing publications that users recognise and abide by the legal requirements associated with these

- Users may download and print one copy of any publication from the public portal for the purpose of private study or research.

- You may not further distribute the material or use it for any profit-making activity or commercial gain

If the publication is distributed under the terms of Article $25 \mathrm{fa}$ of the Dutch Copyright Act, indicated by the "Taverne" license above, 
ADVANCING
PUBLIC HEALTH
SURVEILLANCE
IN EUROPE

Nicole Rosenkötter 
The research for this dissertation was performed at the Department of International Health within the School for Public Health and Primary Care (CAPHRI), Faculty of Health, Medicine and Life Sciences, Maastricht University. Financial support for the analyses on syndromic surveillance was provided by the European Union under the Programme of Community Action in the Field of Public Health (2003-2008) (Grant Agreement No. 2007208).

Dissertation: Advancing Public Health Surveillance in Europe

Author: Nicole Rosenkötter

Cover Design: Evi Buschlinger, Nicole Rosenkötter

(c) Nicole Rosenkötter, 2017.

All rights served. No part of this publication may be reproduced without permission of the copyright owner.

ISBN: 978-3-00-055311-0

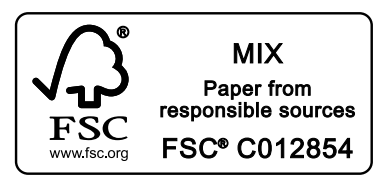

Printed by: Gildeprint - The Netherlands 


\section{ADVANCING PUBLIC HEALTH SURVEILLANCE IN EUROPE}

Dissertation

to obtain the degree of Doctor at the Maastricht University,

on the authority of the Rector Magnificus Prof. dr. Rianne Letschert, in accordance with the decision of the Board of Deans

to be defended in public

on Thursday, 23 February 2017, at 12:00 hours

by

Nicole Rosenkötter 
Supervisor

Prof. dr. Helmut Brand

\section{Co-supervisor}

Dr. Kai Michelsen

\section{Assessment Committee}

Prof. dr. Silvia Evers

Chair

Prof. dr. Maria Jansen

Dr. Marieke Verschuuren

Dr. Thomas Ziese
Robert Koch-Institute, Germany 


\section{Contents}

Introduction

7

Part 1 I Assessing the status quo 27

Chapter 1 I Achievements, failures and missed opportunities of EU health policy 29

Part 2 I "Off-label-use" of data for information and knowledge generation 59

Chapter 2 I Syndromic influenza surveillance 61

Chapter 3 I Surveillance of non-infectious events under the IHR (2005) 87

Chapter 4 I Inequalities in health care utilisation of children

Part 3 I Developing infrastructure 117

Chapter 5 I Key features of an EU health information system 119

General Discussion 141

Valorisation 165

Summary I Zusammenfassung

Acknowledgements

Curriculum Vitae 



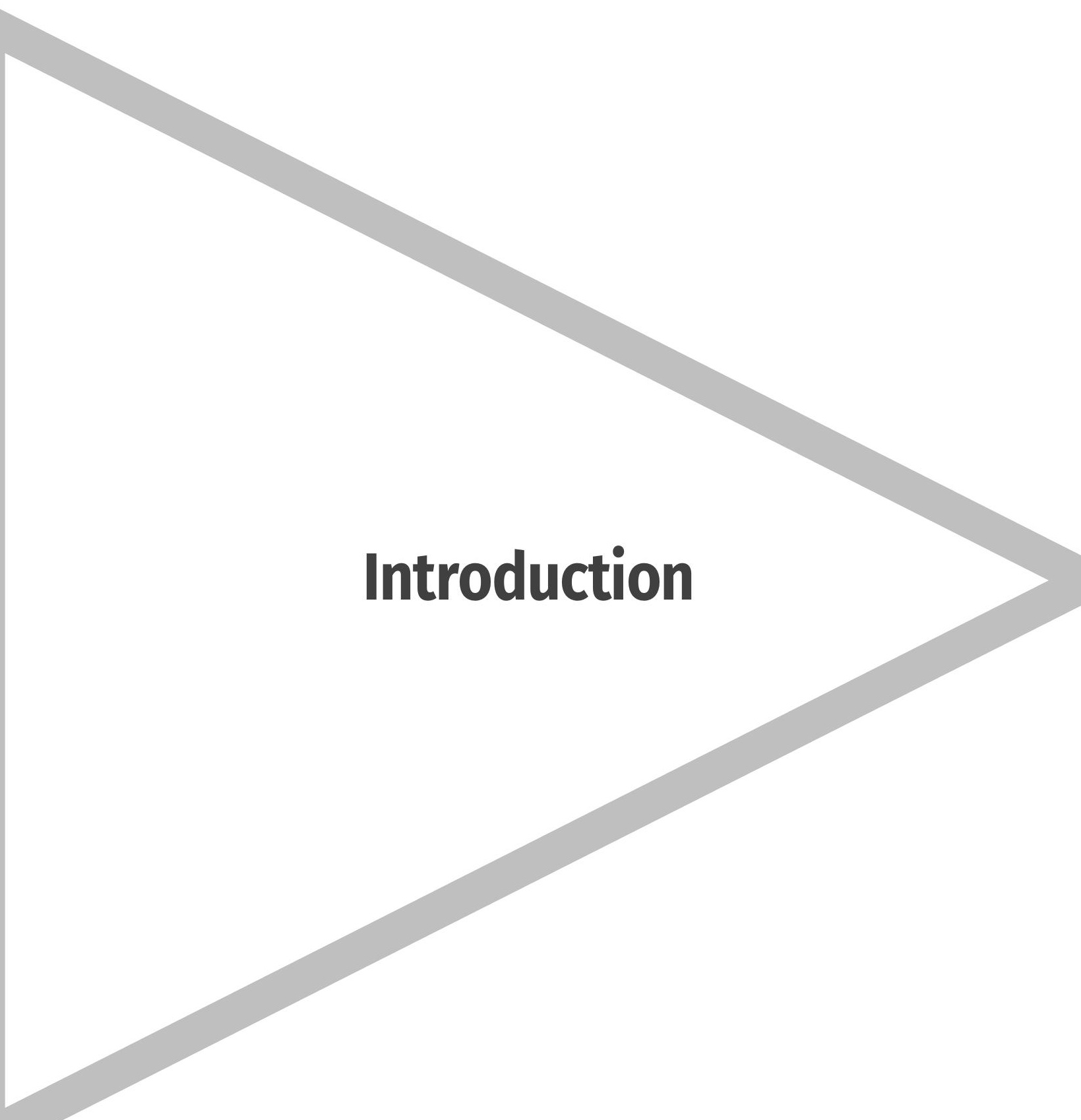




\section{Public health surveillance - a general introduction}

"[...] achieving better health for the whole population by taking the reduction of health inequalities seriously is a banner worth rallying behind. Monitoring of the health of the population, its determinants, and its distribution is central to that societal aim."

Public health surveillance makes use of sound data and information for the routine assessment of population health and health system performance. Public health surveillance systems (or health information systems) support governments and other stakeholders to act in an evidenceinformed manner when identifying health needs, adjusting (health) policy actions and allocating resources, when reacting on certain health threats, or when assessing progress with regard to certain health targets.

Public health surveillance as a corresponding activity is defined as "[...] ongoing systematic collection, analysis and interpretation of health-related data essential to the planning, implementation and evaluation of public health practice, closely integrated with the timely dissemination of these data to those who need to know so that action can be taken". ${ }^{2-5}$ Public health surveillance is regarded as an essential governmental core capacity, ${ }^{6,7}$ which entails that it is a prerequisite for good governance - a relevant governance principle also on European Union (EU) level. ${ }^{8}$

One might argue that the EU has just a supporting competence for health issues, thus, public health surveillance capacities should rather be in place on local, regional, and national level. This can be contrasted with the following aspects:

(1) According to Article 168 (1) of the Treaty of Lisbon, the EU has to assess the health impact of all EU policies and activities. ${ }^{9}$

(2) The free movement of people and goods within the European Union poses a risk for the dissemination of serious cross-border health threats and requires surveillance and control efforts on EU-level.

(3) The Open Method of Coordination is a soft law mechanism of the EU that is also applied on health. With this mechanism, it is aimed to achieve consensus on certain policy areas..$^{10}$ It includes aspects of public health surveillance, like the definition of indicators for benchmarking, monitoring and evaluation of national policies.

(4) The EU is increasingly targeting the organisation of national health services by the formulation of country specific recommendations for economic reforms within the European Semester process. ${ }^{11}$ It is therefore a principle of good governance, that EU policies and actions like 
programmes, recommendations, decisions are based and evaluated on factual data, information and knowledge derived from an EU public health surveillance system.

(5) More general, the Union of 28 member states, with unique differences in health system setup and organisation, is comparable to a natural laboratory that enables cross-country learning about effective policy actions. ${ }^{12}$

Common and agreed EU-level public health surveillance structures that enable the assessment of populations' health, health determinants, and health systems performance are needed, for identifying differences across member states and for making this valuable potential of cooperation and mutual learning accessible..$^{13,14}$

Even though the impact of public health surveillance is often difficult to prove some examples derived from EU co-funded projects depict its relevance for cross-country learning by introducing discussion, in-depth analysis and change:

- EU-wide comparisons revealed an unexpected high perinatal mortality rate in the Netherlands ${ }^{15}$ which led to discussion about information (data) available on perinatal health and improvements in prevention and perinatal care. ${ }^{16}$

- EU-wide comparisons of cancer surveillance showed low survival rates in the United Kingdom. This information led to further analyses and the implementation of a National Cancer Plan to reduce inequalities and improve care. ${ }^{17}$

In the past, the legitimation of public health surveillance was expanded in the Treaties of the European Union - from the Maastricht Treaty to the Treaty of Amsterdam and finally the Lisbon Treaty. ${ }^{9,18-20}$ Based on this legitimation, various important European Commission (EC) programmes that supported the development of common public health surveillance elements have taken place. On example is the definition of European Core Health Indicators (ECHI). But, after about twenty years of actions, a comprehensive and sustainable EU-level public health surveillance infrastructure is still missing. ${ }^{21-25}$

Therefore, it is aimed in this thesis to identify conditions and factors relevant to advance public health surveillance in Europe. The thesis is focussed on the three perspectives: EU policy (Part 1), public health surveillance data and information sources (Part 2), and EU-level public health surveillance infrastructure requirements (Part 3). To illustrate what is generally required for public health surveillance an overview of its core elements is provided first, followed by an explanation of the applied terminology in this thesis. A brief overview of past EU-level policies and actions on data and public health surveillance infrastructure as well as a derivation of existing gaps will follow later in this introduction. The introduction is completed by providing the concrete research questions of this thesis and an outline of the main chapters. 


\section{General elements and aims of public health surveillance}

Key elements in the definition of public health surveillance ${ }^{2-5}$ are the indications that public health surveillance is a routine task ("ongoing") and follows a concept ("systematic") for the "collection, analysis, and interpretation of (...) data". Furthermore, it is emphasised that public health surveillance is "essential" for "public health practice" and that the results of public health surveillance need to be disseminated to those who are responsible for taking action.-5 This latter element of the public health surveillance definition emphasises its core aim, namely to create knowledge and to support evidence-informed policy-making.

The transformation process from data to knowledge (and wisdom) is illustrated in the DataInformation-Knowledge-Wisdom-hierarchy (DIKW) ${ }^{26}$ which is usually applied as central model for information management, information systems and knowledge management, ${ }^{27}$ thus, core aspects of public health surveillance. The DIKW-hierarchy puts the single elements data-informationknowledge-wisdom into a consecutive relationship. ${ }^{27}$ Moreover, the model delivers a clear explanation of the core aspects of information systems. This thesis' sections on data and information as well as on potential infrastructure features can be directly linked to the DIKWhierarchy. The DIKW core aspects can be understood as follows:

- Data are discrete, objective facts or observations, which are unorganised and unprocessed, and do not convey any specific meaning.

- Information is organised or structured data. This processing lends the data relevance for a specific purpose or context, and thereby makes it meaningful, valuable, useful and relevant.

- Knowledge can be seen as a mix of information, understanding, capability, experience or prior knowledge, skills and values. It enables the transformation of information into recommendations or instructions. Two forms can be distinguished, explicit knowledge which derives from facts ('Know What': e.g. databases, scientific results) and tacit knowledge ('Know How') as an individual component.

- Wisdom is created by understanding and deciding about the suitable measures that could be implemented. It is the ability to act in accordance to the possibilities and boundaries of a certain situation.

Transferring these general descriptions to public health surveillance and the resources and tasks related to it, data can be understood as the raw facts stemming for example from vital statistics, disease registries, surveys or other sources. Data from these sources are transformed to health indicators like infant mortality rate, life expectancy or the rate of regular smokers (information). Thus, data are processed, often in a standardised way, to ensure comparability, validity, and reliability, to make data meaningful for a wider circle of experts. Knowledge is generated in public health surveillance by regularly monitoring health indicator development and by summarising and interpreting the results in public health reports, policy briefs, press releases, or other outputs 
suitable for dissemination to a wider audience. In this stage knowledge derived from health indicator monitoring should be augmented with information and knowledge from scientific studies, reviews, or expert advice in order to explain the monitoring results and to develop recommendations or instructions how to act on a certain situation. The derived knowledge is expected to enable decision-making (wisdom) of relevant stakeholders and policy makers regarding the extent and the design of required actions.

\section{Terminology: Monitoring vs. surveillance}

In the European context the terms surveillance and monitoring are sometimes used for different issues or are used interchangeably. The term surveillance is often used for infectious disease surveillance. Health monitoring is applied for assessing morbidity and mortality of various diseases on population level, populations' health behaviour and other health determinants. In the US the term surveillance was also originally connected exclusively to infectious diseases. ${ }^{2,28}$ This however changed during the 1970s, when the focus of the US Centers for Disease Control and Prevention was broadened to all causes of morbidity and mortality. ${ }^{28}$

The Dictionary of Epidemiology brings some clarification for distinguishing the concepts surveillance and monitoring through the notion that surveillance is continuous and ongoing while monitoring tends to be intermittent or episodic. ${ }^{4}$

When definitions for the terms surveillance and monitoring are extracted from the literature it becomes obvious that the term monitoring is used in the clinical and public health setting which leads to varying expressions and characteristics within the definitions. ${ }^{29}$ The term surveillance reaches more consistency in the expression of its characteristics by recurrently emphasising the ongoing and systematic collection of data, analysis and interpretation and the use of this data for public health action. ${ }^{29}$ Therefore, the term surveillance will be the one that is predominately used in this thesis.

\section{EU public health surveillance: policy actions, data and infrastructures}

The EU and other international bodies have worked in the past twenty years towards the development of an EU-level public health surveillance infrastructure by various policy actions, by applying funds on public health surveillance, by synthesising data and defining necessary health indicators, and by developing elements of a public health surveillance system. However, the EU public health surveillance infrastructure is still incomplete and lacks certain elements like the ongoing maintenance and further development of the data and information base, a hub that supports member states in data provision, or a routine entity that generates knowledge through 
regular monitoring and reporting of trends over time and space. In contrast to general public health surveillance, infectious disease surveillance is more advanced on EU-level (Box 1).

\section{Box 1 The status of EU-level infectious disease surveillance}

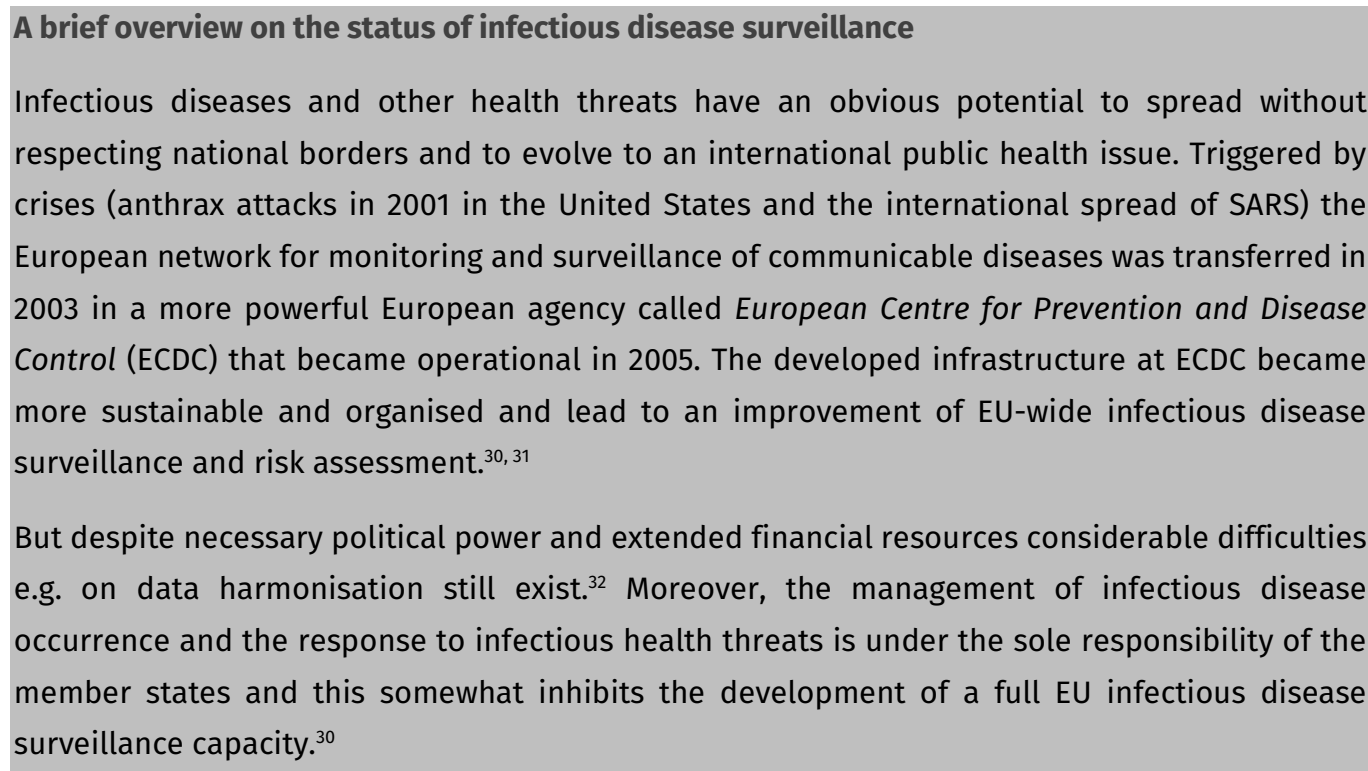

In the following a brief overview on EU-level public health surveillance policy actions, potential data and information sources for public health surveillance, and infrastructure development is given and potential gaps are derived.

\section{Policy actions}

"One of the clearest areas where the EU can add value to national efforts on health is through comparison of information and data, and synthesizing evidence and best practice." 33

Since the 1990s, the European Commission (EC) has been actively stimulating the development of an EU public health monitoring and reporting system with a multitude of EU-funded projects, networks and joint actions. ${ }^{31}$

Up to the present time, actions on public health surveillance were imbedded within the EU funding schemes starting with the Community action programme on health monitoring within the Framework of action in the field of public health (1997-2001). ${ }^{34}$ This Community action programme was focussed on three areas (1) the establishment of community health indicators, (2) the development of a community-wide network for sharing health data, (3) analysis and reporting. ${ }^{34}$ All of these actions followed the overall aim to establish a Community health monitoring system. ${ }^{34}$ Also the successor programmes, namely the first (2003-2008) $)^{35}$ and second Public health 
programme (2008-2013), ${ }^{36}$ focused on the development of infrastructures to improve the availability of health information and the generation and dissemination of knowledge for public health development and policy advice.

In order to strengthen cooperation and coordination across the EU and to complement national policies as requested in Article 168 of the Treaty of Lisbon, ${ }^{9}$ an EU health strategy was formulated in 2007. The health strategy Together for Health calls for EC action to provide a "system of European Community health indicators with common mechanisms for collection of comparable health data at all levels, including a communication on and exchange of health-related information." ${ }^{37}$ This strategy was accompanied in 2013 by the policy framework Investing in Health $^{38}$ which aims to link EU social and health policies more closely to the overall Europe 2020 strategy. ${ }^{39}$ The strategy reemphasised the relevance of working towards a public health surveillance infrastructure to be able to assess the efficiency of health systems. ${ }^{39}$ The request for policy actions to further develop public health surveillance was reiterated in the evaluation ${ }^{40}$ of the set of European Core Health Indicators (ECHI) ${ }^{1}$ and the Council Conclusions on modern, responsive and sustainable health systems. ${ }^{41}$

What needs to be investigated?

A missing comprehensive public health surveillance infrastructure is quite peculiar given the long history of programmes, strategies and actions on public health surveillance in general and for the EU's role as a platform for cross-country learning in particular. ${ }^{12}$ However, these actions were based on European Commission (EC) programmes and related EC co-funded projects, joint actions and EC expert groups. It seems that this so-called low politics route ${ }^{42}$ was too weak to put the development of sustainable public health surveillance structures and required resources effectively on the political agenda. This suggests that probably a high politics route, in which political leaders initiate action, might be more successful. ${ }^{42}$ The Council Conclusions on modern, responsive and sustainable health systems are a first step in this direction. But, how aware are various EU-level actors about achievements and existing EU-level public health surveillance gaps? To enable this high politics route, knowledge about the status of EU public health surveillance among all other EU-level public health policy actions would be needed.

\section{Data sources and information development}

"My interest is not data, it's the world. And part of world development you can see in numbers." (Hans Rosling)

Data and information are the basis for public health surveillance (see earlier section on DIKWhierarchy). In practice, much has been achieved on a technical level in the EU. During a multiphase action from 1998-2012 a set of European Core Health Indicators (ECHI) relevant for health 
monitoring and health policy-making has been defined, maintained and partly implemented. ${ }^{21,22,}$ ${ }^{24}$ The indicator set covers the areas demography and socioeconomic conditions, health status, health determinants, and health interventions (health services, health promotion). Eurostat and the national statistical offices have worked to increase both, the amount, and quality, of data collected in certain areas such as the European Union Statistics on Income and Living Conditions, the European Health Information Survey, the System of Health Accounts, mortality and demographic statistics. Since 2008 member states are urged to make use of the ECHI indicator set by an EU Regulation on Community Statistics on Public Health and Health and Safety at Work. ${ }^{43}$ Additionally, a European Health Interview Survey (EHIS) and a European Health Examination Survey (EHES) was developed to support the collection of some ECHI indicators (e.g. information on morbidity, Body Mass Index, life style factors, measurements like cholesterol, blood pressure) that cannot be retrieved from general official health statistics. Since 2013, European member states are legally bound to implement the EHIS nationally, the implementation of the EHES is optional. 44,45

\section{What needs to be investigated?}

Despite these successes the data base is still incomplete. ${ }^{24}$ Moreover, data that can be used for public health surveillance are subject of (1) new data needs due to changing political priorities and (2) new possibilities for data retrieval:

(1) In 2013 the EC established an Expert Panel which should give advice for effective ways of investing in health. ${ }^{46}$ The assessment of health system performance is one of the topics for which advice was requested. The related expert group pointed on problem areas like data availability and data quality for health system performance assessment ${ }^{47}$ which underlines the necessity of continuous data management, support and data organisation in order to be able to provide the necessary information for evidence-informed policy making.

Political priorities also changed with regard to the identification and tackling of international health threats. The International Health Regulations (IHR (2005)) of the World Health Organization (WHO) define core capacities and response measures to prevent and to respond to acute public health emergencies of international concern (PHEIC). ${ }^{48}$ The regulations are an international, legally binding instrument and they define, in contrast to the previous infectious disease focused IHR version, an all-hazard approach. ${ }^{48,49}$ Potential PHEICs in the IHR (2005) can be infectious, zoonotic, related to food safety, of chemical or radiologic/nuclear origin, as well as events transmissible via persons, vectors, cargo, goods, and environmental diffusion. This new orientation raises new data needs, and a need for new surveillance approaches.

(2) The availability of data collected electronically in the health care system or by search engines, news feeds, etc. supported discussions about the use of big data for public health surveillance and approaches like "infodemiology", "infosurveillance" 50 and syndromic surveillance. ${ }^{51,52}$ The 
immediate availability of these data sources raises hopes, in particular for reducing the usual time gaps between data collection and data availability.

Given these points, already existing routine public health-related data need to be investigated for their potential to support health system performance assessment or public health surveillance under the IHR (2005).

\section{EU infrastructures for public health surveillance}

"The Council of the European Union invites the Commission and the member states to cooperate with a view to establishing a sustainable and integrated EU health information system, built on what has been already achieved through different groups and projects, such as ECHI-ECHIM projects, exploring in particular the potential of a comprehensive European health information research infrastructure consortium (ERIC) as a tool." 11

Public health surveillance is ideally operationalised in a health information system, necessary aspects of a comprehensive system have been previously described in the public health surveillance definition and the DIKW-hierarchy. Such an infrastructure allows professionals and lay people to use, interpret, and share information and to transform it into knowledge ${ }^{53,54}$ as well as to enable decision-making regarding the extent and the design of required actions.

Experts in European public health (policy) regularly request the need for an EU-level health information system..$^{21-25,31}$ So far, a sustainable and comprehensive health information system that includes in addition to a data presentation mechanism also routine data management, monitoring and reporting facilities is not available on EU-level. Attempts have been made by a feasibility study on how to organise EU health monitoring in 1997,13,55 by EUPHIX (European Public Health Information and Knowledge System, 2004-2008) - an EC co-founded project,$-{ }^{56}$ and lastly by the EC (DG SANCO) itself who tried to establish a Wikipedia approach (HEIDI-WIKI).

Currently, data on ECHI are provided by the EC and are online available via the ECHI data tool. Moreover, the need for a public health surveillance infrastructure was taken into account within the third EU Public Health Programme (2014-2020). This programme included in 2014 a call to analyse the potential of a European Research Infrastructure Consortium (ERIC) for an EU health information system. A group of former EU health information project leaders handed in a proposal that was accepted for funding. ${ }^{57}$ This project will function as a so-called bridge project towards a future ERIC and offers new perspectives with regard to the realisation of an EU-level health information system.

In addition to the EC, that has a legal mandate for health at the EU-level, there are two other important stakeholders in the field. The World Health Organization Regional Office for Europe (WHO/EURO) and the Organization for Economic Co-operation and Development (OECD) are 
running well-established databases and reporting systems. All three entities have intensified collaboration in past years, e.g. by a common reporting system (System of Health Accounts), joint data collection for non-monetary health care statistics, and, OECD and EC in particular, in writing joint health reports for the EU (Health at a Glance series). All of them expressed their intent for improved coordination and to work towards a single, integrated European Health information system..$^{58}$ In parallel to these developments, WHO/EURO started a European Health Information Initiative, ${ }^{59}$ that can be regarded as instrumental for improving the coordination of European health information in the European region. The WHO European region comprises 53 member states, including all 28 EU member states. In 2013, all 53 WHO/EURO member states agreed on a set of indicators for monitoring WHO/EUROs health policy framework Health 2020.

What needs to be investigated?

This rough overview of international activities in the European region shows that the field is highly active. Due to different mandates, liabilities, and responsibilities there are parallel as well as joint developments that could potentially result in a comprehensive and useful European health information system. However, so far the discussion about its realisation is still not finalised and the development of a respective system could be advanced by identifying the necessary and commonly agreed key features of an EU-level health information system.

\section{Structure of the thesis, research aims and methodological approaches}

This entire thesis deals in its core with public health surveillance in a European public health perspective, ${ }^{60}$ thus the role and the implications of the European Union and its institutions on public health surveillance. Also local and regional public health surveillance approaches are examined within this thesis and might influence European public health accordingly. The thesis is designed around the main research question:

What is the status of public health surveillance in EU health policy and how can it be advanced in terms of data, information and infrastructure?

This question indicates already the three investigated perspectives - a health policy perspective, a data and information perspective, and an infrastructure perspective. Figure 1 gives an overview on the main research question, the five sub-research questions and the general methodological approaches. The sub-research questions are analysed within this thesis and provide a contribution to answer the main research question.

The variety of applied methods in this thesis underlines the different research foci. Qualitative analysis was deemed most suitable for exploring expert perceptions under the health policy perspective of this thesis. Quantitative approaches were applied for epidemiological public 
health surveillance research within this thesis' data and information perspective. And, within the infrastructure perspective of this thesis a mixed method design was used for concept development of key features of an EU health information system.

In Part 1 the status quo of EU public health policy is assessed in general and for EU public health surveillance efforts in particular. As laid out in the previous sections, attempts to further develop EU public health surveillance capacities have a long history and were always mentioned in the forefront of EU programmes and strategies. However, a comprehensive EU public health surveillance system is not available yet, potentially due to the fact that political power, legislation, available infrastructure, and budgets never reached sufficient power as e.g. the organisation of EU infectious disease surveillance. ${ }^{31}$

Therefore, we aimed to identify in a qualitative study how key experts in EU health matters perceive EU health policy actions from 1992 to 2012 in general, reflected in terms of achievements, failures and missed opportunities. Thereby, we had the chance to identify achievements as well as gaps in EU health policy and could identify the status quo of EU public health surveillance policies and actions beside other EU health policy areas.

Part 2 focusses on data sources and monitoring approaches that are not commonly used for general public health surveillance. In three case studies we explored their applicability and potential for advancing public health surveillance. This part is focussed on the data and information aspects of the DIKW-hierarchy.

We applied electronically available emergency medical care data for syndromic influenza surveillance and discussed the applicability of these data for monitoring the health impact of non-infectious health threats. The third study investigated the applicability of school-entry screening data for monitoring of child health service utilisation and its usefulness as a data source for health system performance assessment.

The case studies in Part 2 rely mainly on quantitative approaches by conducting a time series analysis with emergency medical care data and a multiple logistic regression analysis with school-entry screening data. All three case studies are intended to identify the potential of these data sources and monitoring approaches for advancing EU public health surveillance activities.

Part 3 focusses on the need for a EU public health surveillance infrastructure, or more precisely necessary key features of a health information system on EU-level. We aimed to explore the features that public health experts expect to be part of a European health information system. The results of this research are compared with the core aspects of the DIKW-hierarchy. We applied a mixed methods approach in this study and the results are intended to be supportive for advancing the European public health surveillance infrastructure at a later stage. 


\begin{tabular}{|c|c|c|c|c|}
\hline \multicolumn{5}{|c|}{$\begin{array}{l}\text { What is the status of public health surveillance in EU health policy and how can it } \\
\text { be advanced in terms of data, information and infrastructure? }\end{array}$} \\
\hline $\begin{array}{l}\text { POLICY } \\
\text { Assessing the } \\
\text { status quo }\end{array}$ & \multicolumn{3}{|c|}{$\begin{array}{l}\text { DATA and INFORMATION } \\
\text { "Off-label-use" of data for information and knowledge generation } \\
\text { in public health }\end{array}$} & $\begin{array}{l}\text { INFRASTRUCTURE } \\
\text { Developing } \\
\text { infrastructure }\end{array}$ \\
\hline $\begin{array}{l}\text { How do key experts in } \\
\text { EU health matters } \\
\text { perceive EU health } \\
\text { policy actions from } \\
1992 \text { to 2012, reflected } \\
\text { in terms of } \\
\text { achievements, failures } \\
\text { and missed } \\
\text { opportunities? }\end{array}$ & $\begin{array}{l}\text { What is the validity and } \\
\text { timeliness of different } \\
\text { European emergency } \\
\text { medical care data } \\
\text { sources for syndromic } \\
\text { influenza surveillance } \\
\text { during the } \\
\text { autumn/winter wave of } \\
\text { A(H1N1) influenza 2009? }\end{array}$ & $\begin{array}{l}\text { What is the potential of } \\
\text { indicator-based } \\
\text { syndromic surveillance } \\
\text { approaches for the } \\
\text { surveillance of non- } \\
\text { infectious health } \\
\text { threats under the } \\
\text { International Health } \\
\text { Regulations (2005)? }\end{array}$ & $\begin{array}{l}\text { What is the potential of } \\
\text { school-entry screening } \\
\text { data for assessing the } \\
\text { relationship of parents' } \\
\text { educational level and } \\
\text { families' migrant } \\
\text { background to pre- } \\
\text { school children's health } \\
\text { care utilisation? }\end{array}$ & $\begin{array}{l}\text { What features do } \\
\text { public health experts } \\
\text { expect to be part of a } \\
\text { European health } \\
\text { information system } \\
\text { and how do they rate } \\
\text { and organise them? }\end{array}$ \\
\hline Qualitative study & Quantitative study & Narrative review & Quantitative study & Mixed method analysis \\
\hline
\end{tabular}

Figure 1 Research questions and methods of the thesis.

\section{Outline}

Part 1 - the policy perspective: Assessing the status quo

Three aspects motivated us to perform the first study of this thesis (Chapter 1):

(1) the available evidence of the impact of EU health policies, infrastructure, and actions on EU policies in general and actions in EU member states is elusive,

(2) the identification of the value of public health relevant EU-level actions across all policies is lacking, and

(3) the twentieth anniversary of the first EU health mandate was just around the corner, thus an ideal moment in time to look back.

We conducted a qualitative study on expert perceptions of health relevant EU policies within the time period 1992 to 2011. We were in particular interested in how key experts in EU health matters perceive EU (health) policy actions, reflected in terms of achievements, failures and missed opportunities. Additionally, we were able to identify those EU policy outputs that were regarded as influential. We ranked policy outputs in the areas (a) secondary legislation and court decisions; (b) soft laws, strategies, and programmes; (c) agencies, centres, organisations; (d) networks, policy platforms, cooperation; and (e) others. This broad approach enabled us to assess the status quo of EU public health surveillance within the broad field of EU health policy actions. The results of this study triggered the work on a European public health surveillance infrastructure that is presented in Chapter 5 
Part 2 - the data and information perspective: "Off-label-use" of data and information for knowledge generation in public health

The studies presented in Chapter $\mathbf{2}$ and Chapter $\mathbf{3}$ of this thesis are focussed on a public health surveillance approach called syndromic surveillance. The studies are linked to the SIDARTHa project (European Emergency Data-based Syndromic Surveillance) which was an EC co-funded project within the second public health programme.

Syndromic surveillance is a flexible approach that makes use of routinely collected often electronically available data. It uses information on clinical signs and symptoms, often before laboratory or comprehensive diagnostic confirmation is available. ${ }^{61}$ The syndromic surveillance approach was firstly introduced after the 2001 terror events in the US. Emergency medical care data are a commonly used data source for syndromic surveillance.

In Chapter 2 we were able to evaluate the performance of a common syndromic surveillance approach by using emergency medical dispatch data, ambulance data and/or emergency department data from three European regions. We tested this data retrospectively during the autumn/winter wave of the $\mathrm{A}(\mathrm{H} 1 \mathrm{~N} 1)$ influenza pandemic and were able to compare sensitivity and specificity, as well as the timeliness of the approach for each emergency medical care data source and for each region.

In Chapter 3 we aimed to explore the potential of indicator-based syndromic surveillance approaches for the surveillance of non-infectious health threats under the International Health Regulations (2005) (IHR (2005)). This research aim derived from the fact that the IHR (2005) follows a broad event definition that is not limited to events of infectious origin. But, regardless of the broad event definition case descriptions in the literature, as well as surveillance infrastructures, are primarily geared towards infectious diseases. In this narrative review, we focus on noninfectious health threats. We searched the literature for real and theoretical non-infectious events that had the potential to constitute a Public Health Emergency of International Concern as defined in the IHR (2005). Furthermore, we discussed how the syndromic surveillance approach, which is using health information that were not primarily collected for public health surveillance purposes, can support the identification of non-infectious health threats or related health effects.

Data from a routine regional screening activity were used in Chapter $\mathbf{4}$ for public health surveillance. We applied data from the school-entry screening program of North RhineWestphalia (NRW), Germany. In this programme every child between five to seven years is exanimated and tested by the local public health service before entering school. The examination has the aim to assess the health status of the child and the past participation in prevention activities. The focus of the screening is on the individual child, the screening has a social compensatory character. In Chapter 4 we used these individual data in a quantitative study to 
assess social determined inequalities in health care utilisation of children in North RhineWestphalia. More precisely, we were interested in the potential of school-entry screening data for assessing the relationship of parents' educational level and families' migratory background to pre-school children's health care utilisation. The results of this study will be used in the General Discussion of this thesis to discuss the potential of this data source for public health surveillance in a European context (e.g. for specific aspects of health systems performance and inequalities in health care utilisation).

\section{Part 3 - the infrastructure perspective: Developing infrastructure}

The status quo of the infrastructure for general public health surveillance (excluding infectious disease surveillance) was perceived as missed opportunity or failure in the study presented in Chapter 1. Despite the obvious value of an EU health information system and the reached progress, its development and the discussion about its realisation is still not finalised. A mixed method design, by the means of a concept mapping analysis, was applied in Chapter $\mathbf{5}$ to identify the necessary key features relevant to build up a comprehensive EU health information system that supports evidence-informed (health) policy making. Since views on the key features of an EU health information system might differ, this study attempts to conceptualise the opinions and valuations of potential user groups like public health professionals and policy makers.

\section{General discussion}

In the General Discussion, the results of the conducted research are summarised. The results are used for a deduction of key results of the policy (Part 1), data and information (Part 2), and infrastructure (Part 3) perspectives of this thesis. This is followed by a discourse about conditions that could support the development of advanced European public health surveillance capacities. The discussion is followed by concluding remarks for advancing public health surveillance in Europe. 


\section{References}

1. Marmot M, Goldblatt P. Importance of monitoring health inequalities. BMJ 2013; 347: f6576.

2. Langmuir AD. The surveillance of communicable diseases of national importance. The New England Journal of Medicine 1963; 268: 182-92.

3. Thacker SB, Berkelman RL. Public health surveillance in the United States. Epidemiologic Reviews 1988; 10: 164-90.

4. Porta M. A dictionary of Epidemiology. 5th ed: Oxford University Press; 2008.

5. World Health Organization. Public Health Surveillance. 2014. http://www.who.int/topics/public_health_surveillance/en/ (accessed 16.08.2014).

6. Institute of Medicine. The Future of the Public's Health in the 21st Century. Washington, DC: The National Academies Press; 2003.

7. World Health Organization - Regional Office for Europe, Regional Committee for Europe. European Action Plan for Strengthening Public Health Capacities and Services. Copenhagen: World Health Organization, Regional Office for Europe; 2012.

8. European Commission. European Governance - A White Paper (COM(2001) 428 final). Official Journal of the European Union 2001; C287: 1-29.

9. European Union. Treaty on the Functioning of the European Union. Lisbon; 2007.

10. Mossialos E, Permanand G, Baeten R, Hervey TK. Health Systems Governance in Europe The Role of European Union Law and Policy. Cambridge: Cambridge University Press; 2010.

11. Azzopardi-Muscat N, Clemens T, Stoner D, Brand H. EU Country Specific Recommendations for health systems in the European Semester process: Trends, discourse and predictors. Health Policy 2015; 119(3): 375-83.

12. Briatte F. The politics of European public health data. In: Greer SL, Kurzer P, eds. European Union Public Health Policy Regional and global trends. Abingdon, UK: Routledge; 2013: 5163.

13. Aromaa A. Health observation and health reporting in Europe. Revue d'epidemiologie et de sante publique 1998; 46(6): 481-90.

14. McKee M, Ryan J. Monitoring health in Europe: opportunities, challenges and progress. Eur J Public Health 2003; 13(3 Suppl): 1-4.

15. Buitendijk S, Zeitlin J, Cuttini M, Langhoff-Roos J, Bottu J. Indicators of fetal and infant health outcomes. Eur J Obstet Gynecol Reprod Biol 2003; 111(Suppl 1): 66-77.

16. Achterberg PW. Met de besten vergelijkbaar? Internationale verschillen in sterfte rond de geboorte. Bilthoven: RIVM, 2005.

17. Berrino F, Verdecchia A, Lutz JM, Lombardo C, Meicheli A, Capocaccia R, the EUROCARE Working Group. Comparative cancer survival information in Europe. European Journal of Cancer 2009; 45: 901-8.

18. European Union. The Maastricht Treaty. The Treaty on the European Union (TEU). Maastricht; 1992.

19. European Union. Treaty on European Union (Consolidated Version), Treaty of Amsterdam. European Union; 1997. 
20. Rosenkötter N, Brand H, McKee M, Riley N, Verma A, Verschuuren M. The realisation of a European health information system-time to get the politicians involved. Eur J Public Health 2014; 24(2): 184-5.

21. Verschuuren M, Kramers P, Gudfinnsdottir GK, Aromaa A. Providing a solid evidence base for policy makers: ECHI initiative. Eurohealth 2011; 16(3): 4-7.

22. Kilpeläinen K, Tuomi-Nikula A, Thelen J, Gissler M, Sihvonen AP, Kramers P, Aromaa A. Health indicators in Europe: availability and data needs. Eur J Public Health 2012; 22(5): 716-21.

23. Aromaa A. Implementation of joint health indicators in Europe - Joint Action for ECHIM. Arpo Aromaa on behalf of the ECHIM core group. Archives of Public Health 2012; 70(1): 22.

24. Verschuuren M, Gissler M, Kilpelainen K, Tuomi-Nikula A, Sihvonen AP, Thelen J, et al. Public health indicators for the EU: the joint action for ECHIM (European Community Health Indicators \& Monitoring). Archives of Public Health 2013; 71(1): 12.

25. European Public Health Association. Health Monitoring and Information. EUPHActs, 2014. http://www.eupha.org/repository/publications/EUPHActs_2014-

1_Health_monitoring_and_information_September_2014.pdf (accessed 15.05.2015).

26. Ackoff RL. From Data to Wisdom. Journal of Applied Systems Analysis 1989; 16: 3-9.

27. Rowley J. The wisdom hierarchy: representations of the DIKW hierarchy. Journal of Information Science 2007; 33(2): 163-80.

28. Lee LM, Thacker SB, Centers for Disease C, Prevention. The cornerstone of public health practice: public health surveillance, 1961-2011. Morbidity and Mortality Weekly Report Surveillance Summaries 2011; 60 Suppl 4: 15-21.

29. Van Cangh T. Towards a European surveillance of chronic non-communicable diseases? Maastricht: Maastricht University; 2012.

30. Greer SL. The European Centre for Disease Prevention and Control: hub or hollow core? J Health Polit Policy Law 2012; 37(6): 1001-30.

31. Elliott $\mathrm{H}$. European Union health information infrastructure and policy. In: Greer SL, Kurzer P, eds. European Union Public Health Policy Regional and Global Trends. Abingdon, UK: Routledge; 2013.

32. Reintjes R. Variation matters: epidemiological surveillance in Europe. J Health Polit Policy Law 2012; 37(6): 955-65.

33. Greer S, Fahy N, Elliott HA, Wismar M, Jarman H, W. P. Everything you always wanted to know about European Union health policies but were afraid to ask. Copenhagen: World Health Organization Regional Office for Europe; 2014.

34. European Parliament, Council of the European Union. Decision on adopting a programme of Community action on health monitoring within the framework of action in the field of public health (1997-2001) 1400/97/EC. Official Journal of the European Communities 1997; L193:1-10.

35. European Parliament, Council of the European Union. Decision on adopting a programme of Community action in the field of public health (2003-2008) (1786/2002/EC). Official Journal of the European Union 2002; L271:1-11. 
36. European Parliament, Council of the European Union. Decision on establishing a second programme of Community action in the field of health (2008-13) (1350/2007/EC). Official Journal of the European Union 2007; L301: 3-13.

37. European Commission. White paper. Together for Health: A strategic approach for the EU 2008-2013 (COM(2007) 630 final). 2007.

38. European Commission. Investing in Health Brussels: European Commission, 2013.

39. Seychell M, Hackbart B. The EU Health Strategy - Investing in Health. Public Health Reviews 2013; 35 (epub ahead of print).

40. Public Health Evaluation and Impact Assessment Consortium (PHEIAC). Evaluation of the use and Impact of the European Community Health Indicators ECHI by Member States. Brussels: European Commission, 2013.

41. Council of the European Union. Council Conclusions on the "Reflection process on modern, responsive and sustainable health systems". Brussels: Council of the European Union; 2013.

42. Princen S, Rhinard M. Crashing and creeping: agenda-setting dynamics in the European Union. Journal of European Public Policy 2006; 13(7): 1119-32.

43. European Parliament and the Council. Regulation (EC) No 1338/2008 on community statistics on public health and health and safety at work. Official Journal of the European Union 2008; L354: 70-81.

44. European Parliament, Council of the European Union. Commission Regulation on implementing Regulation (EC) No 1338/2008 of the European Parliament and of the Council on Community statistics on public health and health and safety at work, as regards statistics based on the European Health Interview Survey (EHIS). Official Journal of the European Union 2013; L47: 20-48.

45. Kuulasmaa K, Tolonen H, Koponen P, Kilpelainen K, Avdicova M, Broda G, et al. An overview of the European Health Examination Survey Pilot Joint Action. Archives of Public Health 2012; 70(1): 20.

46. European Commission. Commission Decision of 5 July 2012 on setting up a multisectoral and independent expert panel to provide advice on effective ways of investing in health (2012/C 198/06). Official Journal of the European Union 2012; C198: 7-10.

47. Expert Panel on effective ways of investing in Health. Definition and Endorsement of Criteria to Identify Priority Areas When Assessing the Performance of Health Systems. Brussels: European Commission; 2014.

48. World Health Organization. International Health Regulations (2005). Geneva, Switzerland: World Health Organization; 2008.

49. Baker MG, Fidler DP. Global public health surveillance under new International Health Regulations. Emerging infectious diseases 2006; 12(7): 1058-65.

50. Eysenbach G. Infodemiology and infoveillance tracking online health information and cyberbehavior for public health. American journal of preventive medicine 2011; 40(5 Suppl 2): S154-8. 
51. Henning KJ. What is syndromic surveillance? MMWR Morbidity and Mortality Weekly Report 2004; 53 Suppl: 5-11.

52. Paquet C, Coulombier D, Kaiser R, Ciotti M. Epidemic intelligence: a new framework for strengthening disease surveillance in Europe. Eurosurveillance 2006; 11(12): 212-4.

53. Gissler M, Dumitrescu A, Addor V. Improving the performance of National Health Information Systems. The 2002-2003 reform in Finland from an international perspective. Copenhagen: World Health Organization Regional Office for Europe; 2006.

54. Verschuuren M, Achterberg PW, Kramers PGN, van Oers H. Monitoring the health of the population. In: Rechel B, McKee M, eds. Facets of Public Health in Europe. Berkshire: Open University Press; 2014: 23-41.

55. Nielsen TM, Jorgensen HD. Factors to consider when establishing a Europe-wide network for exchange of health information. In: Brender J, Scherer JR, Pihlkjar J, McNair P, eds. Medical Informatics Europe 1996 - Human Facets in Information technology. Amsterdam: IOS Press; 1996.

56. Achterberg PW, Kramers PG, van Oers HA. European community health monitoring: the EUPHIX-model. Scandinavian Journal of Public Health 2008; 36(7): 676-84.

57. Rosenkötter N, van Bon-Martens M. Public health monitoring and reporting: maintaining and improving the evidence base. Eurohealth 2015; 21(1): in press.

58. World Health Organization - Regional Office for Europe. Partnerships for health in the European Region. Moscow: WHO Regional Committee for Europe, 60th session; 2010.

59. World Health Organization - Regional Office for Europe. European Health Information Initiative. Copenhagen: WHO/EURO; 2014.

60. Brand H. From 'public health in Europe' to 'European public health'. Eur J Public Health 2010; 20(2): 127-8.

61. Triple-S Project. Assessment of syndromic surveillance in Europe. The Lancet 2011; 378(9806): 1833-4. 
Introduction $\mathbf{2 5}$ 



\section{Part 1 I Assessing the status}

\section{quo}



Chapter 1 I Achievements, failures and missed opportunities of EU health policy

Twentieth anniversary of the European Union health mandate: taking stock of perceived achievements, failures and missed opportunities - a qualitative study

Rosenkötter N, Clemens T, Sørensen K, Brand H

BMC Public Health 2013. 13: 1074. 


\section{Abstract \\ Background}

The European Union (EU) health mandate was initially defined in the Maastricht Treaty in 1992. The twentieth anniversary of the Treaty offers a unique opportunity to take stock of EU health actions by giving an overview of influential public health related EU-level policy outputs and a summary of policy outputs or actions perceived as an achievement, a failure or a missed opportunity.

\section{Methods}

Semi-structured expert interviews ( $\mathrm{N}=20$ ) were conducted focusing on EU-level actions that were relevant for health. Respondents were asked to name EU policies or actions that they perceived as an achievement, a failure or a missed opportunity. A directed content analysis approach was used to identify expert perceptions on achievements, failures and missed opportunities in the interviews. Additionally, a nominal group technique was applied to identify influential and public health relevant EU-level policy outputs.

\section{Results}

The ranking of influential policy outputs resulted in top positions of adjudications and legislations, agencies, European Commission (EC) programmes and strategies, official networks, cooperative structures and exchange efforts, the work on health determinants and uptake of scientific knowledge. The assessment of EU health policies as being an achievement, a failure or a missed opportunity was often characterized by diverging respondent views. Recurring topics that emerged were the Directorate General for Health and Consumers (DG SANCO), EU agencies, life style factors, internal market provisions as well as the EU Directive on patients' rights in crossborder healthcare. Among these recurring topics, expert perceptions on the establishment of DG SANCO, EU public health agencies, and successes in tobacco control were dominated by aspects of achievements. The implementation status of the Health in All Policy approach was perceived as a missed opportunity.

\section{Conclusions}

When comparing the emerging themes from the interviews conducted with the responsibilities defined in the EU health mandate, one can identify that these responsibilities were only partly fulfilled or acknowledged by the respondents. In general, the EU is a recognized public health player in Europe which over the past two decades, has begun to develop competencies in supporting, coordinating and supplementing member state health actions. However, the assurance of health protection in other European policies seems to require further development. 


\section{Background}

The Maastricht Treaty from 1992 marked the beginning of the health mandate of the European Union (EU) as enshrined today in Article 168 of the Lisbon Treaty (TFEU, Treaty on the Functioning of the European Union) [1]. The original EU health mandate focused primarily on stimulating cooperation between member states and supporting national actions (Art. 129 (1), Treaty of the European Union (TEU)) [2]. It embodied the Union with only limited legislative powers on health matters. Although this initial mandate was enhanced through subsequent Treaties, today Article 168, still gives the EU relatively circumscribed power in areas of public health (Art. 168 (4), TFEU). Healthcare continues to remain a national competence and in this regard, the EU "shall respect the responsibilities of the member states for the definition of their health policy and for the organization and delivery of their health services" (Art. 168 (7), TFEU). Despite the restricted Treaty-based mandate for health, the EU has a relevant role to play in national public health and health systems policies and has expanded its remit in areas beyond the Treaty [3]. Areas affected by EU provisions are extensively described in the literature [4-11]. To illustrate the main developments in the area of what can be called "EU health policy" a timeline is illustrated in Box 1. However, because of its limited legal mandate, some EU legal initiatives were highly contested $[12,13]$.

Therefore, one can pose the question of what has been achieved over the last twenty years. It may be argued that, despite its narrow legislative scope, the health mandate has triggered important European actions in certain public health areas like tobacco control $[14,15]$, infectious disease control [16,17], European guidelines [18-20] and the development of an EU public health infrastructure [21]. In recent years, the EC has summarized in annual reports a diverse nature of key public health achievements such as communications and recommendations, health policies, EC co-financed actions and established networks (e.g. high level groups, scientific committees, platforms) [22-24]. However, stakeholders in the field provide examples indicating that public health relevant EU policies such as single EU policy assessments on the Common Agriculture Policy (CAP) [25,26], pharmaceuticals [27], or the Health in All Policy (HiAP) approach [28] do not always meet the expectations of the public health community. In these papers the authors express concerns about potentially detrimental health effects $[25,26]$ or disappointment about the support of the policies and approaches aimed at improving health in Europe [27,28]. Also, EU agencies such as the European Centre for Disease Prevention and Control (ECDC) are described as agencies with a limited legal mandate, competences and resources for EU public health but, at the same time, with promising prospects to develop as a renowned international player in the field [29].

In addition, an evaluation of the EU Health Strategy acknowledges its status as a guiding framework for EC health policies and joint EC and member state actions on health but also identifies the missing impact of the Strategy on other EC policies as well as on member state 
health policies and actions [30]. Evaluations of the EU public health programmes, which are one of the EC's financial instruments to implement its strategic health goals, criticize missing prioritization of topics, barriers for participation in projects for some member states and ineffective dissemination of project results [31,32]. Hence, the available evidence of the impact of EU health policies, infrastructure, and actions is elusive, and the identification of the value of public health relevant EU-level actions across all policies is lacking.

In this paper, we aim to explore and provide an overview of influential public health relevant EUlevel policy outputs and a summary of policy outputs or actions perceived as an achievement, a failure or a missed opportunity by interviewing key experts in the field. By this, we intend to establish a qualitative indication of which EU health policies have contributed to the improvement of population health in Europe.

Box 1 Timeline of main developments in EU health policy.

\section{Before having a legal EU health mandate}

1957 Treaty of Rome: Health is not a priority. Two aspects are considered: Social security of cross-border workers and occupational health.

1971 Regulation (EEC) 1408/71 on the application of social security schemes to employed persons and their families moving within the Community (accompanied by implementing Regulation (EEC) No 574/72).

1985 EC launches the action programme "Europe against Cancer".

1993 Maastricht Treaty: The legal basis for undertaking actions in the field of public health is defined in Article 3(0) and Article 129.

After the introduction of a legal EU health mandate by the Maastricht Treaty

1995 The European Agency for the Evaluation of Medicinal Products (EMEA), now European Medicines Agency (EMA), has been formed in London.

1997 Treaty of Amsterdam: Health Impact Assessment is implemented.

1999 Directorate General for Health and Consumers (DG SANCO) is established.

2000 Lisbon Agenda recognizes health protection as a prerequisite for economic growth measured with the indicator Healthy Life Years.

2002 The European Food Safety Authority (EFSA) has been established in Parma.

2002 First Programme of Community action in the field of public health (2003-2008) launched.

2003 The Tobacco Advertising Directive 2003/33/EC is adopted after the first version has been annulled by the European Court of Justice.

2004 Commission decision to set up an Executive Agency for the Public Health Programme. It has the task to manage Community action in the field of public health. 
2005 The European Centre for Disease Prevention and Control (ECDC) in Stockholm is operational.

2007 White Paper: Together for Health: A Strategic Approach for the EU 2008-2013.

2007 Decision for a Second Programme of Community action in the field of health (2008-13).

2011 Directive 2011/24/EU on the application of patients' rights in cross-border healthcare has been adopted.

\section{Methods}

The study focused on the evolvement of the health mandate since 1992, the year the Maastricht Treaty was signed. The study was carried out in two consecutive phases: (1) qualitative interviews, suitable to identify expert perceptions, and (2) voting on influential and public health relevant EU policy outputs and actions based on nominal group technique. The study adhered to the RATS guidelines on qualitative research [33].

\section{Study participants}

Experts were purposely selected to ensure heterogeneity of opinions. The selection was based on their individual profile and professional affiliation. We selected experts that were renowned in the field due to their current or former affiliation to specific EU-level bodies and institutions, research institutes with EU focus, or EU-level non- governmental organization. Selected experts were actively involved in public health research, policy-making, policy advice or advocacy performed at EU level, internally or externally. In addition, snowball sampling was applied until data saturation was reached. Data saturation was assumed as soon as no new EU public health policy actions and their perceptions were mentioned during the interviews.

The potential participants were contacted between December 2011 and March 2012 by a short information email to identify whether they were interested to participate in the interview study. of 22 contacted experts, twenty participated in this study, one participant could not confirm participation due to time constraints and another did not respond to the invitation. Of those twenty experts nine belonged to the initial purposively selected sample and eleven were identified during the snowball sampling procedure based on recommendations of already interviewed experts. The majority of experts was affiliated to an institution located in Brussels $(n=10)$. The composition of the study sample in terms of represented professional affiliations is outlined in Table 1.

Upon agreement by the participant, an appointment for the interview was made and participants received an informative letter with more in-depth information about the goal of the study and an informed consent form in which the voluntary basis of the participation has been clarified and anonymized data handling was assured. 
Table 1 Professional functions of interviewed participants.

\begin{tabular}{l|l}
\hline Function & Number of participants \\
\hline EU / national civil servant & 7 \\
EU / national politicians & 2 \\
Academia & 5 \\
Public health advisor / & 6 \\
advocate & \\
Total & 20 \\
\hline
\end{tabular}

\section{Qualitative interviews}

Interviews were conducted either face-to-face $(n=4)$ or via telephone, or Voice over IP $(n=16)$ in the period between January and March 2012 and were held in English, Dutch or German by one of the three principal investigators (NR, TC, KS). The interviews lasted from 35 to 90 minutes. All interviews were audio-recorded, transcribed verbatim and anonymized.

The interviews were performed using a specifically designed semi-structured interview guide. The guide was developed on the basis of previous desktop research and an internal brainstorming session of an advisory research group consisting of the three principal investigators, four senior researchers, and one junior researcher of the Department of International Health at Maastricht University to identify items relevant for investigating expert perceptions on European public health policy. During the course of this process, a list of public health relevant EU policy outputs, processes or procedures that were regarded as achievements, failures or missed opportunities were first gathered individually and then, following a group discussion, a common list was compiled. This output was used to construct the interview guide containing six guiding themes from which open-ended questions were formulated. The guiding themes included (1) a description of the individual role of the expert in European public health, (2) the individual definition of European public health, (3) the assessment of public health relevant EU-level actions as being an achievement, missed opportunity or failure, (4) the formulation of five influential European policy outputs, (5) consequences of European health policy, and (6) the policy process at the European level. The semi-structured interview guide was used as a framework for the interviews and allowed the interviewers to address other relevant topics that emerged during the interviews.

\section{Analysis}

After completion of interviews the three principal investigators initially performed an internal analysis of each separate interview and an analysis across interviews to identify the scope of EUlevel actions and experts' perceptions of these actions as achievements, failures or missed opportunities [34]. Afterwards, a directed (or deductive) content analysis approach [35,36] was applied whereby the initially predefined coding scheme with the main categories of interest 
(achievement, failure, and missed opportunity) was used to summarize the respective topics and the reasoning that appeared during the interviews. Topics that did not fit into one of these main categories were added as new codes and were organized into new categories. The analysis was jointly performed by the principal investigators using NVivo 9 (QSR International Pty Ltd. Version 9).

Furthermore, the results of the content analysis on achievements, failures and missed opportunities were grouped according to the major common themes in a table to provide an overview of the perceptions of the key informants. Prominent EU-level outputs or actions, which were discussed by almost all respondents, are described in more detail in the results section. Where applicable, we used original quotes to illustrate the views and tendencies of experts' assessments. The professional profile and study ID of respondents are indicated behind the respective quotes. Quotes which were originally given in Dutch or German were translated into English.

\section{Nominal group technique}

A slightly adapted nominal group technique [37] was used for triangulation purposes. During the interviews, the participants were asked for five influential policy outputs of European health policy-making. Following the finalization of all interviews, all participant nominations were compiled in one list and reoccurring topics were removed. To ensure comparability of policy outputs and actions, we grouped the nominations into categories under the following headlines: (a) secondary legislation and court decisions; (b) soft laws, strategies, and programmes; (c) agencies, centres, organizations; (d) networks, policy platforms, cooperation; and (e) others. Participants were asked in an online survey to select three outputs per category which were, according to their opinion, most influential. Based on the participants' nominations, a ranking in terms of a frequency distribution of selected influential policy outputs for each category was determined. The online survey was completed by 18 out of 20 participants who took part in the interviews.

\section{Ensuring quality}

The design and analysis of the study was guided by applying Guba and Lincoln's test for trustworthiness [38]. Credibility and dependability have been ensured by enlarging the sample until saturation was reached in terms of the identification of EU policy actions and their perceptions. Moreover, three researchers in the primary research group in combination with an internal advisory research group were involved with the aim of reflecting upon the study design and critically questioning the findings. Additionally, the primary research group met regularly during the interview period to exchange initial findings and experiences on the interview process. The members of the internal advisory research group were experienced in EU public health policy research or qualitative research methodologies. The confirmability was strengthened by the use of several investigators both in the data collection process and in the analysis phase, combined 
with the use of triangulation, where interview participants were also asked to participate in the ranking exercise.

\section{Ethical considerations}

The Medical Ethical Committee of the University Hospital Maastricht and University Maastricht declared that no ethical approval was required for this type of research. All participants were informed about their role and rights as study participant prior to their interview participation. All participants provided written or audio-recorded informed consent to be interviewed.

\section{Results}

Overall, respondents consistently mentioned that, during the twenty-year history of the EU health mandate, specific initiators induced change in European public health policy. The most important identified initiators included the Maastricht Treaty with its later amendments, the health-related rulings of the European Court of Justice, and the health crises such as Boviene spongiforme encefalopathie (BSE) and Severe Acute Respiratory Syndrome (SARS). In addition, the internal market provisions with the foreseen free movement of goods, people, services and capital, initiated change with both negative and positive public health impact. Additionally, a set of conditions was identified in the interviews that described and advanced the role of EU health policy as a reference point for public health. These conditions under which EU health policy made progress during the past twenty years were (i) the regulatory power at the EU-level, (ii) EU-led facilitation of cooperation and comparisons across member states; along with (iii) increased capacity building on EU issues and on EU-level (e.g. professionalization, development of interest groups, associations).

\section{Influential EU health policy outputs}

The ranking of influential policy outputs of EU-level health policy-making is provided in Table 2.

In the category "secondary legislation and court decisions", the patients' rights decisions made by the European Court of Justice $(n=12)$ were chosen by most of the respondents as influential policy output, followed by the Directive on the application of patients' rights in cross-border healthcare [39] ( $n=10)$ and the Directive on advertising and sponsorship of tobacco products [14] $(n=9)$. In the category entitled "soft laws, strategies, and programmes", the first and second EU public health programmes $[40,41](n=9)$ were selected most frequently, followed by the 20082013 health strategy Together for Health [42] $(n=6)$. The third rank is shared by three policy outputs: the Framework for action in the field of public health [43] $(n=5)$ which is the Commission's first proposal setting out EU-level public health after the introduction of the health mandate in the Maastricht Treaty, the Council conclusions Towards modern, responsive and sustainable health systems [44] $(n=5)$, and the current over-arching European strategy Europe 2020 [45] ( $\mathrm{n}=5$ ). In the third category on "agencies, centres and organizations", the European 
Medicines Agency (EMA, $n=15)$ ranked top, followed by the ECDC $(n=13)$ and the European Food Safety Authority (EFSA, $n=9$ ). Among "networks, policy platforms and collaborations", the European presidencies ( $n=13$ ) were selected most often by the respondents, followed by the collaboration of the European Commission (EC), the World Health Organization Regional Office for Europe (WHO-EUR) and the Organization for Economic Co-operation and Development (OECD) $(n=8)$. Moreover, the three entries on the third rank include the EU Health Policy Forum $(n=6)$, the network on epidemiological surveillance and control of infectious diseases $(n=6)$, and the network on Health Technology Assessment $(n=6)$. The fifth category was not topic specific therefore, work on European level health determinants $(n=10)$, the exchange of best practices $(n$ $=8)$, and published scientific reports which influenced EU policy-making $(n=7)$ were ranked on the first three positions.

Table 2 Ranking of influential policy outputs of EU-level public health policy, March/April 2012.

\begin{tabular}{lr}
\hline Categories & N \\
\hline Secondary legislation and court decisions & $\mathbf{1 2}$ \\
\hline Patient rights decisions by the European Court of Justice & $\mathbf{1 0}$ \\
Directive on patients' rights in cross-border care & $\mathbf{9}$ \\
Directive on tobacco advertising & 5 \\
Directive on blood safety & 4 \\
WHO Framework Convention on Tobacco Control & 3 \\
Directive on professional qualifications & 3 \\
Regulation 1408/71 & 2 \\
Directives on tobacco products & 2 \\
REACH regulation of chemical substances & $\mathbf{9}$ \\
\hline Soft laws, strategies and programmes & $\mathbf{6}$ \\
\hline First and second Public Health programme & $\mathbf{5}$ \\
Together for health: 2008-2013 & $\mathbf{5}$ \\
Framework for action in the field of public health & $\mathbf{5}$ \\
Towards modern, responsive and sustainable health systems (2011/C 202/04) & 4 \\
Europe 2020, Europe's growth strategy & 3 \\
Health in all Policies & 3 \\
Information to patients & 3 \\
Open Method of Coordination & 3 \\
Solidarity in health: Reducing health inequalities & 2 \\
Council recommendation on patient safety & 2 \\
Framework Programmes on health research & 2 \\
White paper on Governance & 0 \\
\hline Green paper on the European workforce for health &
\end{tabular}




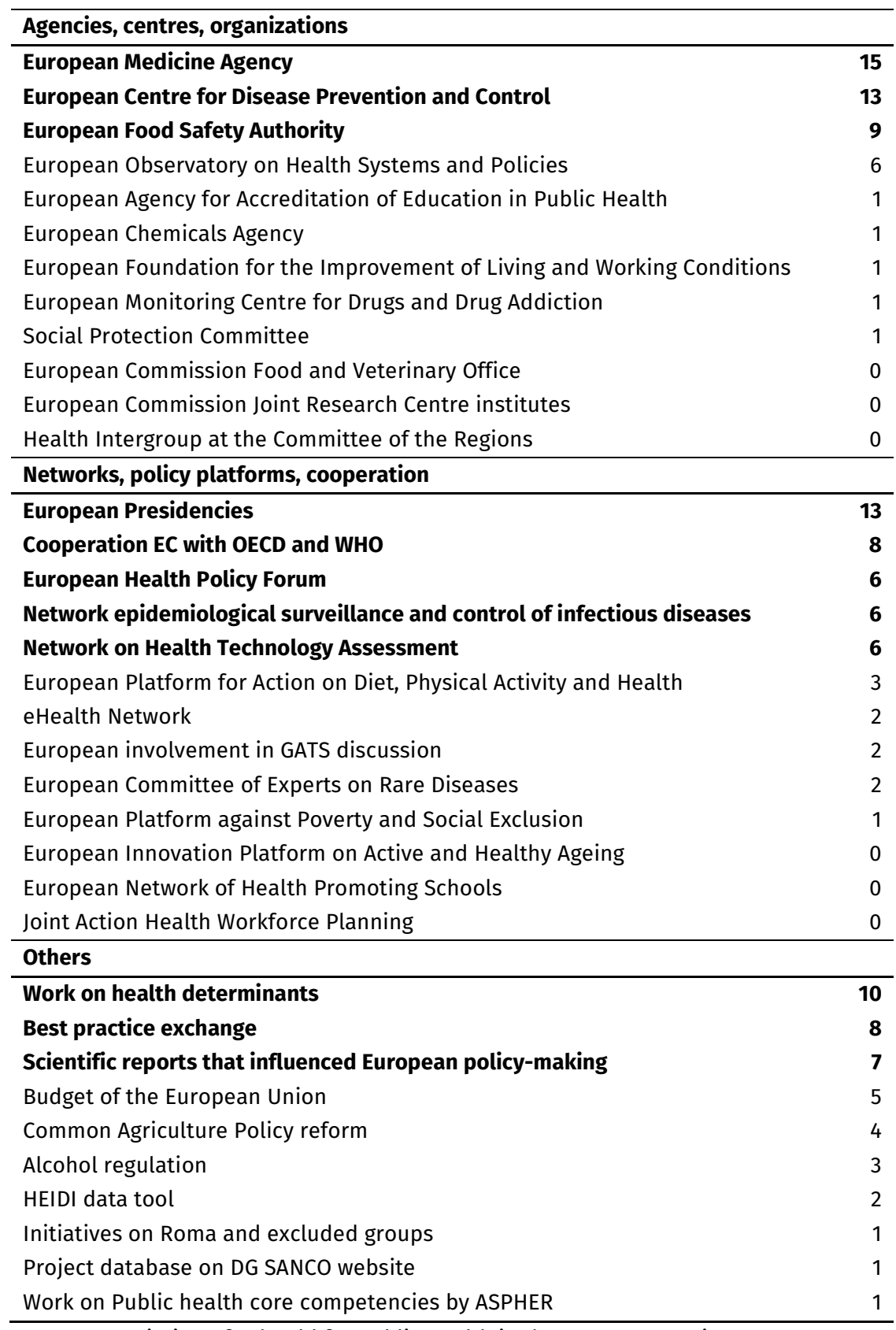

ASPHER: Association of Schoold for Public Health in the European Region

DG SANCO: Directorate General for Health and Consumer Protection

EC: European Commission

GATS: General Agreement on Trade in Services

HEIDI: Health in Europe: Information and Data Interface

OECD: Organization for Economic Cooperation and Development

WHO: World Health Organization

38 Assessing the status quo 


\section{Achievements, missed opportunities, failures}

At a glance, the label "achievement" was allocated to the public health mandate as it is laid down in the Treaties, the establishment of EU-level agencies dealing with public health topics and successes in smoking prohibition, food safety and infectious disease control. The label "missed opportunity" was allocated to the insufficient degree to which the HiAP approach is implemented and the ways in which health promotional aspects of alcohol and nutrition were handled. The label "failure" was less often assigned with the missing integration or link to social policies appearing in some interviews under this heading as well as the strength of the internal market which annulled national protective alcohol legislations in some member states. In Table 3, we provide the full list of EU-level outputs or actions which, based on the content analysis and the identified thematic categories, were mentioned as achievements, missed opportunities or failures by the key informants. Due to a broad and divergent spectrum of perceptions, topics almost always shared aspects of achievements, missed opportunities or failures. In the following section, we focus on those EU-level outputs or actions which were mentioned by the majority of respondents during the interviews and allowed us to draw a comprehensive picture on the breadth and the diversity of expert perceptions.

\section{EU health policy - an overview}

An assessment of the general value of EU-level public health actions over the last twenty years resulted in mainly ambivalent judgments. On the one hand, many relevant activities were performed at an EU-level and the existence of a health mandate contributed to an EU social model. On the other hand, its dependence on political will and economic circumstances influenced the development of EU-level public health policy and led to the perception that more should or could have been achieved within and beyond the possibilities of the current health mandate.

\section{The role of the Directorate General for Health and Consumers}

The establishment of the Directorate General for Health and Consumers (DG SANCO) in 1999 as an independent, formal structure for EU health policy was generally discussed as an achievement. The formation of DG SANCO, and thus, the political decision to separate the health dossier from DG V, the former DG with the responsibility for health policy as well as a focus on employment and social policies, was controversially perceived. The establishment of DG SANCO led, on the one hand, to a more mature health policy field.

"...the DG V was a big DG and then DG SANCO became separate from that. Health had its own commissioner, its own opportunity to protect itself and public health benefits." (\#15, public health advisor/advocate)

On the other hand, aspects of failure were mentioned regarding the detachment of health and social policy at EU-level. According to the respondents being separated led to a loss of 
collaboration for more holistic health policies and actions in health systems and healthcare at EU-level. ${ }^{1}$

Following the formation of DG SANCO, it was seen as a beneficial way forward for the DG to shift its sectorial policy approach from a focus on specific topics such as cancer, drug dependence, health monitoring, accidents and injuries, or pollution-related diseases, to a horizontal one with the formulation of the first health strategy with three cross-cutting objectives: health information, health threats and health determinants [46].

"And this was an important moment in time where the sectorial approach to AIDS, cancer and other issues has been reduced gradually and that more the integral horizontal approach, which was applied at that time already in all member states - hence Europe was running behind in that sense, but ultimately was embraced and taken as guideline for the framing of all sorts of public health actions. " (\#02, EU/national civil servant)

Since it fostered more visibility of the public health field and closer cooperation by financing projects, joint actions and research across Europe, the Public Health Programme of DG SANCO was commonly discussed as being supportive to the development of European public health and the mobilization of the public health community.

Aspects of missed opportunity became relevant when assessing the representation of health in other EU policies.

"I don't know what exactly the reason is, but they [DG SANCO] are not strong enough to push for health in [the other] DGs. The obvious example is the latest EU 2020 strategy, you cannot find reference to health anywhere it's really a disaster, because of [the] weak DG SANCO. Health is not among the headline targets, it's not among the flagships." (\#15, public health advisor/advocate)

While the cooperation with other DGs was recurrently discussed as problematic, the potential for the Partnership on Active and Healthy Ageing under the European Innovation Union appeared as a unique theme and was regarded as an achievement for strengthening health policy on the general EU policy agenda.

“...it is now coordinated under the Innovation Union [of Europe2020], and so Commissioner Neelie Kroes [DG Connect and Vice-Commissioner] is as much in the lead as Commissioner John Dalli [DG SANCO]. And that's a good sign, if we can get more of those sorts of partnerships on specific policies, then I think, we'll get a better understanding." (\#04, EU/national politician)

With regard to assessing the status of DG SANCO cooperation with other international policy actors, respondents had mixed perceptions. Whereas some argued that DG SANCO's collaboration

\footnotetext{
1 Also the majority of EU member states disconnected on national level the Ministry of Health from Social Affairs. Examples of countries with a combined ministry at the time of writing are Estonia, Finland, France, and Sweden.
} 
with international organizations like the WHO-EUR or the OECD is improving and therefore, can be considered as an achievement, others asserted that this collaboration was not sufficiently established and can therefore be categorized as a missed opportunity.

The role of health agencies: the example of ECDC

The establishment and the work of EU public health agencies like the EMA, the ECDC, the EFSA, and the European Monitoring Centre for Drugs and Drug Addiction (EMCDDA) were regarded as an achievement and as an important step forward towards the strengthening of the European dimension in health. The work and the scope of the agency mandates was a recurring topic and subject to diverging perceptions. As an example, in the case of the ECDC, its development was assessed as an achievement whilst its scope was considered a missed opportunity.

The bioterrorism attacks on the United States of America in 2001 and the SARS crisis led to calls for better international coordination of infectious disease surveillance and the establishment of ECDC in 2004 [47]. Hence, the setting up of ECDC was commonly perceived as an achievement, since it gave preceding EU actions in infectious disease control a formal structure and maintained actions in the field. Also, the close collaboration with the respective national public health agencies during outbreaks and in negotiating and developing common guidelines for infectious disease control were regarded as an important task of the ECDC.

However, a number of respondents were critical of the scope of the ECDC mandate and thus, looked at this as a missed opportunity. Questions were raised on whether the ECDC's responsibility in surveillance, risk assessment and training are sufficient or if additional responsibilities in risk communication and management were needed to assure full stewardship during and in the prevention of health crises.

"I suppose the flu epidemic [...]. That should be put on the table not only as a missed opportunity, big failure, having put ECDC at the center of the development, but the ECDC is not authorized to risk communicational management as you know. So, in that sense, it is a failure that member states were not able to coordinate in this very important public health area and use the EU institution, either ECDC or WHO to do that." (\#03, public health advisor/advocate)

Moreover, interview participants reported tensions between member states and EU agencies regarding the transfer of responsibilities from national to EU-level.

"And the member states are very reluctant to hand over power regarding public health to the Commission, or to Brussels. Now if you focus on infectious diseases, that is much better because they understand that there is a need, but again it is not easy." (\#30, EU/national civil servant)

Since the largest burden of disease in the EU is caused by non-infectious rather than infectious diseases, a call was put forward to further increase the mandate of ECDC to all public health relevant aspects and not focus only on infectious diseases. 


\section{Health in All Policies (HiAP)}

The HiAP approach was generally assessed as an achievement regarding its potential to address health determinants outside the health sector.

"[the article on the health mandate] is very important, because thereby a mandate is created that the Commissioner for Health and Consumer Affairs [...] approaches his colleagues whenever they make new legislation to ensure that the health protection dimension is guaranteed; it gives partly a mandate to break into the policy and law development in sectors which in principle do not have any links with public health. [...] this is very difficult. But its potential is very strong." (\#2, EU/national civil servant)

However, in regard to its degree of implementation participants commonly perceived HiAP as a missed opportunity. Health Impact Assessment, the implementing tool to HiAP, was regarded as a "tick box exercise" (\#03, \#15, both public health advisor/advocate) rather than a thorough consideration of health in other policies areas. Explanations given during the interviews demonstrated that conditions to achieve HiAP seemed not to be established yet and that there seems to be difficulty in bringing DG SANCO interests in line with the interests of other DGs without over-emphasizing the health aspect. Political assertiveness in convincing other Commissioners and DGs about the relevance for intersectoral cooperation was perceived to be lacking, even though an Inter-service group on Public Health with the participation of more than twenty EC departments was established for this purpose.

\section{Approach to life style factors}

Generally, the work regarding tobacco was regarded as an achievement of how European health policy-making effectively addressed a life style risk factor for health.

"The progress around tobacco [Directive on tobacco advertising, Directive on tobacco products, transparency register], the fact that we have a piece of international law on tobacco [WHO Framework Convention on Tobacco Control] is massive and that was European led." (\#05, public health advisor/advocate).

This quote echoed the perception of the majority of respondents who emphasized the leading role of the EU regarding the support and commitment to the WHO Framework Convention on Tobacco Control. Moreover, it was argued that the achievements regarding the regulation of tobacco advertising and smoking prohibition in public places would not have been achieved by single member states independently and thus this was a common achievement initiated and supported by European cooperation. Nevertheless, aspects of a missed opportunity or even failure were mentioned in this regard since some would have appreciated stronger legislative measures to achieve a more harmonized realization of smoke-free legislation across the EU. 
It was considered that the achievements recognized in EU tobacco legislation were missed in the regulation of other health-related life style factors such as nutrition and alcohol. Whilst regulations in the area of food safety were generally acknowledged as an achievement by preventing food-borne health threats; a potential mandate to address the composition of food and thereby, prevent, inter alia obesity or non-communicable diseases seemed to be neglected and was labelled as a missed opportunity.

“...food safety has been majorly put forward over the last twenty years, in the sense that we know that the food will not be contaminated. But then it is a missed opportunity in the sense that beyond food safety there is health promotion and then one wanted the Union to have more powers to regulate issues on the content of saturated fat for instance or the percentages of sugar and so on." (\#03, public health advisor/advocate)

With regard to governmental activity on these issues, the EU Platform for Action on Diet, Physical Activity and Health was named as an example of an achievement as well as a failure.

"I think the diet platform [...] can be seen as a failure and opportunity. [...] If we had not created that platform then arguably the issue wouldn't have been tackled at all. And in a way that has been really brought some issues of complexity to the political discussion around issues around marketing of food, around self-regulation, reformulation, some of the initiative like salt in diet has come as a commitment from that platform." (\#05, public health advisor/advocate)

The failure aspect of the EU Platform for Action on Diet, Physical Activity and Health was related to the perception that a platform is a rather weak policy instrument and that more political will to tackle these issues with stronger EU policy or legal instruments would have had more impact. Additionally, the lack of timely cooperation of public health professionals with other sectors such as agriculture was raised as missed opportunity. It was illustrated that agriculture policy has public health relevant links regarding affordability, accessibility, and the availability of food. However, it was also argued that this cooperation has been developed further over the recent years.

"And it is correct, that the Common Agriculture Policy has not been taken up health in the beginning, but by now they are doing this very consciously. [...] Thus, I really see an improvement; I actually do not see a situation anymore in which health was influenced really negatively [by the Common Agriculture Policy]." (\#26, EU/national civil servant)

Internal market provisions

Internal market provisions were perceived as ambivalent by the respondents. The EU is based on internal market rules that also affect EU health policy.

"The engine of European health policies is still the market." (\#23, academia) 
However, the influence of EU market regulations, for example on alcohol policies, was perceived as a failure when member states had more protective and stricter national legislation as was the case in the Nordic countries. Respondents claimed that EU internal market regulations that are more attentive to health issues would be appreciated in this case. Moreover, the potential given by Articles 36 and 114 of the TFEU, which put limitations on the Single Market, was mentioned and it was perceived as a missed opportunity that this potential had not been fully taken up by public health experts:

"[...] the public health aspect, which is written into Article 95 [now Article 114, TFEU] on the internal market, you can put limits on the internal market on the grounds of public safety, public morality and public health, is almost never used. What if DG Internal Market was turned into our greatest weapon?" (\#32, public health advisor/advocate)

This was positively exemplified by the case of tobacco control which applied internal market rules for public health purposes to assure harmonized labelling, packaging, nicotine content, etc. across the EU. However, the application of the health argument to put limitations on the internal market rules was also perceived as being negatively connoted by non-public health experts:

"If you just go to the DG Internal Market and grab the first person you see and ask them what public health means, they will tell you it's the exception member states use to defend local weird monopolies on peculiar alcohol, or something like that. It's an exception to a rule." (\#19, academia)

\section{Patients' rights Directive}

The recent EU patients' rights Directive in cross-border healthcare [39] was mainly regarded as an important achievement. This assessment was not necessarily driven by satisfaction with the scope of the Directive but, instead, because it is the first EU secondary legislation ever enacted specifically on healthcare.

"[...] the cross-border Directive will turn out to be incredibly important. Particularly because it is so symbolic important if you like because it does represent really the first time that the EU has got any concrete in relation to healthcare as opposed to public health. The consequences of this remains to be seen." (\#29, EU/national civil servant)

"Therefore, I see the patients' Directive as a true success from a legislative perspective" (\#23, academia)

The achievement aspect was supported by perceptions that the Directive will lead to more crossborder cooperation and will have an impact on quality of care as well as on priority setting in healthcare and the packaging of healthcare services. Thereby, it was expected that the Directive will not only influence people who seek healthcare services in other countries but also those who seek services in their home country. In this regard, some expected that the Directive would also ultimately empower patients as consumers of healthcare services. 
"The cross-border Directive [...] will have consequences of more consumer empowerment, consumer rights, patient rights, more consumer participation and more literacy,..." (\#03, public health advisor/advocate)

However, there were also critical voices that interpreted the Directive, as targeting a limited segment of the European population and hence, potentially increasing health inequalities. These respondents also questioned the willingness of the general population to seek healthcare treatment outside their home country. Furthermore, respondents were critical of the extent to which more EU involvement in healthcare of member states would lead to quality assurance in general:

"It is positive in the way people can be treated where they want, but it is still my point of view that we [...] want to have our own level of quality and we don't want others to decide what level it should be. Perhaps, because we have a very high quality [...]. But of course we don't mind to tell others about it, we don't mind others to come in, we don't mind to help others to get the same standard - that is cooperation, so I always say I love cooperation but I do mind the harmonization." (\#18, EU/national politician)

Table 3 Summary of public health relevant EU-level actions and their perception as achievement, failure or missed opportunity.

\begin{tabular}{|c|c|c|c|}
\hline Topics & achievement & missed opportunity & failure \\
\hline Treaty & $\begin{array}{l}\text { Inclusion of the health } \\
\text { mandate as enshrined in } \\
\text { Article } 129 \text { of the Treaty of } \\
\text { the European Union. }\end{array}$ & $\begin{array}{l}\text { Missing implementation of } \\
\text { a connection/share of } \\
\text { power between economic } \\
\text { and social EU policy. }\end{array}$ & \\
\hline \multirow[t]{3}{*}{$\begin{array}{l}\text { Directorate General for } \\
\text { Health and Consumers (DG } \\
\text { SANCO) }\end{array}$} & $\begin{array}{l}\text { Existence and persistence } \\
\text { of DG SANCO. }\end{array}$ & $\begin{array}{l}\text { DG SANCO is not strong } \\
\text { enough to push health in } \\
\text { other DGs. }\end{array}$ & $\begin{array}{l}\text { DG SANCO set-up: Missing } \\
\text { link to social policy. }\end{array}$ \\
\hline & Public Health Programme & $\begin{array}{l}\text { Public health did not } \\
\text { become a key aspect of EU } \\
\text { policy. }\end{array}$ & \\
\hline & & $\begin{array}{l}\text { Sustainability development } \\
\text { strategy: DG SANCO is not } \\
\text { playing an active role in } \\
\text { the marketing of the } \\
\text { strategy. }\end{array}$ & \\
\hline Cooperation & $\begin{array}{l}\text { Cooperation between EU, } \\
\text { WHO and OECD. }\end{array}$ & $\begin{array}{l}\text { Missing connection and } \\
\text { joint forces between EC } \\
\text { and WHO. }\end{array}$ & \\
\hline
\end{tabular}




\begin{tabular}{|c|c|c|c|}
\hline Topics & achievement & missed opportunity & failure \\
\hline \multirow[t]{4}{*}{ EC agencies } & Development of Agencies: & & \\
\hline & ECDC, EFSA, EMA, EMCDDA. & & \\
\hline & $\begin{array}{l}\text { Legislation on infectious } \\
\text { disease control. }\end{array}$ & $\begin{array}{l}\text { ECDC mandate should } \\
\text { include responsibilities in } \\
\text { risk management of } \\
\text { infectious diseases. }\end{array}$ & \\
\hline & $\begin{array}{l}\text { European Programme for } \\
\text { Intervention Epidemiology } \\
\text { Training (EPIET). }\end{array}$ & $\begin{array}{l}\text { ECDC profile should cover } \\
\text { also non-communicable } \\
\text { diseases and SDoH. }\end{array}$ & \\
\hline \multirow[t]{2}{*}{ EMA } & $\begin{array}{l}\text { Coordination of the } \\
\text { approval of efficacy, safety } \\
\text { and quality of drugs. }\end{array}$ & $\begin{array}{l}\text { Cost-effectiveness of } \\
\text { pharmaceuticals is not } \\
\text { taken into account. }\end{array}$ & $\begin{array}{l}\text { Problem of not being able } \\
\text { to tackle pharmaceutical } \\
\text { pricing. }\end{array}$ \\
\hline & & $\begin{array}{l}\text { Reversal of the approval of } \\
\text { already approved drugs } \\
\text { not handled on EU-level. }\end{array}$ & \\
\hline \multirow[t]{2}{*}{ EFSA } & $\begin{array}{l}\text { Control of health claims of } \\
\text { food products. }\end{array}$ & $\begin{array}{l}\text { EFSA mandate should } \\
\text { include/be stronger on } \\
\text { health promotion aspects } \\
\text { of nutrition (e.g. regulation } \\
\text { of advertisement of } \\
\text { unhealthy food products). }\end{array}$ & \\
\hline & Food Safety Directive & & \\
\hline \multirow[t]{2}{*}{$\begin{array}{l}\text { Health in All Policies (HiAP) } \\
\text { approach }\end{array}$} & $\begin{array}{l}\text { Health mandate assures } \\
\text { that health protection } \\
\text { should be guaranteed in all } \\
\text { EU policies. }\end{array}$ & $\begin{array}{l}\text { HiAP and Health Impact } \\
\text { Assessment have never } \\
\text { been implemented fully } \\
\text { (tick box exercise). }\end{array}$ & \\
\hline & $\begin{array}{l}\text { Leads to the discussion of } \\
\text { health in other sectors. }\end{array}$ & & \\
\hline \multirow[t]{2}{*}{ Lifestyle factors } & $\begin{array}{l}\text { Common tobacco } \\
\text { legislations in Europe } \\
\text { (WHO Framework } \\
\text { convention of tobacco } \\
\text { control; tobacco product- ; } \\
\text { tobacco advertising } \\
\text { directive). }\end{array}$ & $\begin{array}{l}\text { The tobacco regulations } \\
\text { could have been designed } \\
\text { stronger (e.g. more } \\
\text { harmonized realisation of } \\
\text { smoking prohibition on } \\
\text { public places). }\end{array}$ & $\begin{array}{l}\text { Tobacco regulation has } \\
\text { some aspects of failure } \\
\text { since a strict, general ban } \\
\text { is not reached. }\end{array}$ \\
\hline & $\begin{array}{l}\text { Food safety measures and } \\
\text { regulations on health } \\
\text { claims. }\end{array}$ & $\begin{array}{l}\text { Missing political will to } \\
\text { tackle obesity and related } \\
\text { life style factors like } \\
\text { unhealthy food products. }\end{array}$ & \\
\hline
\end{tabular}




\begin{tabular}{|c|c|c|c|}
\hline Topics & achievement & missed opportunity & failure \\
\hline $\begin{array}{l}\text { Health Research } \\
\text { Programme }\end{array}$ & $\begin{array}{l}\text { EU health research budget } \\
\text { and outcomes of the } \\
\text { programme. }\end{array}$ & & $\begin{array}{l}\text { Missing integration of the } \\
\text { research programme and } \\
\text { EU health research } \\
\text { outcomes in public health. }\end{array}$ \\
\hline \multirow[t]{3}{*}{ EU budget } & $\begin{array}{l}\text { Largest budget proportion } \\
\text { shifted in the multiannual } \\
\text { financial framework 2007- } \\
2013 \text { from agriculture } \\
\text { financing to the funding of } \\
\text { cohesion and sustainable } \\
\text { growth policies. }\end{array}$ & & \\
\hline & Health research budget & & \\
\hline & $\begin{array}{l}\text { The use of structural funds } \\
\text { for investments in health } \\
\text { (2007-2013). }\end{array}$ & & \\
\hline Internal market provisions & & $\begin{array}{l}\text { Internal market rules as } \\
\text { source for legislation } \\
\text { should be more attentive } \\
\text { to health concerns. }\end{array}$ & $\begin{array}{l}\text { Internal market provisions } \\
\text { cause problems if Member } \\
\text { State regulation is more } \\
\text { protective regarding health } \\
\text { threats than EU regulation. }\end{array}$ \\
\hline \multirow[t]{3}{*}{ Patients Right Directive } & $\begin{array}{l}\text { The Patient Right Directive } \\
\text { in general. }\end{array}$ & $\begin{array}{l}\text { Negotiations on Patients } \\
\text { Right Directive failed to } \\
\text { include a strong emphasis } \\
\text { on the development of } \\
\text { common standards. }\end{array}$ & \\
\hline & $\begin{array}{l}\text { Effect on cross-border } \\
\text { cooperation. }\end{array}$ & & \\
\hline & $\begin{array}{l}\text { Gives legal certainty to } \\
\text { policy makers. }\end{array}$ & & \\
\hline Common Agriculture Policy & $\begin{array}{l}\text { Policy field which starts to } \\
\text { recognize health, e.g. in its } \\
\text { white paper on the CAP } \\
\text { after } 2013(2009 / 2236(\mathrm{INI})) \text {. }\end{array}$ & $\begin{array}{l}\text { Unrecognized potential for } \\
\text { health of the CAP by public } \\
\text { health sector. }\end{array}$ & \\
\hline Health information & $\begin{array}{l}\text { Health Life Years as } \\
\text { indicator in the Lisbon } \\
\text { strategy. }\end{array}$ & & $\begin{array}{l}\text { Missing health information } \\
\text { system. }\end{array}$ \\
\hline
\end{tabular}

Lack of morbidity data. 


\begin{tabular}{|c|c|c|c|}
\hline Topics & achievement & missed opportunity & failure \\
\hline \multicolumn{4}{|l|}{$\begin{array}{l}\text { Different public health } \\
\text { topics }\end{array}$} \\
\hline health inequalities & $\begin{array}{l}\text { EC communication: } \\
\text { Solidarity in health: } \\
\text { reducing health } \\
\text { inequalities in the EU. }\end{array}$ & & \\
\hline HTA & $\begin{array}{l}\text { Strengthening of the HTA } \\
\text { approach in the EU. }\end{array}$ & $\begin{array}{l}\text { Coordinating cross-country } \\
\text { level health technology } \\
\text { assessments. }\end{array}$ & \\
\hline rare diseases & $\begin{array}{l}\text { Coordinated management } \\
\text { of rare diseases. }\end{array}$ & & \\
\hline tuberculosis & & & $\begin{array}{l}\text { Existing drug resistance of } \\
\text { tuberculosis as indicator } \\
\text { for lacking disease } \\
\text { management. }\end{array}$ \\
\hline health of minorities & $\begin{array}{l}\text { Health of minorities (e.g. } \\
\text { Roma) as part of the } \\
\text { European agenda. }\end{array}$ & & \\
\hline social care & & $\begin{array}{l}\text { Social care is hardly seen } \\
\text { as EU competence. }\end{array}$ & \\
\hline $\begin{array}{l}\text { environment (and } \\
\text { health) }\end{array}$ & $\begin{array}{l}\text { Environmental standards } \\
\text { set by the EU. }\end{array}$ & $\begin{array}{l}\text { Missing follow-up process } \\
\text { on the Environment and } \\
\text { Health Action Plan (2004- } \\
\text { 2010). }\end{array}$ & \\
\hline Information to patients & $\begin{array}{l}\text { Blocking of direct to } \\
\text { consumer advertising of } \\
\text { prescription-only } \\
\text { pharmaceuticals. }\end{array}$ & & \\
\hline \multirow[t]{3}{*}{ Governmental issues } & $\begin{array}{l}\text { White paper on governance } \\
\text { (2001) increased } \\
\text { transparency. }\end{array}$ & & \\
\hline & $\begin{array}{l}\text { More standardisation of } \\
\text { methods (evaluation of } \\
\text { indicators, outcomes, } \\
\text { policies) and common } \\
\text { language. }\end{array}$ & & \\
\hline & $\begin{array}{l}\text { Increased understanding of } \\
\text { the public health } \\
\text { community about the } \\
\text { impact of EU policies on } \\
\text { public health. }\end{array}$ & & \\
\hline
\end{tabular}




\begin{tabular}{|c|c|c|}
\hline Topics & missed opportunity & failure \\
\hline Industry involvement & & $\begin{array}{l}\text { Cooperation with industry } \\
\text { influences the health } \\
\text { research agenda and } \\
\text { policy-making. }\end{array}$ \\
\hline & & $\begin{array}{l}\text { Evidence-based policy- } \\
\text { making: the interest of the } \\
\text { industry is against public } \\
\text { health. }\end{array}$ \\
\hline
\end{tabular}

ECDC: European Centre for Disease Prevention and Control

EFSA: European Food Safety Authority

EMA: European Medicines Agency

EMCDDA: European Monitoring Centre for Drugs and Drug Addiction

HTA: Health Technology Assessment

DG: Directorate General

SDoH: Social Determinants of Health

EC: European Commission

OECD: Organization for Economic Cooperation and Development

WHO: World Health Organization

\section{Discussion}

This study provides an overview of public health relevant EU-level actions of the past twenty years. We outlined the diverse nature of expert perceptions on key developments in the field and provided a ranking of the most influential achievements. The assessment of outputs or actions being an achievement appeared across and within interviews along with assessments of outputs or actions being a missed opportunity and less often a failure. Thereby, it turned out that the EU public health field has significantly developed its organizational structures (DG SANCO, supranational agencies dealing with public health) and incorporated public health topics like infectious disease control and tobacco control, whereas the HiAP approach still included untapped potential. This finding confirms The Challenge of Implementation [48] of the HiAP concept in the EU [28,49]. Given the fact that according to Article 9 and Article 168 (1),TFEU [1], a high level of human health protection should be ensured within all EU policies and actions, it was seen as a weakness that the uptake of health consideration in the general EU policy-making process was low [28]. Ollila described the importance of communication and cooperation strategies for a successful realization of the HiAP approach [49]. The deficiency of these strategies was raised during the interviews which indicated that the performance of EU health players is perceived to be particularly poor in this regard.

\section{Concordance of interview responses with tasks formulated in the health mandate of the EU} Interestingly, the study indicated that the Treaty-based tasks such as support of cooperation between member states, development of guidelines and indicators, best practice exchange, and periodic monitoring and evaluation on EU-level public health to ensure "a high level of human health protection" [1] were only partially perceived as fulfilled or acknowledged by the 
interviewed experts. Thematic discussions on actions or policies related to the development of guidelines and indicators appeared with regard to infectious disease surveillance and management of rare diseases but were not a major theme across interviews. The EU-level task to promote best practice exchange among member states was regarded as influential, which is represented by a top position in one of the rankings presented in this paper. With regard to the task of establishing monitoring and evaluation structures, some respondents perceived the status of the EU health information system rather as a failure. This corresponds to observations in the literature indicating that although ground work such as the development of a common EU health indicator set is acknowledged [50,51] further efforts are needed to implement and maintain health indicators [51] and to develop a permanent and sustainable EU public health monitoring and reporting infrastructure that supports decision making in public health on EU level $[50,51]$. Respondents agreed that cooperation in the area of public health between member state representatives and experts as well as with other stakeholder groups has increased and has been facilitated by the EU through various projects, networks, forums, and platforms. This trend was mainly positively perceived since it supported EU-level public health policy by accumulating and exchanging knowledge, generating public support and a legitimacy to act on certain fields [3]. This finding is corroborated by the literature on the potential of new governance instruments for health- and social policy-making at EU-level [11,52-54]. However, these new governance instruments can also be regarded as a rather strategic investment of the EC to keep topics on the agenda until a political window of opportunity opens but as an ineffective policy tool to enforce and implement action in due course [6]. The collaboration of a diverse set of stakeholders as it is the case for example in the EU Platform for Action on Diet, Physical Activity and Health can lead to actions that constitute rather a compromise of various interests. Consequently, the results might be disappointing from the viewpoint of public health experts [6,55]. A final judgment on the impact of facilitating collaboration is to be awaited and may only be made in the long term future. It will require different ways of measuring 'impact' compared to the analysis of domestic adaptations when implementing EU hard law [56].

\section{Characteristics of EU health policy that influenced experts' perception}

The assessments of EC tasks for public health policy making have been influenced by characteristics like the subsidiarity principle throughout several interviews. On the one hand some participants were in favour of more EU influence on health policies and their implementation. In their view integration and harmonization of health policy did not reach far enough and hence their perception of actions was dominated by the category 'missed opportunity'. On the other hand some experts were in favour of keeping certain health issues like health care as national responsibility which led to a perception of too much EU involvement and a negative perception of the evolvement of the health mandate. 
Public health has a cross-cutting nature and cooperation across DG's often poses difficulties. Therefore, convincing evidence is required to demonstrate the health impact of policies outside the health domain and strong partnerships are needed to counter strong industrial lobbying groups $[6,57,58]$. The ease of cooperation and the potential to achieve policy coherence between DG SANCO and DGs with stronger regulatory competences like the internal market (e.g. regarding tobacco, pharmaceuticals) or agriculture policy (regarding food safety, subsidies of unhealthy versus healthy food products) represented another characteristic that influenced the individual perception of EU public health policies. Experts who assessed the value of EU health policy actions under the reality of a rather weak health mandate were more likely to perceive EU actions as achievements. This was in contrast to others who strove for more appreciation of social and health matters in EU policies and who perceived a lot of missed opportunities or failures in this regard as the power of the EU was too weak to realize change and to fulfill the objective of the health mandate to ensure human health protection for citizens in the EU.

In summary, underlying themes such as cooperation among European public health professionals, increasing institutionalization, and characteristics such as the issue of subsidiarity or the possibilities to cooperate across EU policy domains influenced experts' perceptions throughout the topics presented in this paper. These conditions and characteristics are part of what Lamping called the "chaordic dynamics" of European integration in the field of health policies [3]. As our study demonstrated EU health policy does not demonstrate a clear-cut success since the logic of action in the field can involve diverging interests. Nevertheless, the EU public health has quite systematically developed in terms of scope and impact beyond the original mandate.

\section{Limitations}

The ranking of influential policy outputs provided indications on important developments in EU public health policy. However, even though we categorized the outputs, they sometimes differed in character and power which might have led to imbalanced judgments.

Additionally, we received different reasons for labelling EU-level actions or policies as achievements, missed opportunities or failure for public health. Some were identified because they increased the strength or value of EU-level public health policy, whereas, others were identified because they impacted the health of the European population.

The findings of the study may not be empirically generalizable since they were closely linked to qualitative individual perceptions and the settings that participants belonged to. However, we are confident that the broad range of profiles of the experts has ensured the diversity of perceptions on the topics varying from achievement to missed opportunity and failure. Moreover, given that participants were generally active in health policy at EU-level and mainly positive about the EU, this could also have influenced the obtained results to some extent. 


\section{Conclusion}

EU public health policy is subject to divergent perceptions of how successful or unsuccessful specific topics have been tackled and how far European integration in public health policy should go. From the findings, it is unequivocal that the EU has strengthened its role over the past twenty years in supporting, coordinating, and supplementing member states' actions on public health issues as laid down in Article 168 (2), TFEU. The EU is now a recognized player in public health in Europe. However, when it comes "to the promotion of a high level of [...] protection of human health [...] ]in defining and implementing its policies and activities" (Article 9, TFEU), further work is needed to achieve the full potential of the EU health mandate.

\section{Abbreviations}

ASPHER: Association of Schools for Public Health in the European Region; BSE: Boviene spongiforme encefalopathie; DG: Directorate General; DG Connect: Directorate General for Communications Networks, Content and Technology; DG SANCO: Directorate General for Health and Consumers; EC: European Commission; ECDC: European Centre for Disease Prevention and Control; EFSA: European Food Safety Authority; EMA: European Medicines Agency; EMCDDA: European Monitoring Centre for Drugs and Drug Addiction; EU: European Union; GATS: General Agreement on Trade in Services; HEIDI: Health in Europe: Information and Data Interface; HIA: Health Impact Assessment; HiAP: Health in All Policies; HTA: Health Technology Assessment; OECD: Organization for Economic Cooperation and Development; SARS: Severe acute respiratory syndrome; SDoH: Social Determinants of Health; TFEU: Treaty on the Functioning of the European Union; WHO-EUR: World Health Organization- Regional Office for Europe.

\section{Authors' contributions}

All authors were involved in setting up the study. NR and TC coordinated the study. NR, TC and KS carried out the interviews, performed the analysis, and interpreted the results. NR drafted the manuscript. All authors revised the manuscript and approved the final version.

\section{Acknowledgements}

The paper was partly presented at a symposium held on 5th June 2012 in Brussels, Belgium, the European Public Health Conference on 10th November 2012 in Malta, and a conference on the 20th anniversary of the EU health mandate on 22nd May 2013 in Maastricht, the Netherlands. We 
would like to express our sincere thanks to the experts who invested their time and participated in the interviews. Their views and perceptions on European public health policy were highly valued. We would like to thank Wilco Tilburgs and Hassan el Fartakh for their support in transcribing the interviews and Ann Borg for her support and helpful recommendations during the final editing process. We also appreciate the support of our colleagues at the Department of International Health at Maastricht University; in particular Kasia Czabanowska, Matt Commers, Kai Michelsen, Christoph Aluttis and Beatrice Scholtes gave advice in setting up and designing the study, questioning the results, or reviewing the manuscript. 


\section{References}

1. European Union. Treaty on the Functioning of the European Union. Lisbon: European Union; 2007.

2. European Union. The Maastricht Treaty. The Treaty on the European Union (TEU) Maastricht: European Union; 1992.

3. Lamping W, Steffen M. European Union and health policy: the "chaordic" dynamics of integration. Soc Sci Quart. 2009;13(5):1361-1379. doi: 10.1111/j.1540-6237.2009.00659.x.

4. McKee M, Mossialos E, Baeten R, editor. The impact of the EU law on health care systems. Brussels: P.I.E.-Peter Lang; 2002.

5. Mossialos E, McKee M. EU Law and the Social Character of Health Care. Brussels: P.I.E.-Peter Lang; 2002.

6. Greer SL, Hervey TK, Mackenbach JP, McKee M. Health law and policy in the European union. Lancet. 2013;13(9872):1135-1144. doi: 10.1016/S0140-6736(12)62083-2.

7. Greer SL. The Politics Of European Union Health Politics. Maidenhead: Open University Press; 2009.

8. Mossialos E, Permanand G, Baeten R, Hervey TK, editor. Health systems governance in Europe - the role of European Union law and policy. Cambridge: Cambridge University Press; 2010.

9. Hervey TK, McHale JV. Health Law and the European Union. Cambridge: Cambridge University Press; 2004.

10. Steffen M, editor. Health Governance in Europe - Issues, challenges and theories. New York: Routledge; 2005.

11. Greer SL, Kurzer P, editor. European Union Public Health Policies - Regional and global trends. Abingson, UK: Routledge; 2013.

12. Adamini S, Versluis E, Maarse H. European policymaking on the tobacco advertising ban: the importance of escape routes. Health Econ Policy Law. 2011;13(01):65-84. doi: $10.1017 /$ S1744133109990338.

13. Szyszczak E. In: Health Care and EU Law. Van de Gronden J, Szyszczak E, Neergaard U, M K, editor. The Hague: T.M.C. Asser Press; 2011. Patient's rights: a lost cause or missed opportunity? pp. 103-131.

14. European Parliament and Council of the European Union. Directive on the approximation of the laws, regulations and administrative provisions of the Member States relating to the advertising and sponsorship of tobacco products (2003/33/EC) Off J Eur Union. 2003;13:16-19.

15. European Parliament and Council of the European Union. Directive on the approximation of the laws, regulations and administrative provisions of the Member States concerning the manufacture, presentation and sale of tobacco products (2001/37/EC) Off J Eur Union. 2001;13:26-35.

16. European Parliament and Council of the European Union. Decision setting up a network for the epidemiological surveillance and control of communicable diseases in the community (2119/98/EC) Off J Eur Union. 1998;13:1-7. 
17. European Commission. Commission Decision 2000/57/EC on the early warning and response system for the prevention and control of communicable diseases under Decision No 2119/98/EC. Off J Eur Union. 2000;13:32-35.

18. Segnan N, Patnick J, von Karsa L, editor. European guidelines for quality assurance in colorectal cancer screening and diagnosis. Luxembourg: Publication Office of the European Union; 2010.

19. Arbyn M, Anttila A, Jordan J, Ronco G, Schenck U, Segnan N, Wiener HG, Herbert A, Daniel J, von Karsa L. European guidelines for quality assurance in cervical cancer screening. 2. Luxembourg: Office for Official Publications of the European Communities; 2008.

20. Perry N, Broeders M, de Wolf C, Törnberg S, Holland R, Von Karsa L, Puthaar E. European guidelines for quality assurance in breast cancer screening and diagnosis. 4. Luxembourg: Office for Official Publications of the European Communities; 2006.

21. Permanand G, Vos E. In: Health Systems Governance in Europe. Mossialos E, Permanand G, Baeten R, Hervey T, editor. New York: Cambridge University Press; 2010. EU regulatory agencies and health protection; pp. 134-185.

22. Public Health and Risk Assessment Directorate. Key Achievements 2009. Luxembourg: Directorate General for Health and Consumers (DG SANCO); 2010.

23. Public Health and Risk Assessment Directorate. Key Achievements 2010. Luxembourg: European Commission; 2011.

24. Directorate General for Health and Consumers (DG SANCO) Health in the EU. What is in there for you? Recent achievements. Luxembourg: European Commission; 2012.

25. Birt CA. CAP on Health? The impact of the EU Common Agricultural Policy on public health. London: Faculty of Public Health; 2007.

26. Lloyd-Williams F, O'Flaherty M, Mwatsama M, Birt C, Ireland R, Capewell S. Estimating the cardiovascular mortality burden attributable to the European common agricultural policy on dietary saturated fats. Bull World Health Organ. 2008;13:535-541A. doi: 10.2471/BLT.08.053728.

27. Permanand G, Mossialos E, McKee M. Regulating medicines in Europe: the European medicines agency, marketing authorisation, transparency and pharmacovigilance. Clin Med J Royal Coll Physicians. 2006;13(1):87-90. doi: 10.7861/clinmedicine.6-1-87.

28. Stahl TP. Is health recognized in the EU's policy process? An analysis of the European commission's impact assessments. Eur J Public Health. 2010;13(2):176-181. doi: 10.1093/eurpub/ckp082.

29. Greer SL. The European centre for disease prevention and control: hub or hollow core? J Health Polit Policy Law. 2012;13(6):1001-1030. doi: 10.1215/03616878-1813817. [PubMed]

30. Public Health Evaluation and Impact Assessment Consortium. Mid-Term Evaluation of the EU Health Strategy 2008-2013 - Final Report. Bologna: Public Health Evaluation and Impact Assessment Consortium; 2011.

31. European Court of Auditors. The European Union's Public Health Programme (2003-2007): An effective way to improve health? Special Report No 2//2009. Luxembourg: European Court of Auditors; 2009. 
32. Public Health Evaluation and Impact Assessment Consortium. Mid-Term Evaluation Health Programme (2008-2013) - Final Report. Bologna: Public Health Evaluation and Impact Assessment Consortium; 2011.

33. Clark JP. In: Peer Review in Health Sciences. 2. Godlee F, Jefferson T, editor. London: BMJ Books; 2003. How to peer review a qualitative manuscript; pp. 219-235.

34. Miles MB, Huberman AM. Qualitative Data Analysis: An Expanded Sourcebook. 2. Thousand Oaks: SAGE Publications, Inc.; 1994.

35. Mayring P. Qualitative Inhaltsanalyse: Grundlagen und Techniken. 11. Beltz: Weinheim; 2010.

36. Hsieh HF, Shannon SE. Three approaches to qualitative content analysis. Qual Health Res. 2005;13(9):1277-1288. doi: 10.1177/1049732305276687. [PubMed] [Cross Ref]

37. Jones J, Hunter D. Consensus methods for medical and health services research. BMJ. 1995;13(7001):376-380. doi: 10.1136/bmj.311.7001.376.

38. Lincoln YS, Guba EG. Naturalistic Inquiry. New Bury Park, California, United States: SAGE Publisher Inc.; 1985.

39. European Parliament, Council of the European Union. Directive on the application of patients' rights in cross-border healthcare (2011/24/EU) Off J Eur Union. 2011;13:45-65.

40. European Parliament, Council of the European Union. Decision on adopting a programme of community action in the field of public health (2003-2008) (1786/2002/EC) Off J Eur Union. 2002;13:1-11.

41. European Parliament, Council of the European Union. Decision on establishing a second programme of community action in the field of health (2008-13) (1350/2007/EC) Off J Eur Union. 2007;13:3-13.

42. European Commission. White paper. Together for Health: A strategic Approach for the EU 2008-2013 (COM(2007) 630 final) Brussels: Commission of the European Communities; 2007.

43. European Commission. Commission communication on the framework for action in the field of public health (COM(93) 559 final) Brussels: Commission of the European Communities; 1993.

44. Council of the European Union. Council conclusions: towards modern, responsive and sustainable health systems (2011/C 202/04) Off J Eur Union. 2011;13(C202):10-12.

45. European Commission. Communication on Europe 2020. A strategy for smart, sustainable and inclusive growth (COM(2010) 2020 final) Brussels: European Commission; 2010.

46. European Union. Communication from the Commission to the Council, the European Parliament, the Economic and Social Committee and the Committee of the Regions on the health strategy of the European Community (COM(2000) 285 final) Brussels: Commission of the European Communities; 2000.

47. European Union. Regulation of the European parliament and of the council. Establishing a European centre for disease prevention and control. Off J Eur Union. 2004;13:1-11.

48. Koivusalo M. The state of health in all policies (HiAP) in the European union: potential and pitfalls. J Epidemiol Community Health. 2010;13(6):500-503. doi: 10.1136/jech.2009.102020.

49. Ollila E. Health in all policies: from rhetoric to action. Scand J Public Health. 2011;13(6 suppl):11-18. doi: 10.1177/1403494810379895. 
50. Elliott H. In: European Union Public Health Policy Regional and global trends. Greer SL, Kurzer P, editor. Abingdon, UK: Routledge; 2013. European Union health information infrastructure and policy.

51. Verschuuren M, Gissler M, Kilpelainen K, Tuomi-Nikula A, Sihvonen AP, Thelen J, Gaidelyte R, Ghirini S, Kirsch N, Prochorskas R. Public health indicators for the EU: the joint action for ECHIM (European Community Health Indicators \& Monitoring) Archives of public health = Archives belges de sante publique. 2013;13(1):12.

52. Greer SL. The weakness of strong policies and the strength of weak policies: law, experimentalist governance, and supporting coalitions in European Union health care policy. Regul Governance. 2011;13(2):187-203. doi: 10.1111/j.1748-5991.2011.01107.x.

53. Greer SL, Vanhercke B. In: Health Systems Governance in Europe. Mossialos E, Permanand G, Baeten R, Hervey TK, editor. Cambridge: Cambridge University Press; 2010. The hard politics of soft law: the case of health; pp. 186-230.

54. Zeitlin J, Pouchet $P$, editor. The open method of co-ordination in action: the European employment and social inclusion strategies. Brussels: P.I.E. - Peter Lang; 2005.

55. Jarman H. Collaboration and consultation: functional representation in EU stakeholder dialogues. J Eur Integration. 2011;13(4):385-399. doi: 10.1080/07036337.2011.579748.

56. Radaelli C, Pasquier R. In: Europeanization: New Research Agendas. Vink MP, Graziano P, editor. Basingstoke: Palgrave/Macmillan; 2007. Conceptual issues; pp. 35-45.

57. Buchner B. Nutrition, obesity and EU health policy. Eur J Health Law. 2011;13(1):1-8. doi: 10.1163/157180911X546084.

58. McKee M. A European alcohol strategy. BMJ. 2006;13(7574):871-872. doi: 10.1136/bmj.39003.629606.BE. 



\section{Part 2 I "Off-label-use" of}

\section{data for information and}

\section{knowledge generation}





\section{Chapter 2 I Syndromic influenza surveillance}

Validity and timeliness of syndromic influenza surveillance during the autumn/winter wave of A(H1N1) influenza 2009: results of emergency medical dispatch, ambulance and emergency department data from three European regions

Rosenkötter N, Ziemann A, Garcia-Castrillo Riesgo L, Giillet JB, Vergeiner G, Krafft T, Brand H. BMC Public Health 2013. 13:905. 


\begin{abstract}
Background

Emergency medical service (EMS) data, particularly from the emergency department (ED), is a common source of information for syndromic surveillance. However, the entire EMS chain, consists of both out-of-hospital and in-hospital services. Differences in validity and timeliness across these data sources so far have not been studied. Neither have the differences in validity and timeliness of this data from different European countries. In this paper we examine the validity and timeliness of the entire chain of EMS data sources from three European regions for common syndromic influenza surveillance during the $A(\mathrm{H} 1 \mathrm{~N} 1)$ influenza pandemic in 2009.
\end{abstract}

\title{
Methods
}

We gathered local, regional, or national information on influenza-like illness (ILI) or respiratory syndrome from an Austrian Emergency Medical Dispatch Service (EMD-AT), an Austrian and Belgian ambulance services (EP-AT, EP-BE) and from a Belgian and Spanish emergency department (ED-BE, ED-ES). We examined the timeliness of the EMS data in identifying the beginning of the autumn/winter wave of pandemic $A(\mathrm{H} 1 \mathrm{~N} 1)$ influenza as compared to the reference data. Additionally, we determined the sensitivity and specificity of an aberration detection algorithm (Poisson CUSUM) in EMS data sources for detecting the autumn/winter wave of the $A(H 1 N 1)$ influenza pandemic.

\section{Results}

The ED-ES data demonstrated the most favourable validity, followed by the ED-BE data. The beginning of the autumn/winter wave of pandemic $A(\mathrm{H} 1 \mathrm{~N} 1)$ influenza was identified eight days in advance in ED-BE data. The EP data performed stronger in data sets for large catchment areas (EP-BE) and identified the beginning of the autumn/winter wave almost at the same time as the reference data (time lag +2 days). EMD data exhibited timely identification of the autumn/winter wave of $A(\mathrm{H} 1 \mathrm{~N} 1)$ but demonstrated weak validity measures.

\section{Conclusions}

In this study ED data exhibited the most favourable performance in terms of validity and timeliness for syndromic influenza surveillance, along with EP data for large catchment areas. For the other data sources performance assessment delivered no clear results. The study shows that routinely collected data from EMS providers can augment and enhance public health surveillance of influenza by providing information during health crises in which such information must be both timely and readily obtainable. 


\section{Background}

Influenza surveillance systems monitor the occurrence and progress of the disease so as to support influenza management during epidemics. Clinical and virological influenza surveillance systems have been established in the European member states [1,2], and the European Centre for Disease Prevention and Control (ECDC) aggregates data regarding influenza occurrence from these systems to enhance monitoring and reporting of disease trends across Europe [3].

Syndromic surveillance systems based on immediate, usually electronically available, routine health information are increasingly being added to traditional surveillance structures (i.e., clinical / sentinel or virological) to establish more comprehensive surveillance or epidemic intelligence systems [4,5]. Typically based on the use of existing routine data, the systems do not require new data collection mechanisms. However, since the data are not being collected primarily for surveillance purposes, the provided information covers only signs and symptoms and contains no clinically verified or laboratory-confirmed diagnoses [5]. Due to real-time or near real-time data availability, syndromic surveillance systems are designed to enhance the identification of immediately occurring or out-of-season health threats, such as pandemic influenza. Existing syndromic surveillance approaches apply indicator-based components, such as data from emergency departments [6,7], emergency medical dispatch centres [8,9], and telephone help lines [10,11]; as well as information on school-absenteeism [12,13] or over-thecounter drug sales of analgesics [14]. The data may be even broader, systems that apply eventbased information use information from media sources or web queries related to influenza $[15,16]$.

European and international syndromic surveillance systems based on event-based health information exist. The Directorate General for Health and Consumers of the European Commission (EC), for example, directs the Medical Information System (MedISys), which monitors the international media for general disease occurrence information but also specifically for influenza activity [17]. Routine syndromic surveillance systems based on indicator-based components, however, are scarce and are, at least in Europe, the individual efforts of single regions or countries. A European study to identify commonalities and good practice in national or regional syndromic surveillance activities has been lacking for a long time and has now been established by an EC co-founded project [18]. The analysis of the potential for a European-wide application of emergency medical service (EMS) data for indicator-based syndromic influenza surveillance is missing so far [19].

Moreover, existing national and regional EMS data-based syndromic surveillance systems do not focus on the entire chain of available data. Data covering the entire EMS chain consists of outof-hospital emergency medical dispatch (EMD) information on signs and symptoms typically described by laypeople calling for an ambulance; ambulance service (EP) data on the initial diagnostic findings during examination at the emergency scene by paramedics or emergency 
physicians; and in-hospital information from nurses or physicians at the emergency department (ED) covering the patient's main complaints or the initial diagnostic findings during the patient's treatment in the ED [20]. Typically, however, EMS data-based syndromic influenza surveillance systems focus mostly on ED data, only a few include data from the EMD, and to our knowledge, EP data is not yet exploited by any syndromic influenza surveillance system. Thus, little is known about the differences in the performance of syndromic influenza surveillance based on the three levels of available emergency medical service data and the applicability of this health information for syndromic influenza surveillance in various European countries.

To evaluate the performance of a common syndromic influenza surveillance approach based on the EMD, EP and ED data from different European regions during the autumn/winter wave of the $A(H 1 N 1)$ influenza pandemic, we focus on the validity components, sensitivity and specificity, as well as on timeliness measures as described by Buehler et al. [21]. The validity and timeliness assessment is performed retrospectively against traditional influenza surveillance sources.

\section{Methods}

\section{Time period of the analysis}

In Europe, the autumn/winter wave of the pandemic A(H1N1) influenza began around week 43 of 2009 , earlier than the beginning of the normal seasonal influenza cycle. The ECDC registered the modal peak of the autumn/winter wave at approximately week 48 in Europe [22,23]. In this study, the validity and timeliness of syndromic surveillance data were assessed during the time period between week 36 (start 30.8.) to week 52 (end 31.12.) in 2009 ( $N=17$ weeks; $N=123$ days). Due to limited data availability, the first weeks of 2010 were not analysed. However, as reported by ECDC, most of the disease burden in regard to the pandemic $A(H 1 N 1)$ influenza occurred by the end of $2009[22,23]$.

\section{Data sets}

\section{Syndromic surveillance data}

Data for this study were retrieved during the SIDARTHa project on emergency data-based syndromic surveillance [24]. The SIDARTHa project group consisted of EMS institutions from 12 European countries. Three partner institutions, designated as test sites and consisting of EMD centres, ambulance services (EP), or EDs delivered in total five data sets from a local, regional, or national level for this study. The number of specific EMS data sources per country used in this study is not related to the general availability of these data in Europe.

The city- or district-level data sources included ambulance service data for the district of Kufstein in Austria (EP-AT) and emergency department data for the city of Leuven in Belgium (ED-BE) and Santander in Spain (ED-ES). Regional emergency call data were provided by the Dispatch Centre 
Tyrol in Austria (EMD-AT), which at that time covered three out of nine districts in Tyrol. The ambulance service of Belgium (EP-BE) provided national data. For the sake of readability, we refer in the following text to the composite abbreviations of each data source (e.g., EMD-AT), including information on the respective emergency medical service (e.g., EMD for Emergency Medical Dispatch) and the country code (e.g., AT for Austria). The country code does not imply that the data sources are representative for the whole countries. More specific information on the properties of each data set can be found in Table 1.

All data sets included anonymous health information on individual patients who sought the respective EMS. The data were available on a daily scale.

\section{Reference data}

Reference data were retrieved from regional or national clinical (sentinel) influenza surveillance systems. The data included weekly reports from physicians, usually general practitioners (GP), regarding the number of patients treated for ILI and were suitable to assess the course and spatial distribution of influenza [23]. Since the autumn/winter wave of the A(H1N1) influenza pandemic 2009 began sooner than the normal seasonal cycle, the Austrian sentinel system for the Tyrol region was not active. As a substitute, data on the number of documented sick-leave cases with acute respiratory illness (ARI) were retrieved from a major Tyrolean health insurance (Tiroler Gebietskrankenkasse). This health insurance covers approximately $75 \%$ of the Tyrolean population [25].

The reference data included weekly case numbers registered the time of the case occurrence. The properties of the respective reference data sources are given in Table 2 . The table also includes information on the reporting delay between case occurrence and data availability at the respective public health authority.

The onset of the $A(\mathrm{H} 1 \mathrm{~N} 1)$ influenza pandemic was determined by pre-defined thresholds as specified by the respective public health authorities: The Belgian reference data, defined the threshold as more than $141.37 \mathrm{ILI}$ cases per 100,000 inhabitants treated by sentinel GPs per week [26], while the Spanish sentinel system for the Autonomous Region of Cantabria determined a threshold at more than 71 ILI cases per 100,000 inhabitants in GP practices per week. Case occurrence of less than 71 ILI cases per 100.000 inhabitants resulted in a temporary cessation in the epidemic period in 2009 (week 48) in the Autonomous Region of Cantabria. Since no threshold was determined for the Austrian reference data, we applied the official national reported beginning of the $A(\mathrm{H} 1 \mathrm{~N} 1)$ pandemic in Austria, which was based on the number of laboratoryconfirmed $A / H 1 N 1$ influenza cases. In this report, a reference on the determination of the beginning of the epidemic (e.g., a predefined threshold) is missing [27]. A summary of the reference data properties regarding the autumn/winter wave is exhibited in Table 2. 
Table 1 Properties of the syndromic surveillance data sets.

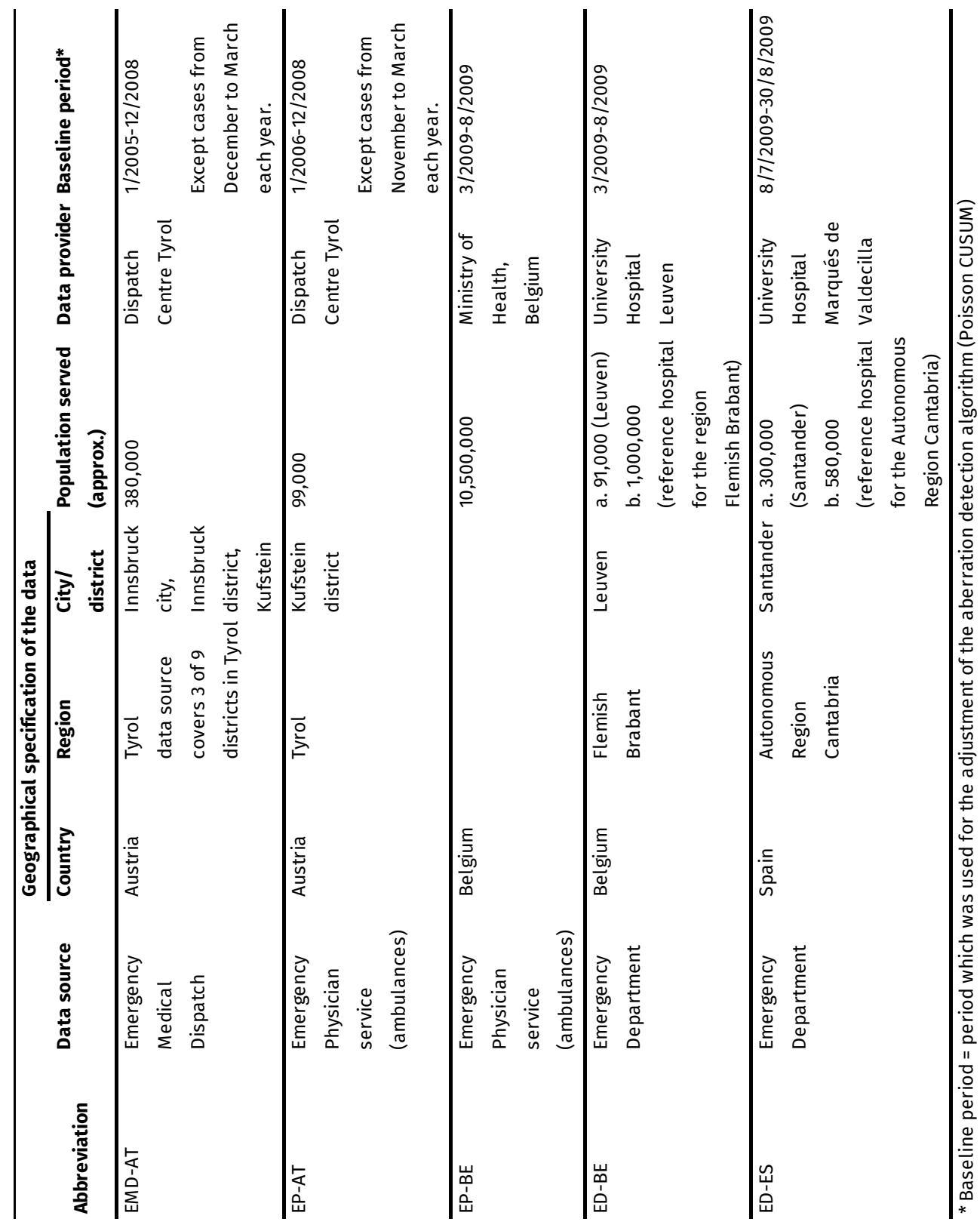

\section{Variables}

The main variables were the date of the emergency occurrence and the information on the health status of the emergency cases. The day on which the emergency case occurred was used to identify the day-of-the-week variation in the data sets. 
The European Influenza Surveillance Network defines relevant health information for ILI for clinical surveillance and recommends a combination of influenza symptoms as an ILI case definition [28]. Since the study presented in this paper is based on routine information from EMS providers, it could use only a set of single pre-defined major symptoms reported by the emergency caller, or chief complaints or a working diagnosis identified during the admission at the ED or provided by the ambulance staff at the emergency scene. As identified in previous studies, these broad-symptom categories or working diagnoses exhibit a moderate sensitivity in meeting a clinically confirmed influenza diagnosis [29] or correspondence to the epidemic curves of the clinical sentinel surveillance system [30].

For the respective data sets in this study, health information was available as single codes from the Advanced Medical Priority Dispatch System (AMPDS [EMD-AT]), the International Classification of Diseases ((ICD-9 [EP-BE]; ICD-10 [EP-AT]), free-text information regarding the chief complaint and/or the working diagnosis (ED-BE), and regional chief complaint triage codes (ED-ES) (Table 3).

Table 2 Properties of the reference data.

\begin{tabular}{|c|c|c|c|c|c|c|c|}
\hline \multirow[b]{2}{*}{$\begin{array}{l}\text { Reference } \\
\text { data for... }\end{array}$} & \multirow[b]{2}{*}{$\begin{array}{l}\text { Reference data } \\
\text { source }\end{array}$} & \multirow[b]{2}{*}{$\begin{array}{l}\text { Geogra- } \\
\text { phical } \\
\text { level }\end{array}$} & \multirow[b]{2}{*}{$\begin{array}{l}\text { reporting } \\
\text { delay* }\end{array}$} & \multicolumn{4}{|c|}{$\begin{array}{l}\text { Influenza pandemic according to reference } \\
\text { data in } 2009\end{array}$} \\
\hline & & & & Start week & $\begin{array}{l}\text { Peak } \\
\text { week }\end{array}$ & $\begin{array}{l}\text { Duration } \\
\text { (weeks) }\end{array}$ & $\begin{array}{l}\text { Duration } \\
\text { (days) }\end{array}$ \\
\hline $\begin{array}{l}\text { EMD-AT', } \\
\text { EP-AT }^{+}\end{array}$ & $\begin{array}{l}\text { Information on } \\
\text { sick leave due to } \\
\text { acute respiratory } \\
\text { infections from a } \\
\text { major Tyrolean } \\
\text { health insurance. }\end{array}$ & $\begin{array}{l}\text { regional } \\
\text { (Tyrol, } \\
\text { Austria) }\end{array}$ & $\begin{array}{l}\text { information } \\
\text { for week x } \\
\text { available on } \\
\text { week } x+1\end{array}$ & 44 & 47 & 9 & $67^{\$}$ \\
\hline $\begin{array}{l}\text { EP-BE, } \\
\text { ED-BE }\end{array}$ & $\begin{array}{l}\text { Notified influenza } \\
\text { cases of the } \\
\text { sentinel general } \\
\text { practitioner } \\
\text { system. }\end{array}$ & $\begin{array}{l}\text { national } \\
\text { (Belgium) }\end{array}$ & $\begin{array}{l}\text { information } \\
\text { for week } x \\
\text { available on } \\
\text { week } x+3\end{array}$ & 40 & 44 & 10 & 70 \\
\hline ED-ES & $\begin{array}{l}\text { Notified influenza } \\
\text { cases of the } \\
\text { sentinel general } \\
\text { practitioner } \\
\text { system. }\end{array}$ & $\begin{array}{l}\text { regional } \\
\text { (Cantabri } \\
\text { a, Spain) }\end{array}$ & $\begin{array}{l}\text { information } \\
\text { for week x } \\
\text { available on } \\
\text { week } x+3\end{array}$ & $\begin{array}{c}41 \\
(\text { period 1) } \\
49 \\
(\text { period } 2)\end{array}$ & 43 & 8 & 56 \\
\hline
\end{tabular}

*week: Monday (day 1), ..., Sunday (day 7)

${ }^{\top}$ The course of the autumn/winter wave was derived from regional data of the Tyrolean health insurance; the start week of the autumn/winter wave was derived from national data [27].

\$last week of 2009 (week 52) contained 11 days

Relevant codes for monitoring ILI were defined for each EMS coding system based on available literature and the expertise of EMS experts from the SIDARTHa consortium (Table 3). Since the 
health information derived from the AMPDS codes (EMD-AT) was not specific enough to differentiate between respiratory syndrome and ILI, we analysed the respiratory syndrome in this data set. In the ED-ES data, the ILI case definition was designed as a fixed list of combined chiefcomplaint triage codes comparable to the ILI definition contained in the reference data set of the Spanish sentinel surveillance system (Autonomous Region Cantabria) (Table 3).

Table 3 Health information used for respiratory syndrome and influenza-like illness coding and respective code distribution in 2009.

\begin{tabular}{|c|c|c|c|c|c|}
\hline \multirow{2}{*}{$\begin{array}{l}\text { source } \\
\text { EMD- } \\
\text { AT }\end{array}$} & \multirow{2}{*}{$\begin{array}{l}\text { syndrome } \\
\text { respiratory } \\
\text { syndrome }\end{array}$} & \multicolumn{2}{|c|}{ health information codes } & \multicolumn{2}{|c|}{ distribution 2009} \\
\hline & & $\begin{array}{l}\text { AMPDS } \\
\text { v12.0 }\end{array}$ & Boolean operator: OR & $\mathrm{N}$ & $\%$ \\
\hline & & $6 \mathrm{C} 1$ & Breathing problems - Abnormal breathing & 465 & 26.9 \\
\hline & & $6 \mathrm{C} 1 \mathrm{~A}$ & $\begin{array}{l}\text { Breathing problems - abnormal breathing + } \\
\text { asthma }\end{array}$ & 71 & 4.1 \\
\hline & & 6D1 & Breathing problems - Not alerting & 750 & 43.3 \\
\hline & & $6 \mathrm{D} 1 \mathrm{~A}$ & Breathing problems - not alerting + asthma & 230 & 13.3 \\
\hline & & $6 \mathrm{D} 2$ & $\begin{array}{l}\text { Breathing problems - Difficulty in speaking } \\
\text { between breaths }\end{array}$ & 22 & 1.3 \\
\hline & & $6 \mathrm{D} 2 \mathrm{~A}$ & $\begin{array}{l}\text { Breathing problems - difficulty in speaking } \\
\text { between breaths + asthma }\end{array}$ & 4 & 0.2 \\
\hline & & $6 \mathrm{D} 3$ & Breathing problems - changing colour & 154 & 8.9 \\
\hline & & $6 \mathrm{D} 3 \mathrm{~A}$ & Breathing problems - changing colour + asthma & 31 & 1.8 \\
\hline & & $6 \mathrm{D} 4$ & Breathing problems - clammy & - & - \\
\hline & & $6 \mathrm{D} 4 \mathrm{~A}$ & Breathing problems - clammy + asthma & - & - \\
\hline & & $26 \mathrm{~A} 4$ & Sick person - Fever/chills & 4 & 0.2 \\
\hline & & 26026 & $\begin{array}{l}\text { Sick person - Sore throat (without difficulty } \\
\text { breathing or swallowing) }\end{array}$ & - & - \\
\hline Total & & & & 1731 & 100.0 \\
\hline \multirow[t]{12}{*}{ EP-AT } & $\mathrm{ILI}^{*}$ & ICD-10 & Boolean operator: OR & $\mathrm{N}$ & $\%$ \\
\hline & & 100 & Acute nasopharyngitis [common cold] & 1 & 1.6 \\
\hline & & j02 & Acute pharyngitis (includes sore throat) & - & - \\
\hline & & j04 & Acute laryngitis and tracheitis & 3 & 4.7 \\
\hline & & J06 & $\begin{array}{l}\text { Acute upper respiratory infections of multiple } \\
\text { and unspecified sites }\end{array}$ & 8 & 12.5 \\
\hline & & j09 & Avian Influenza & - & - \\
\hline & & 110 & Influenza due to other identified influenza virus & 1 & 1.6 \\
\hline & & J11 & Influenza, virus not identified & 8 & 12.5 \\
\hline & & 116 & $\begin{array}{l}\text { Pneumonia due to other infectious organisms, } \\
\text { not elsewhere classified }\end{array}$ & 3 & 4.7 \\
\hline & & 118 & Pneumonia, organism unspecified & 28 & 43.8 \\
\hline & & R05 & Cough & 3 & 4.7 \\
\hline & & R50 & Fever of other and unknown origin & 9 & 14.1 \\
\hline Total & & & & 64 & 100.0 \\
\hline
\end{tabular}


Table 3 Health information used for respiratory syndrome and influenza-like illness coding and respective code distribution in 2009 (continued).

\begin{tabular}{|c|c|c|c|c|c|}
\hline \multirow[t]{22}{*}{ EP-BE } & $\mathrm{ILI}^{*}$ & ICD-9 & Boolean operator : OR & $\mathrm{N}$ & $\%$ \\
\hline & & 460 & Acute nasopharyngitis [common cold] & 22 & 1.2 \\
\hline & & 462 & Pharyngitis, acute & - & - \\
\hline & & 464 & Acute laryngitis and tracheitis & - & - \\
\hline & & 464.0 & Acute laryngitis & - & - \\
\hline & & 464.1 & Acute tracheitis & - & - \\
\hline & & 464.2 & Acute laryngotracheitis & - & - \\
\hline & & 465 & $\begin{array}{l}\text { Acute upper respiratory infections of multiple or } \\
\text { unspecified sites }\end{array}$ & - & - \\
\hline & & 465.0 & Acute laryngopharyngitis & - & - \\
\hline & & 465.8 & $\begin{array}{l}\text { Acute upper respiratory infections of other } \\
\text { multiple sites }\end{array}$ & - & - \\
\hline & & 465.9 & $\begin{array}{l}\text { Acute upper respiratory infections of unspecified } \\
\text { site }\end{array}$ & - & - \\
\hline & & 480.9 & Viral pneumonia unspecified & 56 & 3.0 \\
\hline & & 488 & $\begin{array}{l}\text { Influenza due to certain identified influenza } \\
\text { viruses }\end{array}$ & - & - \\
\hline & & 488.0 & Influenza due to identified avian influenza virus & - & - \\
\hline & & 488.1 & $\begin{array}{l}\text { Influenza due to identified novel h1n1 influenza } \\
\text { virus }\end{array}$ & - & - \\
\hline & & 487 & Influenza & - & - \\
\hline & & 487.0 & Influenza with pneumonia & - & - \\
\hline & & 487.1 & Influenza with other respiratory manifestations & - & - \\
\hline & & 487.8 & Influenza with other manifestations & 109 & 5.9 \\
\hline & & 486 & Pneumonia organism unspecified & 986 & 53.2 \\
\hline & & 786.2 & Cough & 63 & 3.4 \\
\hline & & 780.6 & $\begin{array}{l}\text { Fever and other physiologic disturbances of } \\
\text { temperature regulation }\end{array}$ & 618 & 33.3 \\
\hline Total & & & & 1854 & 100.0 \\
\hline \multirow[t]{2}{*}{ ED-BE } & $\mathrm{ILI}^{*}$ & \multicolumn{2}{|c|}{ chief complaint or working diagnosis, Boolean operator: OR } & $\mathrm{N}$ & $\%$ \\
\hline & & \multicolumn{2}{|c|}{$\begin{array}{l}\text { free text including cough, muscle pain, flu, H1N1, sore } \\
\text { throat, influenza, fever }\end{array}$} & $\mathrm{na}^{\dagger}$ & $\mathrm{na}^{\dagger}$ \\
\hline Total & & & & 5681 & 100.0 \\
\hline \multirow[t]{2}{*}{ ED-ES } & $\mathrm{ILI}^{*}$ & \multicolumn{2}{|c|}{ case definition, Boolean operator : AND } & $\mathrm{N}$ & $\%$ \\
\hline & & \multicolumn{2}{|c|}{$\begin{array}{l}\text { (i) the appearance of sudden symptoms and at least one of } \\
\text { the four general symptoms (fever or slight fever } \\
\text { (feverishness), headache, muscle pain, general malaise), } \\
\text { and (ii) at least one of the three respiratory symptoms } \\
\text { (cough, sore throat, difficulty breathing), as well as (iii) the } \\
\text { absence of other diagnostic suspicion. }\end{array}$} & 1127 & 100.0 \\
\hline \multicolumn{2}{|l|}{ Total\$ } & & & 1127 & 100.0 \\
\hline
\end{tabular}

* ILI = influenza-like illness

† na = not applicable

The share of AMPDS, ICD-9 or ICD-10 codes presented in Table 3 indicates the structure of ILI or respiratory syndrome in the syndromic surveillance data sources. In the EMD-AT data, respiratory 
syndrome cases were coded primarily as severe breathing problems. ILI cases in ICD-coded data sets (EP-AT, EP-BE) mostly received a working diagnosis of pneumonia or fever. The exploitation of a broad range of free text items, which allowed different writings and short forms, made it impossible to describe the structure of ILI in ED-BE data.

Cases to which respiratory syndrome or ILI was assigned were aggregated per week and per day for further analysis.

\section{Statistical analysis}

\section{Characteristics of syndromic surveillance data}

The characteristics of the individual syndromic surveillance data sources during the respective baseline period and the test period (week 36/2009 to week 52/2009) were analysed using general descriptive statistics. The selection of suitable baseline periods for the individual data sources (Table 1) was driven by data availability and a thorough descriptive analysis of variations in daily case numbers per year and per month to ensure stability (reported elsewhere [31]). Due to comprehensive data availability in the Austrian data sets (EMD-AT and EP-AT), we were able to exclude the spring and summer period of 2009, during which the 2009 influenza pandemic started, from the baseline period of these data sets. In the other data sets, limited data availability led to the inclusion of these periods. Additionally, day-of-the-week variation was analysed in the baseline data sets employing Kruskal-Wallis test statistics (significance level $p<0.05$ ).

\section{Aberration detection}

Aberrations in the daily number of patients with respiratory syndrome or ILI during the test period (week 36/2009 to week 52/2009) were investigated using a one-sided Cumulative sum (CUSUM) aberration detection algorithm for Poisson-distributed data [32] in combination with the Fast Initial Response (FIR) mechanism [32,33]. The FIR technique ensures that large CUSUM values do not inflate subsequent values, thus controlling for an over-production of signals. It also allows a head start of the algorithm to retrieve quicker signals [33]. The Poisson CUSUM algorithm is based on the individual baseline mean from which the reference value $k$, the head start value $S_{0}$, and the threshold value $h$ are determined.

More specifically the reference value $k$ was determined by the following equation:

$k=\left(\mu_{d}-\mu_{a}\right) /\left(\ln \left(\mu_{d}\right)-\ln \left(\mu_{a}\right)\right)$

The acceptable process mean $\left(\mu_{a}\right)$ was set close to the baseline mean $\left(\mu_{d}\right)$ as described by Lucas [34]. When $k$ was larger or equal to one, the value was rounded to the nearest integer.

The daily Poisson CUSUM value was calculated as follows [34]:

$S_{H, i}=\max \left(0, Y_{i}-k+S_{H, i-1}\right)$ 
The threshold value $h$ for the CUSUM algorithm and the head start value $S_{0}$ were retrieved from a table provided by Lucas [34]. $Y_{i}$ represented the daily number of respiratory syndrome or ILI cases. A signal was produced whenever the daily CUSUM value $S_{H, i}$ was greater than or equal to the respective threshold value $h$, indicating a significant change in the time series. The respective set-ups and threshold values for the Poisson CUSUM algorithm per data set are listed in Table 4.

We accounted for significant day-of-the-week variation with a stratified application of the Poisson CUSUM algorithm. If a day-of-the-week variation was evident, the Poisson CUSUM was calibrated separately for each stratum (Table 4). This calibrated algorithm was subsequently applied on the stratum-specific days during the test period.

\section{Timeliness}

Three approaches were used to assess timeliness: (1) comparison of peaks in the time series of reference data and syndromic surveillance data; (2) correlation of the time series of reference data and syndromic surveillance data; (3) comparison of signals generated by the Poisson CUSUM aberration detection method in the respective EMS data source against the beginning of the pandemic as defined in the reference data [35]. Since availability of reference data was only provided on a weekly basis, EMS data was aggregated per week for peak comparison and correlation analysis.

First, the epidemic peak periods (peak week) in EMS and reference data were compared based on the times series of the data sets during week 36 to week 52 in 2009.

Second, a cross-correlation function of weekly aggregated EMS and reference data time series was calculated for the period of week 36 to week 52 in 2009 [35,36]. The cross-correlation function indicates the similarity of two time series for different time lags, and this study was interested in the time lag that maximized the cross- correlation function. A correlation was considered significant if the upper boundary of the $95 \%$ confidence limit was crossed; a significant correlation combined with a negative time lag indicated that the epidemic curve of the syndromic surveillance data source developed earlier than the curve in the reference data, whereas, a significant correlation combined with a positive time lag indicated that the epidemic curve in the syndromic surveillance data sets developed later.

Third, timeliness was assessed by comparing the first signal detected by the Poisson CUSUM algorithm in each data source against the beginning of the official pandemic period in the respective reference data source. We counted the number of days from the Monday of the first official week of the autumn/winter $A(\mathrm{H} 1 \mathrm{~N} 1)$ influenza pandemic as outlined in the reference data to the first day with a signal in the respective EMS data set.[37] A second approach took into consideration the amount of time required to collect and process the reference and syndromic surveillance data (reporting delay, see Table 2). Days were counted from the day of data 
availability in the reference data to the day after a Poisson CUSUM signal occurred in the syndromic surveillance data sources.

Table 4 Characteristics of the daily number of respiratory syndrome or influenza-like illness cases during baseline and the test period (week 36 to week 52, 2009) and test statistics on the probability distribution of daily counts and the identification of day-of-the-week effects, and Poisson CUSUM parameters during individual baseline periods.

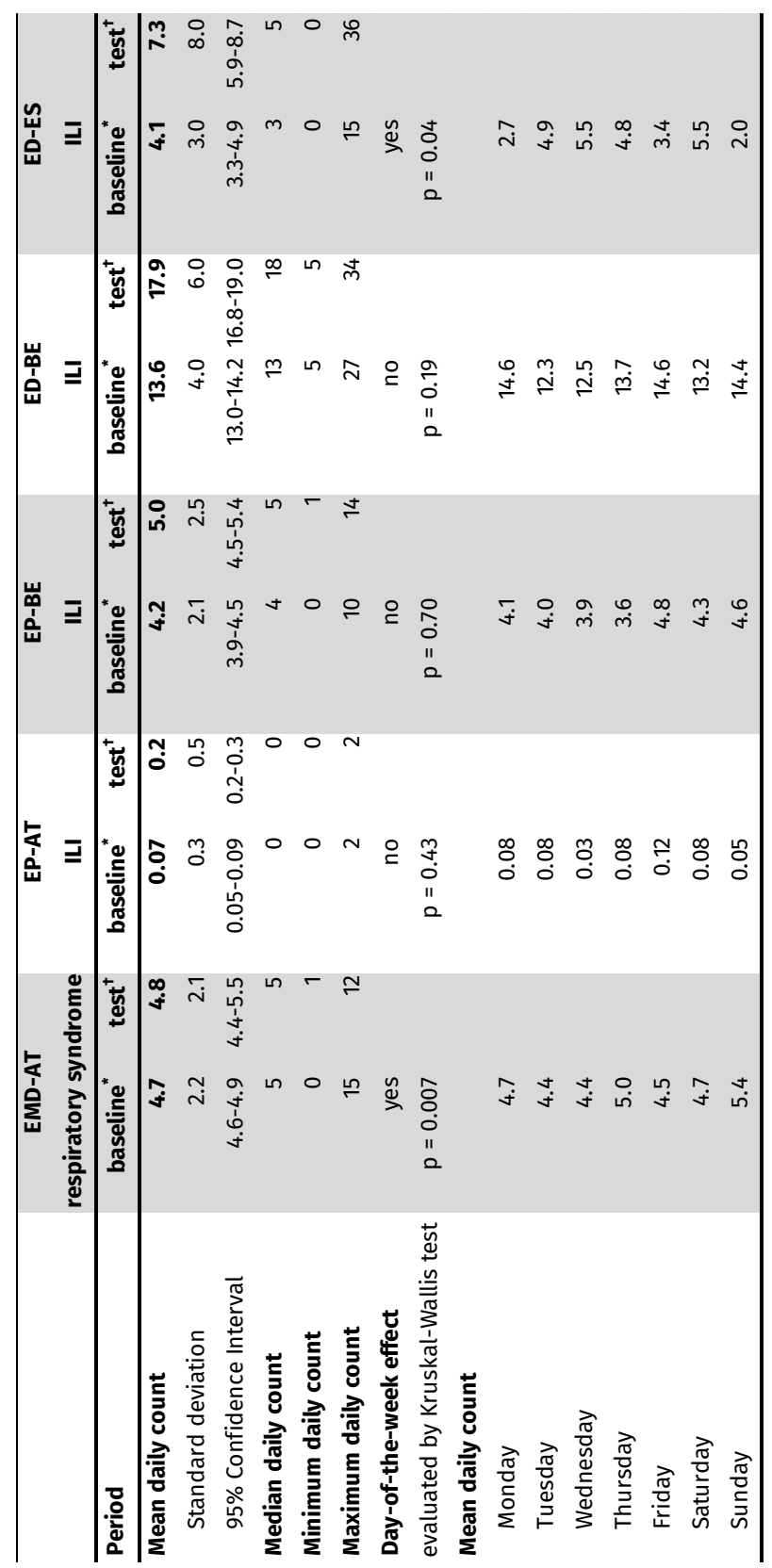


Table 4 Characteristics of the daily number of respiratory syndrome or influenza-like illness cases during baseline and the test period (week 36 to week 52, 2009) and test statistics on the probability distribution of daily counts and the identification of day-of-the-week effects, and Poisson CUSUM parameters during individual baseline periods (continued).

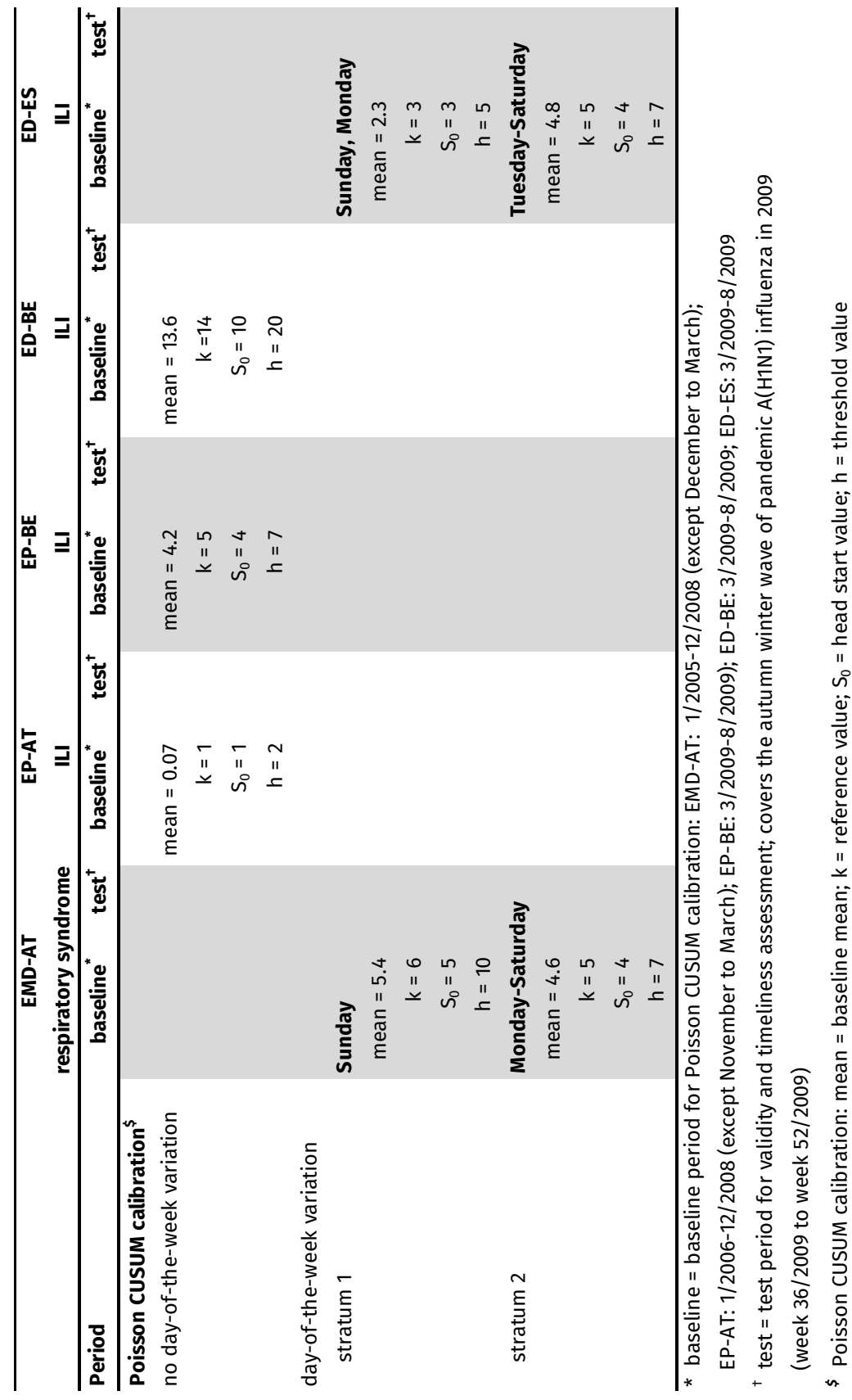


Validity assessment based on aberration detection

Since epidemic periods were indicated weekly in the reference data and aberrations in syndromic surveillance data were indicated daily, a weekly and daily approach was applied to the sensitivity and specificity calculations to ensure a range of potential sensitivity and specificity measures.

In the weekly approach, sensitivity and specificity calculations were based on true-positive and true-negative flagged weeks. A week was flagged as true-positive when an aberration was detected on at least one day in a week that belonged to the officially confirmed pandemic period in the reference data. A true-negative week was flagged when CUSUM gave no signal during a week that did not belong to the official pandemic influenza period.

In the daily approach, sensitivity and specificity calculations were based on true-positive and true-negative flagged days that were in accordance with the officially pandemic or non-pandemic periods respectively. The calculations were performed similarly to the weekly validity calculations.

A false detection rate also was calculated, indicating the proportion of false-positive flagged weeks or days to all Poisson CUSUM-flagged weeks or days.

\section{Software}

The descriptive statistics and the correlation analyses were performed with IBM SPSS Statistics Version 21.0 (IBM Corp., Armonk, New York), and the CUSUM algorithm was programmed in Microsoft Excel 2010 (Microsoft, Redmond, Washington).

\section{Results}

The characteristics of the emergency data sets are provided for the baseline period of each data set and for the test period (week 36/2009 to week 52/2009) (Table 4). The mean daily number of cases was higher in all data sets during the test period in 2009 than during the baseline period. The daily occurrence of ILI cases was generally a rare event in EP-AT data. The baseline periods were used to determine the parameters of the Poisson CUSUM aberration detection algorithm. Day-of-the week effects were present in EMD-AT data (Sunday stratum, Monday to Saturday stratum) and the ED-ES data (Sunday to Monday stratum, Tuesday to Saturday stratum). Table 4 also presents the calibrations of the Poisson CUSUM parameters for each data set.

\section{Timeliness assessment}

In Austria, the A(H1N1) reference data exhibited a peak in week 47 (Figures 1a and b). However, due to the strong variability in the EMD-AT data (Figure 1a) and the low case numbers in the EPAT data (Figure 1b), a similar peak in these data sources could not be ascertained. Both data sets also demonstrated no significant correlation with the reference data (Table 5). Based on detected aberrations by the Poisson CUSUM algorithm, we identified one signal in EMD-AT that coincided 
with the beginning of the pandemic period in the reference data (Figure 1a, Table 5). Since no aberrations were identified in the EP-AT data, this approach was not viable.

Table 5 Results of three timeliness methods for the identification of the start of the autumn/winter wave of the A(H1N1) influenza pandemic (as reported by the reference data) with syndromic surveillance data in 2009.

\begin{tabular}{|c|c|c|c|c|}
\hline \multirow{2}{*}{ data source } & \multirow{2}{*}{$\begin{array}{c}\text { peak } \\
\text { comparison } \\
\text { (weeks) }\end{array}$} & \multirow{2}{*}{$\begin{array}{l}\text { cross-correlation } \\
\text { function } \\
\text { (weeks) }\end{array}$} & \multicolumn{2}{|c|}{$\begin{array}{l}\text { first aberration detected by Poisson } \\
\text { CUSUM (days) }\end{array}$} \\
\hline & & & $\begin{array}{l}\text { without reporting } \\
\text { delay+ }\end{array}$ & $\begin{array}{c}\text { with reporting } \\
\text { delay+ }\end{array}$ \\
\hline EMD-AT & na* & not significant & 0 & -6 \\
\hline EP-AT & na* & not significant & na* & na* \\
\hline \multirow[t]{2}{*}{ EP-BE } & -1 & -1 & +10 & +2 \\
\hline & & 0.60 & & \\
\hline ED-BE & -1 & not significant & 0 & -8 \\
\hline \multirow[t]{2}{*}{ ED-ES } & +1 & +1 & $+19($ period 1$)$ & $+11($ period 1$)$ \\
\hline & & 0.89 & 0 (period 2$)$ & -8 (period 2) \\
\hline
\end{tabular}

${ }^{*}$ na $=$ not applicable

+ reporting delay refers to the time needed for collecting and processing the data.

Table 6 Sensitivity, specificity, and false detection rate of Poisson CUSUM signals for syndromic influenza surveillance during week 36 (30.8.) to week 52 (31.12.) in 2009.

\begin{tabular}{|c|c|c|c|c|c|c|}
\hline \multirow{3}{*}{$\begin{array}{l}\text { data } \\
\text { source }\end{array}$} & sensitivity* & specificity $^{\dagger}$ & sensitivity* & specificity $^{\dagger}$ & \multicolumn{2}{|c|}{ false detection rate ${ }^{\neq}$} \\
\hline & $\%$ & $\%$ & $\%$ & $\%$ & & $\%$ \\
\hline & \multicolumn{2}{|c|}{ weekly } & \multicolumn{2}{|c|}{ daily } & weekly & daily \\
\hline \multirow{2}{*}{ EMD-AT } & $(3 / 9)$ & $(5 / 8)$ & $(5 / 67)$ & $(53 / 56)$ & $(3 / 6)$ & $(3 / 8)$ \\
\hline & 33.3 & 62.5 & 7.5 & 94.6 & 50.0 & 37.5 \\
\hline \multirow{2}{*}{ EP-AT } & $(0 / 9)$ & $(8 / 8)$ & $(0 / 67)$ & $(56 / 56)$ & $(0 / 0)$ & $(0 / 0)$ \\
\hline & 0.0 & 100.0 & 0.0 & 100.0 & & \\
\hline \multirow{2}{*}{ EP-BE } & $(6 / 10)$ & $(6 / 7)$ & $(12 / 70)$ & $(51 / 53)$ & $(1 / 7)$ & $(2 / 14)$ \\
\hline & 60.0 & 85.7 & 17.1 & 96.2 & 14.3 & 14.3 \\
\hline \multirow{2}{*}{ ED-BE } & $(10 / 10)$ & $(4 / 7)$ & $(26 / 70)$ & $(45 / 53)$ & $(3 / 13)$ & $(8 / 34)$ \\
\hline & 100.0 & 57.1 & 37.1 & 84.9 & 23.1 & 23.5 \\
\hline \multirow{2}{*}{ ED-ES } & $(6 / 8)$ & $(8 / 9)$ & $(30 / 56)$ & $(63 / 67)$ & $(1 / 7)$ & $(4 / 34)$ \\
\hline & 75.0 & 88.9 & 53.6 & 94.0 & 14.3 & 11.8 \\
\hline
\end{tabular}

*Brackets: Number of weeks / days with at least one true-positive Poisson CUSUM signal in syndromic surveillance data divided by number of pandemic weeks/days according to reference data.

† Brackets: Number of true-negative weeks / days (no Poisson CUSUM signal) in syndromic surveillance data divided by number of weeks / days outside the pandemic period according to reference data.

‡ Brackets: Number of weeks/days with a false-positive Poisson CUSUM signal in syndromic surveillance data divided by all Poisson CUSUM signals of syndromic surveillance data

In Belgium, the reference data peaked in week 44; however, the weekly aggregated EP-BE (Figure 2a) and ED-BE data (Figure 2b) peaked in week 43. This trend in timeliness was confirmed by the correlation analysis in the EP-BE data, which showed a significant correlation of 0.60 one week ahead of the reference data (Table 5). No statistical confirmation could be achieved in ED-BE 
data, which showed a non-significant correlation of 0.48 at time lag 0 (Table 5). The timeliness assessment based on the first signal generated by the Poisson CUSUM algorithm during the influenza pandemic as defined in the reference data demonstrated a slightly different picture. When taking the reporting delay of the data sets into consideration the first signal of EP-BE data was retrieved two days later than the reference data, while the signal in the ED-BE data was retrieved eight days in advance (Table 5 , Figure $2 b$ and $a$ ).

The Autonomous Region of Cantabria in Spain encountered the A(H1N1) influenza pandemic peak in week 43 whereas the ED-ES data peaked one week later in week 44 (Figure 3). This observation was confirmed by a significant correlation of 0.89 at time lag +1 (Table 5 ). In the reference data of the Autonomous Region of Cantabria, the pandemic paused for one week (week 48) and thus two pandemic periods were available for timeliness assessment based on the Poisson CUSUM algorithm, first during week 41 to week 47 and second during week 49 . This assessment showed a delayed identification of the first period (+11 days) and an earlier identification of the second period (-8 days) (Table 5).
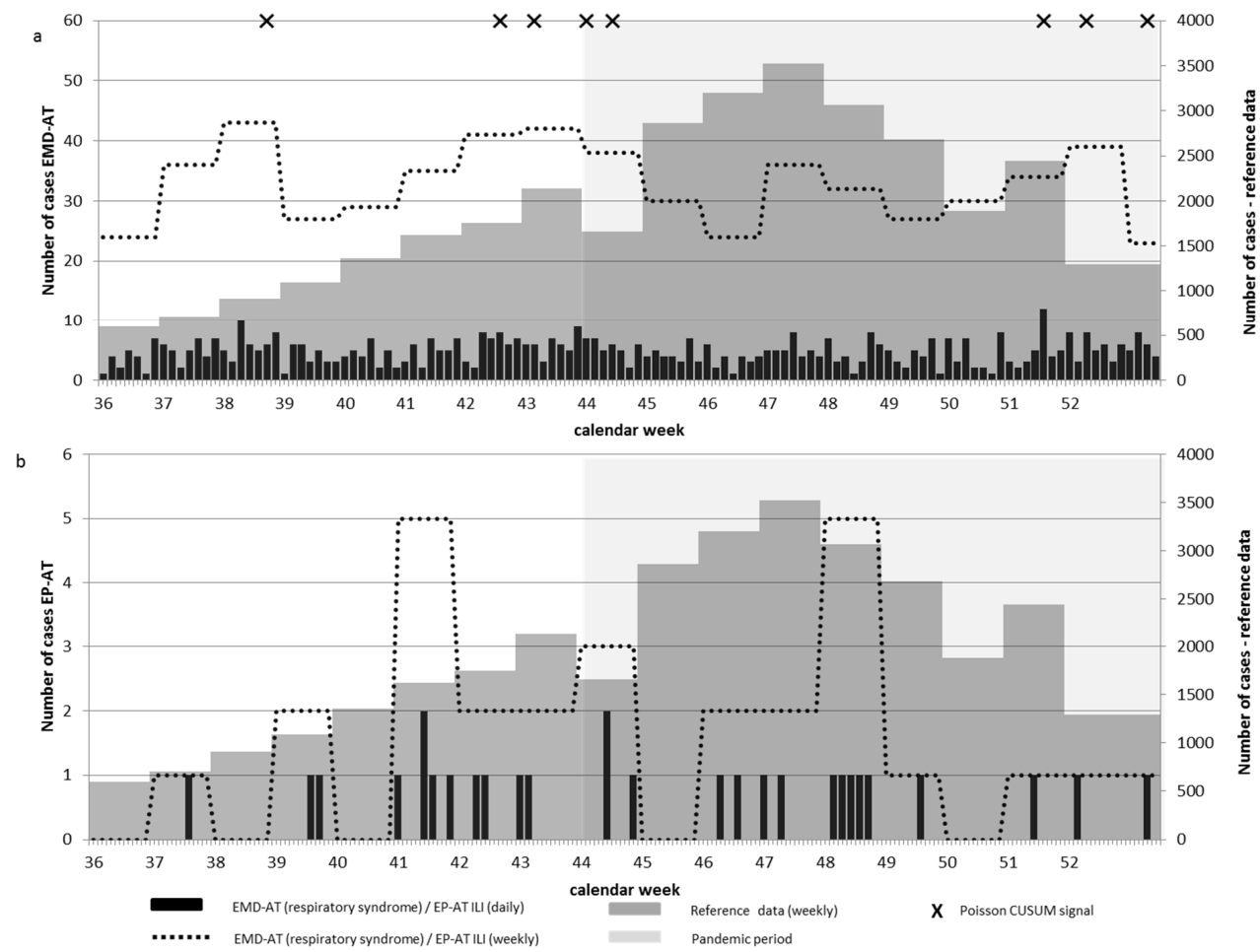

Figure 1 Time series of Austrian syndromic surveillance and reference data and documentation of Poisson CUSUM signals, week 36 (30.8.) to 52 (31.12.) in 2009. 


\section{Validity assessment}

Table 6 depicts sensitivity, specificity, and false detection rate for each data set. The number of Poisson CUSUM signals identified during the epidemic or non-epidemic periods are also presented in Table 6 and are indicated in the time series of Figures 1, 2, and 3.

The ED data sets showed the strongest potential for correctly identifying the outbreak and nonoutbreak periods (Table 6). The EP data sources exhibited promising results for data encompassing the entire Belgium ambulance services (EP-BE) over data for only one district in Tyrol (EP-AT). The daily measurement of sensitivity demonstrated a lower but similar pattern across the assessed data sets. The false detection rate was highest in the ED-ES and EP-BE data followed by ED-BE data.
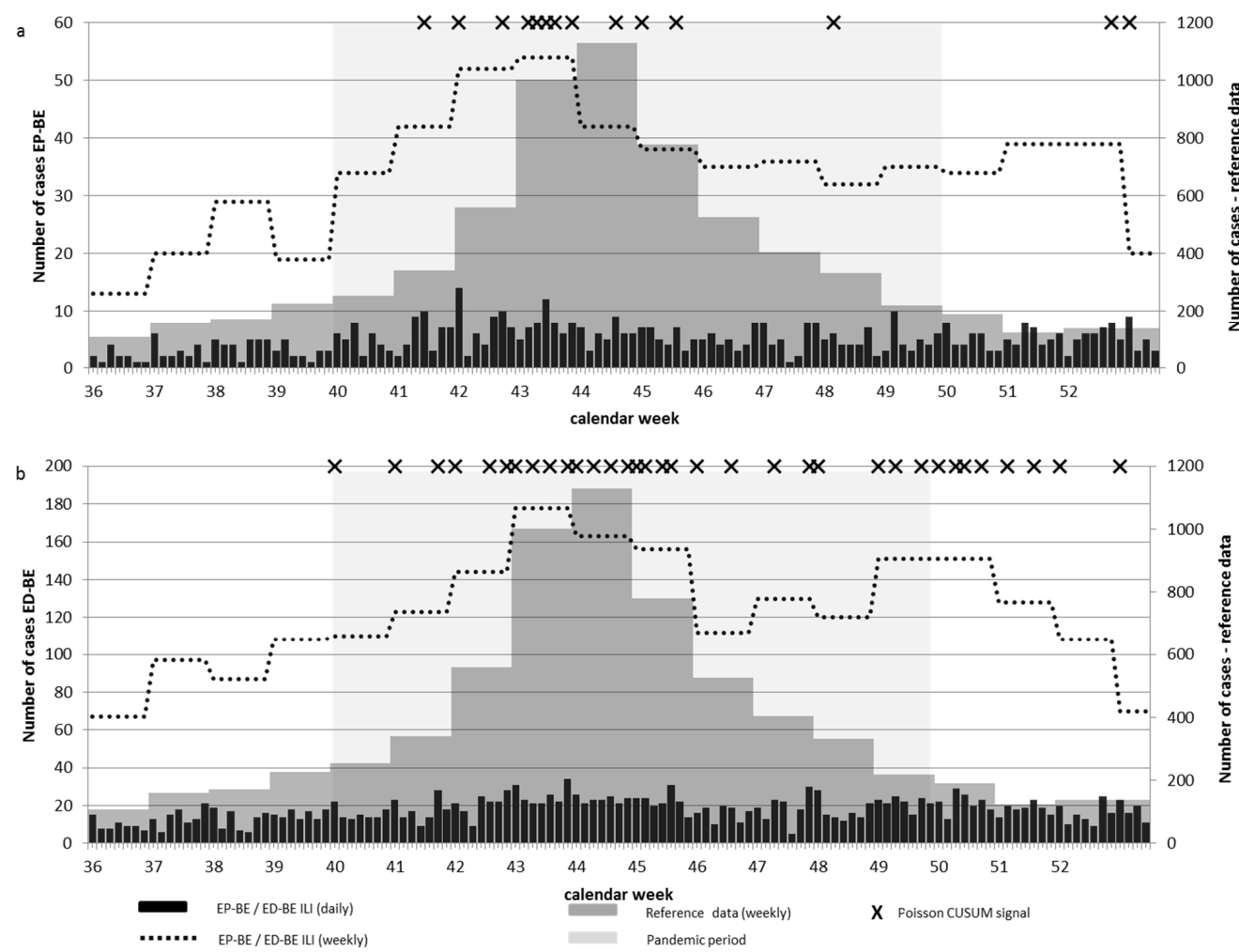

Figure 2 Time series of Belgian syndromic surveillance and reference data and documentation of Poisson CUSUM signals, week 36 (30.8.) to 52 (31.12.) in 2009. 


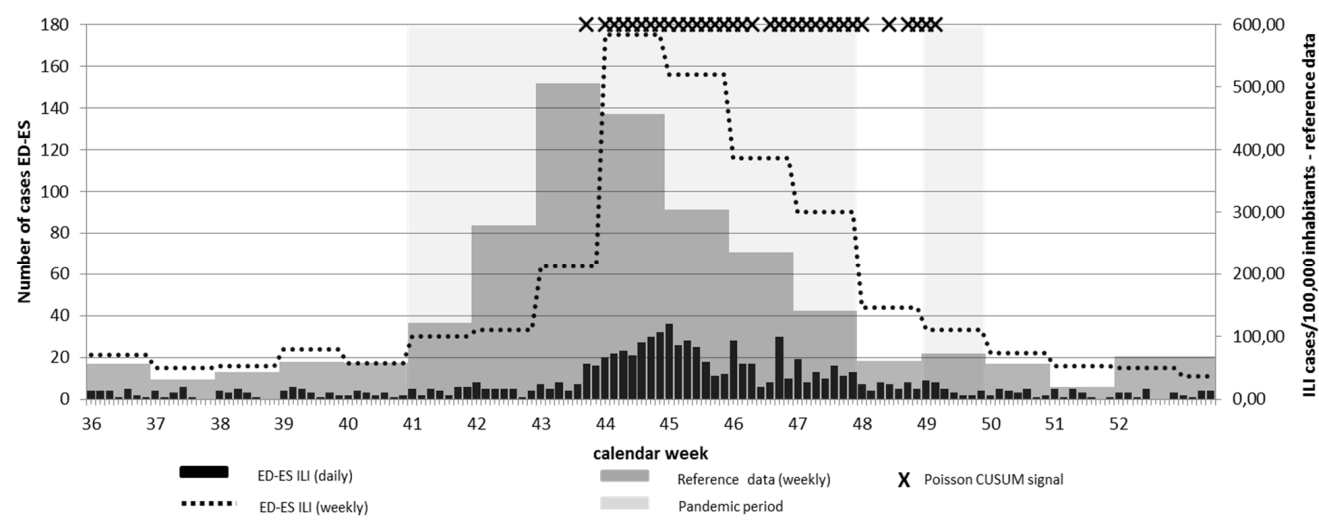

Figure 3 Time series of Spanish syndromic surveillance and reference data and documentation of Poisson CUSUM signals, week 36 (30.8.) to 52 (31.12.) in 2009.

\section{Discussion}

The autumn/winter wave of the $A(H 1 N 1)$ pandemic influenza in 2009 was used as a test case to evaluate a common approach for indicator-based syndromic influenza surveillance across various European countries and EMS data sources. The highest validity was achieved by ED data from local university hospitals (ED-ES and ED-BE) followed by national data from the Belgian ambulance service (EP-BE). The timeliness assessment results indicate that detection of the beginning of the pandemic influenza occurred approximately one week sooner than in the respective reference data set in the ED-BE data and two days later in the EP-BE data. For the other data sources timeliness assessment delivered no clear results.

\section{Emergency department data}

ED data presented the strongest validity and timeliness in this study. The only disadvantage was the delayed identification of the beginning of the autumn/winter wave in the ED-ES data. However, in this same data source the Poisson CUSUM algorithm identified the second period of pandemic influenza one week sooner than the Spanish (Autonomous Region of Cantabria) reference data.

A comparable timeliness for ED data-based syndromic influenza surveillance was identified by a study from Cowling et al., that also applied the CUSUM algorithm for aberration detection [37]. Plagianos et al. compared ILI case numbers in EDs with case numbers in ambulatory care facilities and identified a more rapid developing peak in ED data during the spring/summer wave of $A(H 1 N 1)$ influenza in New York in 2009 [38]. This was indicated in our study during the autumn/winter wave in the ED-BE but not in the ED-ES data.

A study on seasonal influenza after the A(H1N1) influenza pandemic in 2009, which was also based on ED-ES data, indicates that the baseline period employed for the Poisson CUSUM calibration in 78 Part $2 \mathrm{I}$ "Off-label-use" of data 
this study might be inflated as a result of the summer wave of pandemic $A(H 1 N 1)$ influenza. A lower baseline mean derived from a clear non-influenza season led to identification of seasonal influenza one week earlier in 2010/2011 and to an identification at the same time as in the reference data in the 2011/2012 seasonal influenza period [39]. The same might be true for the ED-BE data since the baseline period for this data source also included the spring/summer of 2009 due to limited data availability.

The stronger correlation and validity in ED-ES data contained in this study may be influenced by two factors. First, there are differences in the ILI coding practices. While patients in the ED-BE data were categorised as ILI cases due to one single chief complaint or working diagnosis, patients included in the ED-ES data fulfilled a more specific combined-case definition comparable to the case definition of the regional sentinel surveillance system. Second, the treatment-seeking behaviour and the use of ED services may differ between the two countries, indicating a more frequent exploitation of Spanish ED services by patients with mild conditions who could have been treated in primary care facilities $[40,41]$. These circumstances may have improved the representation of ILI cases in the ED-ES data and led to a better correspondence of the ED-ES data to the reference data.

\section{Ambulance service data}

We identified no studies that applied ambulance service data (EP) for syndromic influenza surveillance. While the EP-BE data exhibited validity and timeliness measures comparable to the ED data, this result could not be confirmed by the EP-AT data since low case occurrence inhibited validity and timeliness assessment. Although it would have been possible to decrease the Poisson CUSUM threshold value for the EP-AT data, which could have resulted in certain aberration detection, we decided that the value in detecting an occasional accumulation of one or two ILI cases during a high influenza season is minimal.

Explanations for the performance differences in the two EP data sources may not be routed in differences in the coding practice between the EP-AT and the EP-BE data, as the distribution of ICD codes in ILI cases was almost comparable in both data sets. The difference may be explained by the diverging size of the catchment area of each data set: while the EP-AT data covered just one district in Austria (Tyrol), the EP-BE data were available for the entire country.

\section{Emergency medical dispatch data}

Emergency medical dispatch data (EMD-AT) indicated the beginning of the autumn/winter wave of $A(H 1 N 1)$ influenza earlier than shown in the reference data. However, due to strong variability in the data set, the time series of EMD-AT did not correspond to the pattern seen in the time series of the reference data. Mostashari et al. [8] and Bork et al. [9] have also used EMD data based on comparable EMD coding systems but applied aberration detection algorithms based on regression analysis to control for several influencing variables (e.g. seasonality, holidays, 
temperature) [8] or dynamic forecasting models [9]. They discovered a diminished false detection rate [8] but a comparable timeliness of the system for syndromic influenza surveillance [9]. Due to the high variability and background noise of the broad EMD symptom categories, which was also seen by Coory et al. [42], it is recommended to further monitor the EMD-AT data to specify and fine-tune the aberration detection algorithm.

\section{Limitations}

In this study, the reference data were retrieved mainly from clinical sentinel surveillance, which may be subject to over-, as well as underreporting and provides no indication regarding the virus type and subtype of ILI cases. However, clinical sentinel data are regarded as the preferred source of identifying the course of the pandemic [22], which was of primary interest in this study.

Unfortunately, historical data availability of syndromic surveillance data was limited and influenced the possibilities in calculating solid Poisson CUSUM parameters. Even though it has been demonstrated that short baseline periods are not problematic for the application of the CUSUM algorithm [43], the inclusion of the pandemic spring/summer period in 2009 might have increased the baselines in the Belgian and Spanish data sets which were only available for 2009. An increased baseline subsequently inflates the Poisson CUSUM parameters (reference value k; threshold value $h$ ) and therefore may decrease the validity and timeliness assessment during the autumn/winter period. In general, fine-tuning of the CUSUM parameters is advisable [6] and, as it was demonstrated by Schrell et al. in the ED-ES data, a recalibration of the CUSUM parameters outside the pandemic period may have increased the timeliness of our approach [39].

Additionally, we encountered constraints for the validity assessment of the daily collected data caused by weekly available reference data. We attempted to solve this problem by employing a weekly and daily approach. This allowed us to formulate ranges in which sensitivity and specificity might be located, but it should be emphasized that the daily investigation was very strict and could possibly underestimate the validity measured in this study.

We applied an aberration detection algorithm that is easy to apply, but other approaches such as regression analysis are also often used [44]. In this study, we took day-of-the-week effects into consideration and attempted to ensure that baseline numbers were not affected by seasonal influenza periods. However, other approaches are available that directly control for seasonality, day-of-the-week effects and other influencing factors such as public holidays or vacation time, and may advisably be applied in the future to increase validity and timeliness [11,45]. Additionally, it seems to be worth incorporating the monitoring of age-group specific ILI cases, especially those of children, to enhance the performance of the approach $[6,46]$. Given the low daily case numbers of respiratory syndrome or ILI cases in the analysed data sets, however, the stratification in age groups in this case may not lead to valid results. A weekly analysis may be possible and may solve the issue of too low case numbers [46]. For the identification of public health-relevant 
aberrations in EMS data, future work should also focus on the definition of alert criteria, for example, a definition of the number of consecutive days with significant aberrations in case numbers that lead to a response decision $[39,47]$.

\section{Conclusion}

In our study, data from emergency departments, along with data from the ambulance service covering significant catchment areas exhibited the most favourable performance in terms of validity and timeliness for syndromic influenza surveillance during the autumn/winter wave of the $A(H 1 N 1)$ influenza pandemic in 2009. It could be demonstrated that diverse European routine EMS data sources could be used in a common syndromic surveillance approach to gain information on sudden or out-of-season health threats. However, the individual determination of aberration detection parameters per data set is required to adjust the algorithm to the local setting.

Data from European EMS providers can support public health decision-making since these data provide timely and readily obtainable information on mostly severe cases. This information can enhance and augment various population health information data sources during health crises or other situations in which readily available health data are necessary to identify for example the effects of changing policies. A flexible and easy-to-use syndromic surveillance approach based on EMS data may be of value in improving surveillance activities in Europe.

\section{Abbreviations}

AMPDS: Advanced Medical Priority Dispatch System; ARI: Acute respiratory infection; CUSUM: Cumulative summation detection algorithm; EC: European Commission; ECDC: European Centre for Disease Prevention and Control; ED: Emergency Department; ED-BE: Emergency department data, University Hospital Leuven, Belgium; ED-ES: Emergency department data, University Hospital Marqués de Valdecilla, Santander, Spain; EMD: Emergency Medical Dispatch; EMD-AT: Emergency medical dispatch data Tyrol, Austria which includes the city of Innsbruck, the district of Innsbruck, and the district of Kufstein; EMS: Emergency Medical Service; EP: Ambulance services staffed with emergency physician; EP-AT: Ambulance service data Tyrol, Austria (District of Kufstein); EP-BE: Ambulance service data Belgium; FIR: Fast Initial Response; GP: General Practitioner; ICD: International Classification of Diseases; ILI: Influenza-like illness; MedISys: Medical Information System; SIDARTHa: European Commission co-funded project (European emergency data-based syndromic surveillance system). 


\section{Authors' contributions}

LG, GV, JBG, NR, AZ, TK and HB were involved in the syndrome definition for each data set and design of the study. NR carried out the statistical analysis. NR, AZ, TK and HB drafted the manuscript. All authors reviewed the manuscript and approved the final version.

\section{Acknowledgements}

This research arises from the project SIDARTHa, which has received funding from the European Union in the framework of the Public Health Programme (Grant Agreement Number: 2007208).

We would like to thank the project partners Matthias Fischer, Freddy Lippert, Mark Rosenberg, Alexander Krämer, and Paulo Pinheiro for their support in the conceptualisation of the study. We appreciate the data provision and processing from the University Hospital Leuven, Belgium, by Agnes Meulemans and Jochen Bergs. National Belgium ambulance service data were made available by Lambert Stamatakis. Anita Luckner-Hornischer provided reference data for Tyrol, Austria. Janneke Kraan supported data analysis during an internship at the Department of International Health at Maastricht University.

\section{References}

1. Fleming DM, van der Velden J, Paget WJ. The evolution of influenza surveillance in Europe and prospects for the next 10 years. Vaccine. 2003;13(16):1749-1753. doi: 10.1016/S0264410x(03)00066-5.

2. Paget J, Marquet R, Meijer A, van der Velden K. Influenza activity in Europe during eight seasons (1999-2007): an evaluation of the indicators used to measure activity and an assessment of the timing, length and course of peak activity (spread) across Europe. BMC Infect Dis. 2007;13:141. doi: 10.1186/1471-2334-7-141.

3. Weekly influenza surveillance overview.

http://ecdc.europa.eu/en/publications/surveillance_reports/influenza/Pages/weekly_influ enza_surveillance_overview.aspx.

4. Paquet C, Coulombier D, Kaiser R, Ciotti M. Epidemic intelligence: a new framework for strengthening disease surveillance in Europe. Euro Surveill. 2006;13(12):212-214.

5. Triple S. Assessment of syndromic surveillance in Europe. Lancet. 2011;13(9806):1833-1834. doi: 10.1016/S0140-6736(11)60834-9.

6. Griffin BA, Jain AK, Davies-Cole J, Glymph C, Lum G, Washington SC, Stoto MA. Early detection of influenza outbreaks using the DC Department of Health's syndromic surveillance system. BMC Public Health. 2009;13:483. doi: 10.1186/1471-2458-9-483. 
7. Zheng W, Aitken R, Muscatello DJ, Churches T. Potential for early warning of viral influenza activity in the community by monitoring clinical diagnoses of influenza in hospital emergency departments. BMC Public Health. 2007;13:250. doi: 10.1186/1471-2458-7-250.

8. Mostashari F, Fine A, Das D, Adams J, Layton M. Use of ambulance dispatch data as an early warning system for communitywide influenza-like illness. New York City. J Urban Health. 2003;13(2 Suppl 1):i43-49.

9. Bork KH, Klein BM, Molbak K, Trautner S, Pedersen UB, Heegaard E. Surveillance of ambulance dispatch data as a tool for early warning. Euro Surveill. 2006;13(12):229-233.

10. Smith S, Smith GE, Olowokure B, Ibbotson S, Foord D, Maguire H, Pebody R, Charlett A, Hippisley-Cox J, Elliot AJ. Early spread of the 2009 influenza A(H1N1) pandemic in the United Kingdom--use of local syndromic data, May-August 2009. Euro Surveill. 2011;13(3):pii: 19771.

11. Kavanagh K, Robertson C, Murdoch H, Crooks G, McMenamin J. Syndromic surveillance of influenza-like illness in Scotland during the influenza A H1N1v pandemic and beyond. Journal of the Royal Statistics Society: Series A (Statistics in Society) 2012;13(4):939-958. doi: 10.1111/j.1467-985X.2012.01025.X.

12. Kara EO, Elliot AJ, Bagnall H, Foord DG, Pnaiser R, Osman H, Smith GE, Olowokure B. Absenteeism in schools during the 2009 influenza A(H1N1) pandemic: a useful tool for early detection of influenza activity in the community? Epidemiol Infect. 2011;13(7):1328-1336.

13. Schmidt WP, Pebody R, Mangtani P. School absence data for influenza surveillance: a pilot study in the United Kingdom. Euro Surveill. 2010;13(3):pii: 19467.

14. Das D, Metzger K, Heffernan R, Balter S, Weiss D, Mostashari F. Monitoring over-the-counter medication sales for early detection of disease outbreaks-New York City. MMWR Morb Mortal Wkly Rep. 2005;13(Suppl):41-46.

15. Linge JP, Steinberger R, Weber TP, Yangarber R, van der Goot E, Al Khudhairy DH, Stilianakis NI. Internet surveillance systems for early alerting of health threats. Euro Surveill. 2009;13(13):pii: 19162.

16. Valdivia A, Lopez-Alcalde J, Vicente M, Pichiule M, Ruiz M, Ordobas M. Monitoring influenza activity in Europe with Google Flu Trends: comparison with the findings of sentinel physician networks - results for 2009-10. Euro Surveill. 2010;13(29):pii: 19621.

17. Medical Information System (MedISys)

http://medusa.jrc.it/medisys/homeedition/en/home.html.

18. Fouillet A, Sala-Soler M, Conti S, Kanieff M, Rago G, Perrin J, Dupuy C, Krafft T, Ziemann A, Viso AC. Inventory of syndromic surveillance systems in Europe by the triple-S project. Emerging Health Threats Journal. 2011;13:10946.

19. Ziemann A, Krafft T, Rosenkötter N, Garcia-Castrillo Riesgo L, Vergeiner G, Fischer M, Lippert F, Krämer A, Pinheiro $P$, Brand $H$. et al. Syndromic surveillance: enhancing public health responsiveness to global change - a european perspective. IHDP Update. 2011;13:12-18.

20. Krafft T, Garcia Castrillo-Riesgo L, Edwards S, Fischer M, Overton J, Robertson-Steel I, Konig A. European Emergency Data Project (EED Project): EMS data-based health surveillance system. Eur J Public Health. 2003;13(3 Suppl):85-90. 
21. Buehler JW, Hopkins RS, Overhage JM, Sosin DM, Tong V. Framework for evaluating public health surveillance systems for early detection of outbreaks: recommendations from the CDC Working Group. MMWR Recomm Rep. 2004;13(RR-5):1-11.

22. Amato-Gauci A, Zucs P, Snacken R, Ciancio B, Lopez V, Broberg E, Penttinen P, Nicoll A. Surveillance trends of the 2009 influenza $A(H 1 N 1)$ pandemic in Europe. Euro Surveill. 2011;13(26):pii: 19903.

23. European Centre for Disease Prevention and Control. A review of the experience. Stockholm: ECDC; 2010. The 2009 A(H1N1) pandemic in Europe.

24. SIDARTHa - European emergency data-based syndromic surveillance system. http:/ / www.sidartha.eu.

25. Hofmarcher MM, Rack H-M. Austria: health system review. Health Syst Transit. 2006;13(3):1275.

26. Van Casteren V, Mertens K, Antoine J, Wanyama S, Thomas I, Bossuyt N. Clinical surveillance of the influenza a (H1N1) 2009 pandemic through the network of sentinel general practitioners. Archives of Public Health. 2010;13(2):62-67. doi: 10.1186/0778-7367-68-2-62.

27. Schmidt D, Liu YL, Lachner P. Nationale Referenzzentrale für Influenza-Epidemiologie. Wien: Agentur für Gesundheit und Ernährungssicherheit; 2011. Influenza in Österreich, Saison 2009/2010.

28. Influenza case definitions.

http://ecdc.europa.eu/en/activities/surveillance/EISN/surveillance/Pages/influenza_case_ definitions.aspx.

29. Greenko J, Mostashari F, Fine A, Layton M. Clinical evaluation of the Emergency Medical Services (EMS) ambulance dispatch-based syndromic surveillance system. New York City. J Urban Health. 2003;13(2 Suppl 1):i50-56.

30. May LS, Griffin BA, Bauers NM, Jain A, Mitchum M, Sikka N, Carim M, Stoto MA. Emergency department chief complaint and diagnosis data to detect influenza-like illness with an electronic medical record. West J Emerg Med. 2010;13(1):1-9.

31. Rosenkötter N, Kauhl B, Garcilla-Castrillo Riesgo L, Diaz FJL, Kraan J, Ziemann A, Schorbahn M, Krafft T, Brand H. Retrospective data analysis and simulation study as basis for an automated syndromic surveillance system - results from the SIDARTHa project. SIDARTHa. Bad Honnef. 2010. http://www.sidartha.eu/publications.html.

32. Burkom H. In: Disease surveillance: a public health informatics approach. Lombardo JS, Buckeridge DL, editor. Hoboeken New Jersey: John Wiley \& Sons Inc; 2007. Alerting algorithms for biosurveillance; pp. 159-163.

33. Lucas JM, Crosier RB. Fast initial response for CUSUM quality-control schemes: give your CUSUM a head start. Technometrics. 1982;13(3):199-205. doi: 10.1080/00401706.1982.10487759.

34. Lucas JM. Counted data CUSUM'S. Technometrics. 1985;13(2):129-144. doi: 10.1080/00401706.1985.10488030.

35. Dailey L, Watkins RE, Plant AJ. Timeliness of data sources used for influenza surveillance. J Am Med Inform Assoc. 2007;13(5):626-631. doi: 10.1197/jamia.M2328.

36. SPSS. SPSS Trends, 10.0. Chicago: SPSS Inc.; 1999. 
37. Cowling BJ, Wong IO, Ho LM, Riley S, Leung GM. Methods for monitoring influenza surveillance data. Int J Epidemiol. 2006;13(5):1314-1321. doi: 10.1093/ije/dyl162.

38. Plagianos MG, Wu WY, McCullough C, Paladini M, Lurio J, Buck MD, Calman N, Soulakis N. Syndromic surveillance during pandemic (H1N1) 2009 outbreak, New York, New York. USA. Emerg Infect Dis. 2011;13(9):1724-1726. doi: 10.3201/ eid1709.101357.

39. Schrell S, Ziemann A, Garcia-Castrillo Riesgo L, Rosenkotter N, Llorca J, Popa D, Krafft T. on Behalf of the SPC. Local implementation of a syndromic influenza surveillance system using emergency department data in Santander, Spain. J Public Health (Oxf) 2013;13(3):397-403.

40. Garcia-Armesto S, Abadia-Taira MB, Durán A, Hernández-Quevedo C, Bernal-Delgado E. Spain: health systems review. Health Syst Transit. 2010;13(4):1-295.

41. Gerkens S, Merkur S. Belgium: health system review. Health Syst Transit. 2010;13(5):1-266.

42. Coory MD, Kelly H, Tippett V. Assessment of ambulance dispatch data for surveillance of influenza-like illness in Melbourne. Australia. Public Health. 2009;13(2):163-168. doi: 10.1016/j.puhe.2008.10.027.

43. Hutwagner LC, Maloney EK, Bean NH, Slutsker L, Martin SM. Using laboratory-based surveillance data for prevention: an algorithm for detecting Salmonella outbreaks. Emerg Infect Dis. 1997;13(3):395-400. doi: 10.3201/eid0303.970322.

44. Buckeridge DL. Outbreak detection through automated surveillance: a review of the determinants of detection. J Biomed Inform. 2007;13(4):370-379. doi: 10.1016/j.jbi.2006.09.003.

45. Craigmile PF, Kim N, Fernandez SA, Bonsu BK. Modeling and detection of respiratory-related outbreak signatures. BMC Med Inform Decis Mak. 2007;13:28. doi: 10.1186/1472-6947-7-28.

46. Lemay R, Mawudeku A, Shi Y, Ruben M, Achonu C. Syndromic surveillance for influenza-like illness. Biosecur Bioterror. 2008;13(2):161-170. doi: 10.1089/bsp.2007.0056.

47. Sosin DM. Draft framework for evaluating syndromic surveillance systems. J Urban Health. 2003;13(2 Suppl 1):i8-13. 

Chapter 3 I Surveillance of non-infectious events under the IHR (2005)

Non-infectious events under the International Health Regulations 2005 in Europe - a case for syndromic surveillance

Rosenkötter N, Ziemann A, Krafft T, Garcia-Castrillo Riesgo L, Vergeiner G, Brand H.

Journal of Public Health Policy 2014.35(3): 311-326. 


\begin{abstract}
The scope of the International Health Regulations of 2005 (IHR (2005)) has been expanded. The IHR (2005) are no longer limited to a specific set of infectious diseases, instead they prescribe detection and assessment of any event of potential public health concern regardless of its source or origin. We examine events of non-infectious origin that might fulfill the criteria of a potential public health emergency of international concern under the IHR (2005). These comprise predominately events related to food safety, but also events related to drug safety or of chemical or industrial origin. We argue that to identify these events and assess health effects related to them, existing disease surveillance systems should be augmented with less specific indicatorbased syndromic surveillance strategies that use available routine health-related service data for monitoring purposes.
\end{abstract}

\title{
Introduction
}

The International Health Regulations (IHR (2005)) of the World Health Organization (WHO) define core capacities and response measures to prevent and to respond to acute public health emergencies of international concern (PHEIC). ${ }^{1}$ The regulations are an international, legally binding instrument. They define, in contrast to the previous infectious disease focused IHR version, an all-hazard approach.,

Potential PHEICs can now be infectious, zoonotic, related to food safety, of chemical or radiologic/nuclear origin, as well as events transmissible via persons, vectors, cargo, goods, and environmental diffusion. ${ }^{3}$ But regardless of the broad event definition, case descriptions in the literature, as well as surveillance infrastructures, are primarily geared towards infectious diseases. ${ }^{4}$ Even though infectious diseases might constitute the majority of potential PHEICs, the surveillance infrastructure should in due time be capable to identify threats or health effects of events of non-infectious origin.

Here we focus on non-infectious health threats and on how these threats or related health effects could be identified with syndromic surveillance using routinely collected health information. First, to illustrate the relevance of using additional surveillance tools, we provide an overview of the spectrum of non-infectious events that could meet the criteria of a potential PHEIC. Second, we discuss the potential of indicator-based syndromic surveillance approaches for enabling timely surveillance of non-infectious health threats and related health effects in Europe.

\section{Non-infectious Events Under the IHR (2005)}

The IHR (2005) define an event as the 'manifestation of disease or an occurrence that creates a potential for disease'. ${ }^{1}$ The affected state party should assess, within 48 hours, whether the event 
may constitute a PHEIC. PHEICs are characterized by meeting at least two of the following assessment criteria, given in Annex 2 of the IHR (2005): (1) having a serious public health impact, (2) being an unusual or unexpected event, (3) bearing a risk of international spread, and (4) having implications for international travel and trade activities. ${ }^{3}$

A positive assessment should lead to a report from the affected state party's National IHR Focal Point (NFP) to WHO within 24 hours. The final decision about whether the event constitutes a PHEIC rests with the WHO Director-General who seeks advice of the WHO Emergency Committee. ${ }^{1}$

In our literature review, we identified non-infectious events that had been discussed in relation with the IHR (2005) (Table 1). Most event descriptions affected food safety and correspondingly population health. ${ }^{3,5,6}$ Other events were related to drug safety ${ }^{5,7}$ or were of chemical or industrial origin with a certain potential for environmental diffusion of the hazards..$^{3,5,7}$ In addition, we found events related to hazardous goods, 3 radioactive incidents, ${ }^{3}$ or the application of chemical weapons. $^{6}$

Two non-infectious emergencies triggered attention because they seem to have met PHEIC criteria, but were not notified or declared as such. The first related to food safety. In 2008, melamine adulterated infant formula caused serious health problems in Chinese children, leading to about 50000 hospitalizations and six deaths.8 Other Asian countries reported affected children, ${ }^{8}$ and products containing contaminated milk powder were found worldwide, including in European Union member states. ${ }^{9}$

Had reporting been delayed? Melamine contamination was first identified in summer 2008 and international notification via the International Food Safety Authorities Network (INFOSAN) to WHO and INFOSAN members occurred in mid-September 2008.10 Although the melamine contamination seem to meet PHEIC criteria for health impact, risk of international spread, and implications for international trade, we could find no literature sources that document notification of a potential PHEIC to WHO or a declaration by the WHO Director-General.11

The second event was the radiation incident in 2011 that followed a natural disaster in Japan. Japan's National Focal Point (NFP) notified WHO of the potential PHEIC, but the Director-General did not affirm it as a PHEIC. The WHO said that it did not declare a PHEIC because the public health risk was geographically limited, there was national capacity for monitoring and managing the event, and there was no need to give public health recommendations for countries other than Japan. ${ }^{12}$

As the influenza pandemic of 2009 is the only officially declared PHEIC to date, one gets the impression that despite the broad scope of the IHR (2005), the declaration of a PHEIC has been handled very cautiously and only used for exceptional global circumstances. ${ }^{11}$ Nevertheless, the 
IHR (2005) present an all-hazard approach and require surveillance measures to identify noninfectious events and related health effects of international concern.

Table 1 illustrates the variety of rather unspecific health effects that can be expected. Almost half of the events or the related health effects were identified using routine health service information and medical case descriptions, so-called indicator-based surveillance information. We discuss implications for surveillance activities in the sections that follow.

\section{Identification of Events or Related Health Effects}

Annex 2 of the IHR (2005) is the guiding instrument for assessing whether an event constitutes a potential PHEIC. Public health surveillance is a core capacity that WHO member states should maintain to identify potential PHEICs and related health effects. ${ }^{13}$ In 2007, after the IHR (2005) came into force, WHO suggested that member states develop and improve the relevant core public health capacities by 2012. In that year, most member states obtained a 2-year extension to finalize implementation. . $^{4,15}$

Surveillance capacities defined in the IHR core capacities focus on indicator-based and eventbased surveillance systems. They should be implemented on the primary public health response level of WHO member states. ${ }^{1,13}$ Indicator-based surveillance sources vary from very specific laboratory confirmed data for the identification of traditional notifiable infectious diseases to the use of less specific health information aggregated to predefined syndromes. ${ }^{16}$ Event-based monitoring includes the monitoring of media sources, web-queries, and non-health sources in food safety, agriculture, or meteorology. ${ }^{11,14}$ Event-based systems have become critical elements of the international surveillance infrastructure. ${ }^{8}$ The IHR (2005) also suggests that WHO conduct surveillance by using non-governmental information to identify and assess suspicious events worldwide, ${ }^{1,11}$ a measure introduced to reduce non-compliance by member states. ${ }^{17}$ The Global Public Health Intelligence Network is a WHO event-based surveillance instrument that monitors websites, news wires, and newspaper articles to identify infectious and non-infectious events that can harm population health. ${ }^{18}$ The system offers worldwide identification of events, and timely identification of risks. ${ }^{18}$ For Europe, event-based surveillance systems have been developed to monitor non-infectious health threats (Rapid Alert System for Food and Feed; Rapid Alert System for Non-food Products; Radioactivity Environmental Monitoring platform; Rapid Alerting System for Chemical Health Threats; and Medical Information System). These systems help identify critical health threatening events, but their capacity to assess related health effects may be limited.

To compensate for that, WHO recommends indicator-based surveillance that focuses on the identification of specific diseases or health effects. WHO puts the main emphasize on traditional, notifiable disease surveillance systems that exist in most developed countries. ${ }^{19}$ But, as apparent

90 Part 2 I "Off-label-use" of data 
in Table 1, this infectious disease focus is not sufficient for surveillance under the IHR (2005) because it does not allow monitoring of general, non-specific, or unexpected health effects that occur during non-infectious events. ${ }^{4,20}$ The surveillance framework under the IHR (2005) also suggests less specific syndromes that should be monitored, but those are mainly infectious disease-related and tend to disregard the possibility of monitoring rather diverse health effects during non-infectious events. ${ }^{15}$

Consequently, we argue, surveillance requirements for assessing health effects of non-infectious events are incomplete. A study among NFPs illustrates that member states feel comfortable in assessing infectious disease events, but have difficulties assessing non-infectious health events like contaminated food, water, or chemical incidents. ${ }^{20}$

\section{Non-infectious Health Threats - A Case for Syndromic Surveillance}

Indicator-based syndromic surveillance can fill this gap by using routine health information. Health effects of potential PHEICs may become manifest in the first recognition of an exposure to a hazard, in first symptoms, and in self-care efforts of the affected population or through sudden changes in utilization patterns of health-care services. ${ }^{21}$ All these manifestations are documented in routinely and continuously collected health data.

Syndromic surveillance is a flexible approach that makes use of routinely collected, often electronically available, data. It uses information on clinical signs and symptoms, often before laboratory or comprehensive diagnostic confirmation is available. ${ }^{22}$ It allows for flexible syndrome generation and adaptation to a specific event. ${ }^{23}$ Relevant data sources include general practitioner visits, data on emergency medical care services, and information from telephone helplines, or poison centres. ${ }^{24}$ These data are used to identify or confirm the existence or absence of unspecific effects like respiratory illness, asthma, fever, rash, sun/heat stroke, or other syndromes. $^{24}$

Since the introduction of syndromic surveillance after the 2001 terror events, our understanding of its applicability has changed. Some public health authorities started to use syndromic surveillance for the timely identification of the onset of infectious disease outbreaks like influenza or to gain situational awareness during a broad range of potentially health affecting incidents. ${ }^{25}$ How has syndromic surveillance been used for monitoring of health effects during non-infectious events?

- Emergency department data-based syndromic surveillance was used in France for monitoring disease burden during heat waves. ${ }^{26}$ 
- In the United States, emergency department-based syndromic surveillance supported smoke exposure monitoring after a peat bog wildfire in a rural area that lacked environmental air quality monitoring. ${ }^{27}$

- After a windstorm that led to a power outage and increased use of alternative heating facilities, an increase in carbon monoxide poisoning was identified in the United States by syndromic surveillance information based on emergency medical care data. ${ }^{28}$

- The dispersion of volcanic ash in April 2010 across Europe, an event that fulfilled criteria of a potential PHEIC and was reported by the respective state party (Iceland) to $\mathrm{WHO}^{29}$ was monitored by the syndromic surveillance systems of the United Kingdom. They used data from telephone helplines and General Practitioner services plus other monitoring systems for environmental hazards to quickly identify potential public health effects. ${ }^{30}$ The systems detected increases in diagnoses like asthma or allergic rhinitis, but no changes in ambient air quality were found. UK system operators reasoned that these increases related to seasonal circumstances rather than to the volcano eruption. ${ }^{30} \mathrm{~A}$ similar conclusion was drawn after a rapid assessments of health effects in continental European countries, based on emergency medical care data. ${ }^{31}$

These examples illustrate how routine data, usually not collected for public health surveillance, may be used by local or regional public health authorities to gather information on populations' health and to gain situational awareness during unusual and unexpected situations. ${ }^{23}$ Thereby Public health professionals increasingly face a challenge: to process innumerable bits of data, the 'epidemiological puzzle', and to Syndromic surveillance under IHR (2005) assign meaning to them. Undoubtedly, syndromic surveillance can support solving this puzzle. ${ }^{25}$ As syndromic surveillance will use routine data sources that vary substantially in content and coding, a common flexible indicator-based syndromic surveillance approach is needed to allow information exchange and comparison across Europe.

Of course, syndromic surveillance is not without critics. Interpretation require substantial human resources. ${ }^{32}$ The system will need to be adjusted to its context and early warning algorithms need to be fine-tuned. Defined response protocols can help limit this burden. The common critique, that data used for syndromic surveillance are too unspecific for surveillance purposes, describes an advantage when it comes to non-infectious events.

The supportive nature of syndromic surveillance in describing the existence or absence of health impacts was also confirmed by public health practitioners through a utility assessment of the routinely established syndromic surveillance structures in the United States. ${ }^{23}$ They found that the availability of additional information sources during events - occurrence of respiratory problems during wildfires, injury monitoring after a tornado - was supportive. Capacity for adhoc analysis during a broad set of incidents was highly valuable. ${ }^{23}$ 
Table 1 Overview of theoretical and real-life potential public health emergencies of international concern (PHEIC) of non-infectious origin.

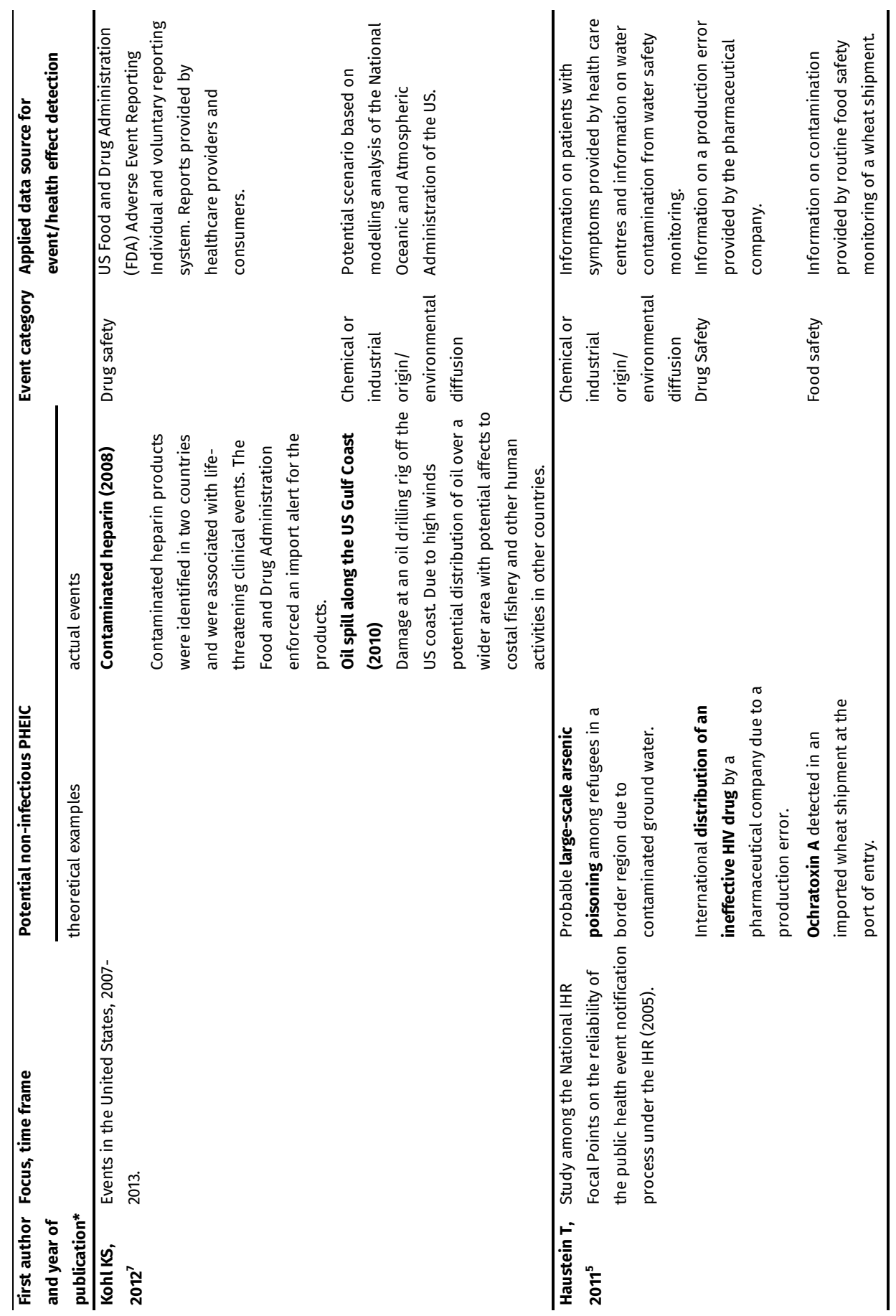


Table 1 Overview of theoretical and real-life potential public health emergencies of international concern (PHEIC) of non-infectious origin (continued).

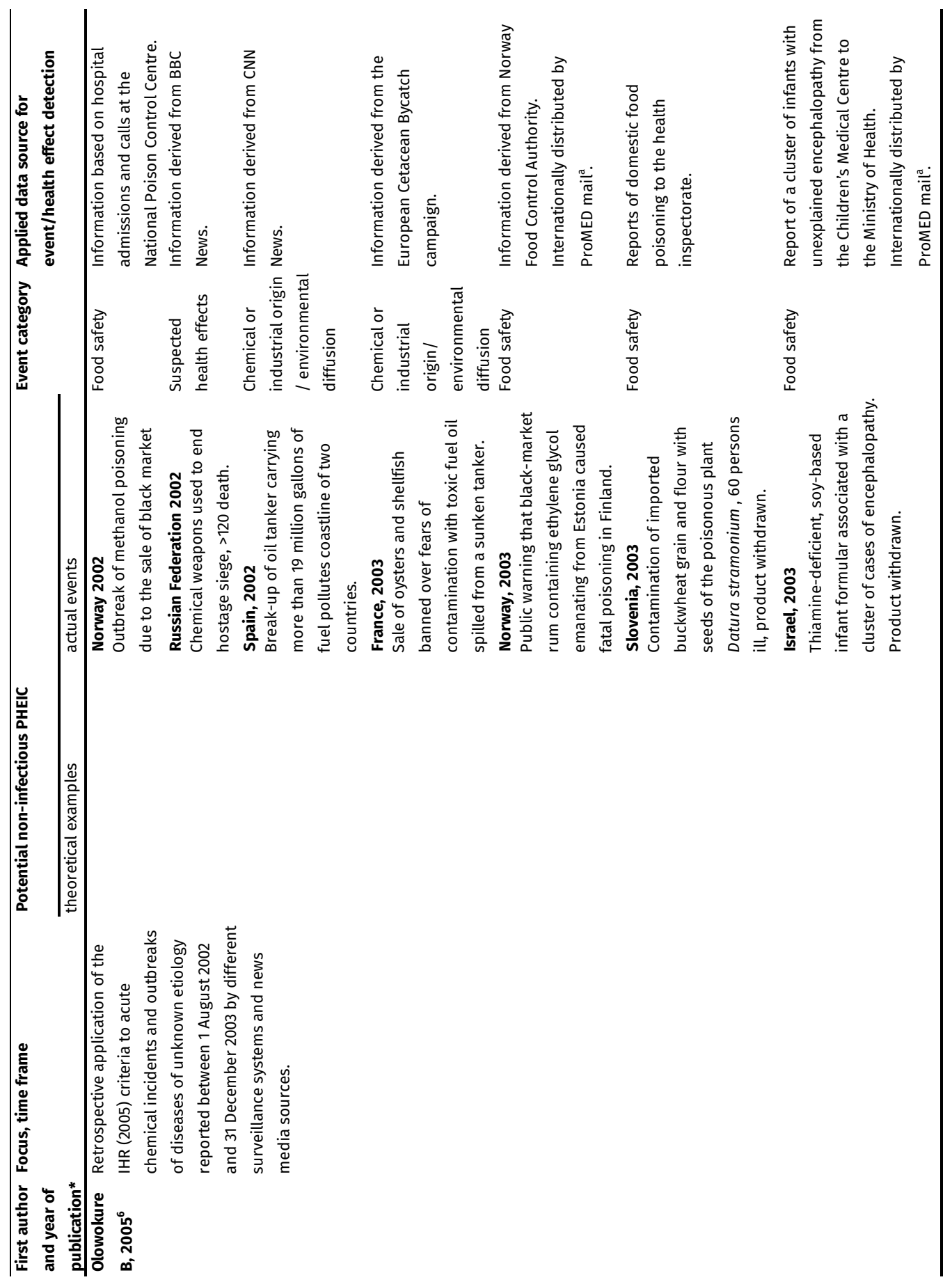

94 Part 2 I "Off-label-use" of data 
Table 1 Overview of theoretical and real-life potential public health emergencies of international concern (PHEIC) of non-infectious origin (continued).

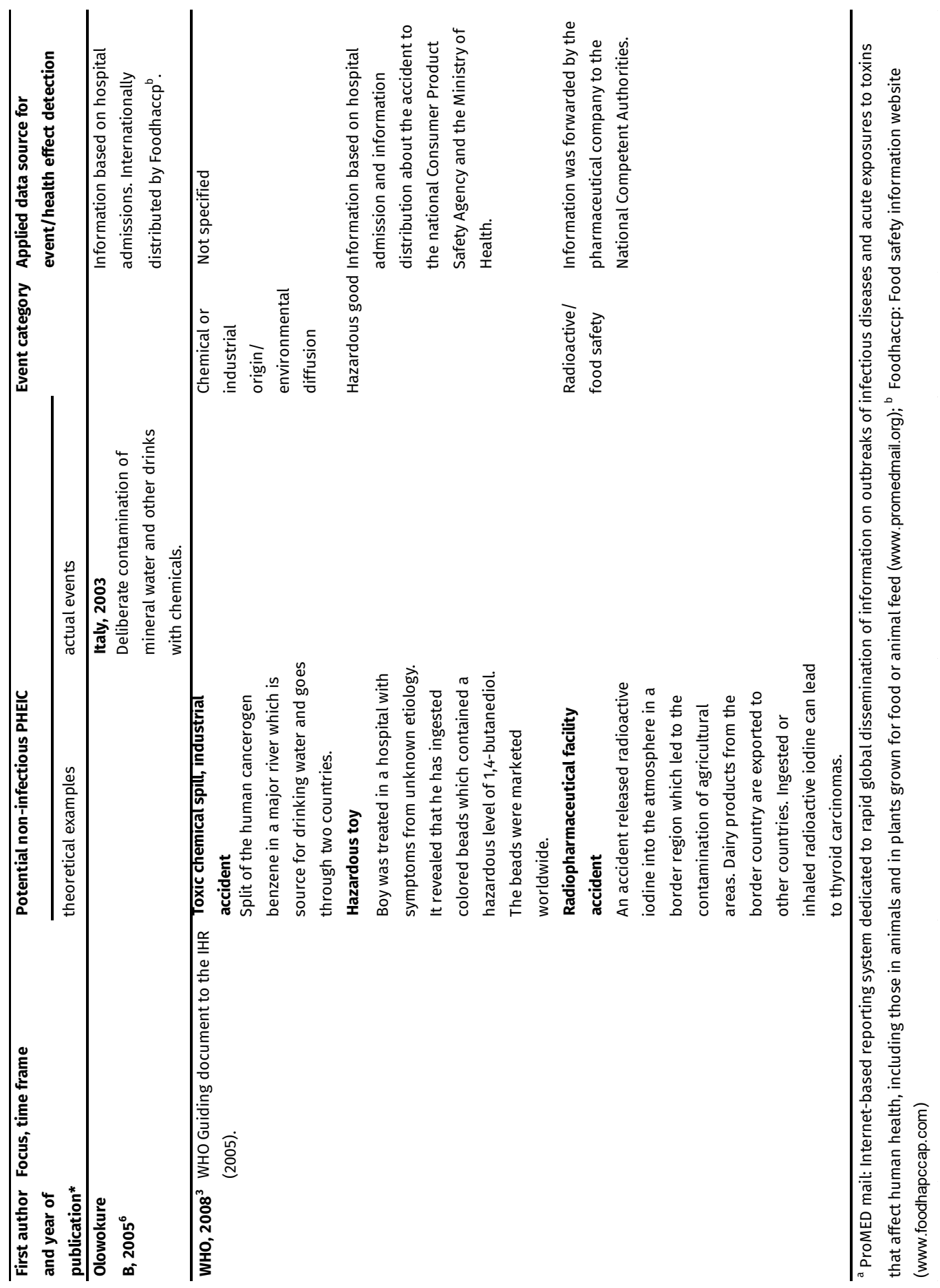




\section{Conclusions}

Non-infectious events that might constitute a PHEIC are diverse in nature and can range from food or drug safety issues to the international distribution of hazardous goods, to chemical incidents with environmental dispersion, to natural disasters. The range of potential health effects is as diverse as the events. In addition to identification of non-infectious disease events through event-based surveillance structures, experiences from indicator-based syndromic surveillance emphasize its value to increase awareness about the potential public health consequences during these situations. So far, no coordinated European approach to make use of available health data exists. No European platform allows information from syndromic surveillance systems to be systematically exchanged among member states. Now, in 2013, the Council of the European Union and the European Parliament seem to have recognized the gap in information exchange about non-infectious health threats because they expanded the focus of their Early Warning and Response System accordingly. ${ }^{33}$ Public health authorities that want to be able to identify health threats or monitor health effects related to non-infectious events under the IHR (2005) should make use of less specific health information to improve and expand indicator-based surveillance. Additional investment in surveillance infrastructures would lead to more comprehensive surveillance systems and would strengthen surveillance capacities under the IHR (2005).

\section{Acknowledgements}

This research, under project SIDARTHa (European Emergency Databased Syndromic Surveillance) received funding from the European Union's Public Health Programme (Grant Agreement Number: 2007208) and was informed by the final report of the SIDARTHa project. We submitted an abstract to the One Health Conference in 2012. We appreciate the feedback and comments from Dr Thomas Hofmann. 


\section{References}

1. World Health Organization. (2008) International Health Regulations (2005). Geneva,

1. Switzerland: World Health Organization.

2. Baker, M.G. and Fidler, D.P. (2006) Global public health surveillance under new International Health Regulations. Emerging Infectious Diseases 12(7): 1058-1065.

3. World Health Organization. (2008) WHO Guidance for the Use of Annex 2 of the International Health Regulations (2005). Decision Instrument for the Assessment and Notification of Events that may Constitute a Public Health Emergency of International Concern. Geneva, Switzerland: World Health Organization.

4. Katz, R.L., Fernandez, J.A. and McNabb, S.J. (2010) Disease surveillance, capacity building and implementation of the International Health Regulations (IHR [2005]). BMC Public Health 10(1): S1.

5. Haustein, T., Hollmeyer, H., Hardiman, M., Harbarth, S. and Pittet, D. (2011) Should this event be notified to the World Health Organization? Reliability of the International Health Regulations notification assessment process. Bulletin of the World Health Organization 89(4): 296-303.

6. Olowokure, B., Pooransingh, S., Tempowski, J., Palmer, S. and Meredith, T. (2005) Global surveillance for chemical incidents of international public health concern. Bulletin of the World Health Organization 83(12): 928-934.

7. Kohl, K.S., Arthur, R.R., O'Connor, R. and Fernandez, J. (2012) Assessment of public health events through International Health Regulations, United States, 2007-2011. Emerging Infectious Diseases 18(7): 1047-1053.

8. World Health Organization. (2008) Food safety. Expert meeting to review toxicological aspects of melamine and cyanuric acid, 1-4 December 2008, http://www.who.int/foodsafety/fs_management/infosan_events/en/index.html, accessed December 2013.

9. Coulombier, D. et al (2008) Melamine contamination of dairy products in China - Public health impact on citizens of the European Union. EuroSurveillance 13(40): 18998.

10. Lin, C.F. (2011) Global food safety: Exploring key elements for an international regulatory strategy. Virginia Journal of International Law 51(3): 637-696.

11. Wilson, K., Brownstein, J.A. and Fidler, D.P. (2010) Strengthening the International Health Regulations: Lessons from the H1N1 pandemic. Health Policy and Planning 25(6): 505-509.

12. Carr, Z. (2013) WHO agenda on public health preparedness and response to radiation emergencies. International Conference on Radiation and Health Risk Management, 26. February 2013, http://www.fmu.ac.jp/radiationhealth/conference/presentation/day2/2127.pdf, accessed December 2013. 
13. World Health Organization. (2012) Checklist and Indicators for Monitoring Progress in the Development of IHR Core Capacities in State Parties. Geneva, Switzerland: World Health Organization.

14. World Health Organization. Implementation of the International Health Regulations (2005). Report by the Director-General. 66 World Health Assembly, April 2013.

15. Ijaz, K., Kasowski, E., Arthur, R.R., Angulo, F.J. and Dowell, S.F. (2012) International Health Regulations - What gets measured gets done. Emerging Infectious Diseases 18(7):10541057.

16. Paquet, C., Coulombier, D., Kaiser, R. and Ciotti, M. (2006) Epidemic intelligence: A new framework for strengthening disease surveillance in Europe. EuroSurveillance 11(12): 212214.

17. Von Tigerstrom, B. (2005) The revised International Health Regulations and restraint of national health measures. Health Law Journal 13: 35-76.

18. Keller, M. et al (2009) Use of unstructured event-based reports for global infectious disease surveillance. Emerging Infectious Diseases 15(5): 689-695.

19. Reintjes, R., Thelen, M., Reiche, R. and Csohan, A. (2007) Benchmarking national surveillance systems: A new tool for the comparison of communicable disease surveillance and control in Europe. European Journal of Public Health 17(4): 375-380.

20. Anema, A., Druyts, E., Hollmeyer, H.G., Hardiman, M.C. and Wilson, K. (2012) Descriptive review and evaluation of the functioning of the International Health Regulations (IHR) Annex 2. Globalization and Health 8: 1.

21. Wilson, K., McDougall, C. and Forster, A. (2009) The responsibility of healthcare institutions to protect global health security. Healthcare Quarterly 12(1): 56-60, 2.

22. Triple, S (2011) Assessment of syndromic surveillance in Europe. Lancet 378(9806): 18331834.

23. Buehler, J.W., Whitney, E.A., Smith, D., Prietula, M.J., Stanton, S.H. and Isakov, A.P. (2009) Situational uses of syndromic surveillance. Biosecurity and Bioterrorism 7(2): 165-177.

24. Conti, S., Kanieff, M. and Rago, G. (2012) Inventory of syndromic surveillance systems in Europe. Workpackage 4, Version 1.0. TRIPLE-S. Syndromic Surveillance Systems in Europe, http://syndromicsurveillance.eu/images/stories/Inventory/deliverable_4_triples_inventory_report.pdf, accessed 26 May 2013.

25. Paterson, B.J. and Durrheim, D. (2013) The remarkable adaptability of syndromic surveillance to meet public health needs. Journal of Epidemiology and Global Health 3(1): 41-47.

26. Josseran, L. et al (2010) Assessment of a syndromic surveillance system based on morbidity data: results from the oscour network during a heat wave. PLoS ONE 5(8): e11984. 
27. Rappold, A.G. et al (2011) Peat bog wildfire smoke exposure in rural North Carolina is associated with cardiopulmonary emergency department visits assessed through syndromic surveillance. Environmental Health Perspectives 119(10): 1415-1420.

28. Baer, A., Elbert, Y., Burkom, H.S., Holtry, R., Lombardo, J.S. and Duchin, J.S. (2011) Usefulness of syndromic data sources for investigating morbidity resulting from a severe weather event. Disaster Medicine and Public Health Preparedness 5(1): 37-45.

29. Briem, H. (2010) Volcanic eruption in Eyjafjallaökull and its effects on health. EPI-ICE 6(2):13.

30. Elliot, A.J. et al (2010) Syndromic surveillance to assess the potential public health impact of the Icelandic volcanic ash plume across the United Kingdom, April 2010. EuroSurveillance 15(23):pii 19583.

31. Rosenkötter, N. On behalf of the SIDARTHa project group et al (2010) SIDARTHa volcanic ash cloud rapid public health impact assessment. 15 May 2010, http://www.sidartha.eu/publications.html, accessed December 2013.

32. Stoto, M.A., Schonlau, M. and Mariano, L.T. (2004) Syndromic surveillance: Is it worth the effort? Chance 17(1): 19-24.

33. European Parliament, Council of the European Union. (2013) Decision No 1082/2013/EU on serious cross-border threats to health. Official Journal of the European Union L293:1-15. 

Chapter 4 I Inequalities in health care utilisation of children

The influence of migratory background and parental education on health care utilisation of children

Rosenkötter N, van Dongen MC, Hellmeier W, Simon K, Dagnelie PC

European Journal of Pediatrics 2012. 171(10): 1533-1540. 


\section{Abstract}

School-entry screening data from North Rhine-Westphalia (NRW), Germany from 2007 were used to investigate child health care utilisation. We focussed on the influence of migratory background and parental education on children's (1) participation in regularly scheduled early recognition examinations, (2) immunisation uptake and (3) referrals due to a school-entry screen-detected complaint. The study sample consisted of 52,171 children out of 17 NRW districts. Bivariable, stratified and multivariable analyses were performed to identify relevant associations between social determinants and health care utilisation outcome parameters. Multivariable logistic regression showed that children belonging to families with a migratory background or low parental education were more likely to have an incomplete documentation of early recognition examinations and to be referred due to a new diagnosis. Children with migratory background were more likely to be sufficiently immunised than children with parents of German ethnicity. For all studied health care utilisation outcomes, kindergarten visit had a supportive effect.

\section{Conclusion}

In general, the results of our regional study were in line with the results from national populationbased studies. Additionally, a larger likelihood of referrals due to school-screen-detected deficits in children with migratory background or low parental education was detected.

\section{Introduction}

Universal access to health care services is a precondition for good health [3,21]. Although it may be assumed that public social security systems, as they exist in Germany, ensure universal access to health care services, inequalities have been described in countries with well-developed social security systems $[1,5,8,10,12,18,19]$. For example the participation rate in regular health check-up examinations during childhood which are nationally recommended in Germany and covered by the health insurance has shown to be up to $20 \%$ lower in families with a low socio-economic status compared to families with a high socio-economic status $[5,10]$. On the other hand, the immunisation status of children was less likely to be complete in families with a high socioeconomic status $[12,10,19]$, which might be attributed to increased scepticism about the usefulness of vaccinations in this population subgroup [9]. Comparable relationships between socio-economic status and health care utilisation have been observed in other European countries as well [8].

In general, these findings were based population-based studies, like for example the German Health Interview and Examination Study of Children and Adolescents (KiGGS) [5,12] or the European KIDSCREEN study [1]. In addition, health care utilisation of children can be analysed with data from regular school-entry screening programmes, which are routinely conducted in most parts of Germany. Koller and Mielck have used school-entry screening data in the city of 
Munich to identify inequalities in health care utilisation in children [6]. Since data on social determinants, such as educational level, were not available at the individual level, Koller et al. used aggregated data on school district level to perform an ecological study [6].

In contrast to Koller and Mielck [6], North Rhine-Westphalia (NRW, Germany) school-entry screening programmes provide individual data for some social determinants. By using NRW school-entry screening data, we aimed to analyse the health care utilisation of children. We intended to verify the results from the analysis of Koller and Mielck [6] and the national population-based KiGGS study [5,12] regarding the influence of migratory background and social status on participation in early recognition examinations and immunisation uptake during childhood. Furthermore, we aimed to go beyond these studies by analysing the relationship between migratory background and educational level of the families and the identification of new diagnoses during school-entry screening, which might indicate a lack of previous health care utilisation.

\section{Materials and methods}

The school-entry screening programme in NRW is compulsory and regulated by law and has the aim to identify if the children are health-wise capable of starting school. For each yearly screening round the census sample of children aged 5 to 6 is invited. The resulting data from these screening examinations were used for a secondary analysis of health service utilisation with an observational, cross-sectional study design.

The study population included all children who participated in the 2007 school-entry screening from districts of NRW that performed medical school examinations in accordance with a standardised model, the so-called Bielefeld Model [7,15], and collected data on social determinants by a predefined questionnaire. The Bielefeld Model is applied by approximately $80 \%$ of the local health authorities and defines the school-entry screening procedure, applies standardised paediatric definitions for diagnostic findings, and provides a standardised and anonymous form for data collection.

The analysis of the occurrence of new diagnoses detected during school-entry screening included only a sub-group of children. Those with at least one diagnostic finding on visual or hearing acuity, or deficits in kinetic or cognitive development were included.

The outcome variables were related to three different domains of child health care utilisation. The first outcome variable was the level of participation of children in the nationally recommended series of nine early recognition examinations which are scheduled at birth to the age of about 5 years. For further analysis this outcome measure was dichotomised: complete (no examination skipped) vs. incomplete (at least one examination skipped). The level of uptake of 
nationally recommended vaccinations during childhood was assessed as the second outcome variable. The vaccination status was regarded as sufficient when in the "International Certificates of Vaccination" of the children nationally recommended vaccinations were documented in the necessary dose. For further analysis this outcome was dichotomised: complete vs. incomplete (at least one vaccination missing or insufficient) immunisation uptake. Participation in both, the early recognition examinations and the immunisation programme, was assessed by investigation of the respective documentation booklets. Based on the findings of a previous study [20], it was assumed that a child had not sufficiently participated if the child's parents failed to hand over the relevant booklet.

Referral (yes/no) to specialist care due to a new school-entry screen-detected diagnosis was the third outcome measure. If at least one complaint (decreased visual or hearing acuity, or deficits in kinetic or cognitive development) had been recorded during the school-entry screening, we distinguished between children who were already under treatment for this complaint, indicating that they had gained access to the health care system in the meantime, and children who were referred to a practitioner for further diagnosis and treatment, indicating that health care utilisation might have been deficient previously. A referral could occur in children who had never been diagnosed before with this complaint, but also in children who had been diagnosed earlier, for instance with decreased visual acuity for which the current glasses were not sufficient anymore. In the following this outcome is shortly named 'referral'.

Parental education is one of the primary independent variables. It was constructed by combining information on the highest educational grade and highest training qualifications of either the child's father or mother [4]. For further analysis this score was trichotomised. Scores 1 to 3 representing a low parental education, scores 4 to 6 medium parental education and scores 7 to 8 high parental education.

To gain information on the migratory background, the other primary independent variable, parents were asked which language they mainly speak at home with the child. The questionnaire differentiated between 'German' and 'other language'. Since 'other language' was not further specified, no information on the cultural background was available. When a language other than German was spoken with the child, a migratory background was assumed. Actually, this variable reflected the level of integration of the families in German society rather than the concept of migratory background as it is commonly used in official population statistics [14].

Independent variables of secondary interest were single-parent household (yes/no), presence of siblings (yes/no), duration of kindergarten attendance (at least vs. less than 12 months) and urbanisation degree of living area (rural/urban). Larger cities are defined in NRW as independent urban municipalities (like Cologne, Düsseldorf, etc.), smaller cities are compiled with rural surroundings to rural districts. This official distinction of NRW regions was used to define the 
urbanisation degree of the living area of the children. NRW consisted 2007 officially of 23 urban municipalities and 31 rather rural districts. Furthermore, the participation in early recognition examinations was used as an additional determinant in the analysis of immunisation uptake and referrals. Since children were often vaccinated during early recognition examinations and comparable tests, e.g. visual or audiometry tests were performed during early recognition examinations and the school-entry screening, an influence on each of the two outcomes can be hypothesized. As a consequence the level of participation in early recognition examinations might act predominately as intermediate variable in the causal pathways linking the determinants of primary interest to the outcomes immunisation uptake and referral. Our main interest was in assessing the residual effect of migratory background and parental education remaining after adjustment for participation in early recognition examinations.

For descriptive purposes absolute and relative frequencies were calculated for all dependent and independent variables. To estimate the strength of the associations between the primary determinants and each of the outcome variables, crude odds ratios (OR) were calculated based on simple cross-table analyses. Subsequently, based on stratified cross-table analyses MantelHaenszel Odds Ratios $\left(\mathrm{OR}_{\mathrm{MH}}\right)$ were calculated for the primary determinants, taking the effects of other single determinants into account. Finally, multiple logistic regression analyses were performed to adjust the associations between the primary determinants and each outcome variable for the combined influence of multiple covariates.

For each multiple logistic regression analysis the initial model was built by entering all predictors that seemed to be relevant based on the literature and the results of the cross-table analyses. Each model was tested beforehand for multicollinearity of the included predictors, which resulted to be absent. For each outcome variable the final model was constructed by backward elimination of covariates. Missing values were treated by case-wise deletion. Interaction effects were presented by showing the main effects.

All statistical analyses were performed with SPSS 15.01 (SPSS Inc., Chicago, IL).

\section{Results}

In 2007, 168,389 children from 54 districts participated in the school-entry screening in NRW. A total number of 116,218 children had to be excluded from data analysis, for various reasons: (1) living in districts in which the Bielefeld Model for school-entry screening was not applied $(n=8,924)$; (2) living in districts in which information on social determinants was not collected consistently ( $n=105,770)$; (3) high potential for coding error for the age variable ( $n=402)$; (4) living in a district with potential coding errors for several variables $(n=1,122$; coding errors occurred for the educational level of the parents and for new school-entry screen-detected complaints). Therefore, the final sample eligible for analysis consisted of 52,171 children ( $31 \%$ of the initial 
sample) from 17 districts in NRW. The children originated equally from rural ( $n=25,529 ; 48.9 \%)$ and urban ( $n=26,642 ; 51.9 \%$ ) districts. Since NRW is a diverse federal state in Germany the included districts are further characterised by clusters which share socio-demographic characteristics, the distribution of districts was made according to an updated analysis of $2011[17,16]$. In the study sample regions from all occurring clusters in NRW are included: Less family-defined university cities ( 1 of 4 districts in NRW), poor cities and districts in structural change ( 8 of 16 districts in NRW); wealthy shrinking and ageing cities and sub-urban regions ( 1 of 6 districts in NRW); growing family zones ( 4 of 15 districts in NRW), growing and prospering regions (1 of 6 districts in NRW), family-defined districts with a tendency of declining and ageing (2of 7 districts in NRW).

The age of the children ranged from 61 to 82 months, and the sample comprised 26,867 boys (51.5\%) and 25,304 girls (48.5\%).

Table 1 Absolute numbers and prevalence $(\% ; 95 \% \mathrm{Cl})$ of independent variables for the outcomes incomplete participation in early recognition examinations, incomplete immunization uptake and referral due to at least one new diagnosis during school-entry screening, school-entry screening NRW, 2007.

\begin{tabular}{|c|c|c|c|c|}
\hline \multirow[b]{2}{*}{$\begin{array}{l}\text { Independent } \\
\text { variables }\end{array}$} & \multicolumn{2}{|c|}{ All school-screened children ${ }^{a}$} & \multicolumn{2}{|c|}{$\begin{array}{l}\text { Sub-population with at } \\
\text { least one diagnose }^{d}\end{array}$} \\
\hline & $\begin{array}{l}\text { Incomplete } \\
\text { participation in early } \\
\text { recognition } \\
\text { examinations (IPERE) }{ }^{\text {b }} \\
\text { n; \%; } 95 \% \mathrm{Cl}\end{array}$ & $\begin{array}{l}\text { Incomplete } \\
\text { immunisation uptake } \\
\text { (IIU)c } \\
\text { n; \%; 95\% CI }\end{array}$ & $\begin{array}{l}\text { referrale } \\
\text { n; \%; 95\% Cl }\end{array}$ & Total \\
\hline Total & 16510 & 30638 & 7636 & 13806 \\
\hline$N=52171$ & $31.6(31.2-32.0)$ & $58.7(58.3-59.1)$ & $55.3(54.5-56.1)$ & \\
\hline $\begin{array}{l}\text { migratory } \\
\text { background }^{\mathrm{f}}\end{array}$ & $\begin{array}{l}15664 \\
31.7(31.3-32.1)\end{array}$ & $\begin{array}{l}29077 \\
58.8(58.4-59.2)\end{array}$ & $\begin{array}{l}7398 \\
55.7(54.9-56.5)\end{array}$ & 13284 \\
\hline$N=49469$ & & & & \\
\hline Yes & $\begin{array}{l}7116 \\
53.5(52.7-54.3)\end{array}$ & $\begin{array}{l}8100 \\
60.9(60.1-61.7)\end{array}$ & $\begin{array}{l}2609 \\
71.0(69.5-72.5)\end{array}$ & \\
\hline No & $\begin{array}{l}8548 \\
23.6(23.2-24.0)\end{array}$ & $\begin{array}{l}20977 \\
58.0(57.5-58.5)\end{array}$ & $\begin{array}{l}4789 \\
49.8(48.8-50.8)\end{array}$ & \\
\hline $\begin{array}{l}\text { parental } \\
\text { educations }\end{array}$ & $\begin{array}{l}11701 \\
28.1(27.7-28.5)\end{array}$ & $\begin{array}{l}24156 \\
57.9(57.4-58.4)\end{array}$ & $\begin{array}{l}5609 \\
53.3(52.3-54.3)\end{array}$ & 10531 \\
\hline$N=41697$ & & & & \\
\hline Low & $\begin{array}{l}4901 \\
45.5(44.5-46.3)\end{array}$ & $\begin{array}{l}6648 \\
61.7(60.8-62.6)\end{array}$ & $\begin{array}{l}2037 \\
62.7(61.0-64.4)\end{array}$ & \\
\hline Medium & $\begin{array}{l}4646 \\
22.3(21.7-22.9)\end{array}$ & $\begin{array}{l}11723 \\
57.1(56,4-57,8)\end{array}$ & $\begin{array}{l}2503 \\
48.9(47.5-50.3)\end{array}$ & \\
\hline High & $\begin{array}{l}2154 \\
20.7(19.9-21.5)\end{array}$ & $\begin{array}{l}5785 \\
55.6(54.6-56.6)\end{array}$ & $\begin{array}{l}1069 \\
49.5(47.4-51.6)\end{array}$ & \\
\hline siblings & 13166 & 24086 & 6139 & 10925 \\
\hline$N=41849$ & $31.5(31.1-31.9)$ & $57.6(57.1-58.1)$ & $56.2(55.3-57.1)$ & \\
\hline Yes & $\begin{array}{l}10612 \\
32.2(31.7-32.7)\end{array}$ & $\begin{array}{l}19066 \\
57.7(57.2-58.2)\end{array}$ & $\begin{array}{l}5012 \\
57.0(56.0-58.0)\end{array}$ & \\
\hline No & $\begin{array}{l}2554 \\
28.8(27.9-29.7)\end{array}$ & $\begin{array}{l}5020 \\
56.7(55.7-57.7)\end{array}$ & $\begin{array}{l}1127 \\
52.9(50.8-55.0)\end{array}$ & \\
\hline
\end{tabular}




\begin{tabular}{|c|c|c|c|c|}
\hline \multirow[b]{2}{*}{$\begin{array}{l}\text { Independent } \\
\text { variables }\end{array}$} & \multicolumn{2}{|c|}{ All school-screened children ${ }^{a}$} & \multicolumn{2}{|c|}{$\begin{array}{l}\text { Sub-population with at } \\
\text { least one diagnose }^{d}\end{array}$} \\
\hline & $\begin{array}{l}\text { Incomplete } \\
\text { participation in early } \\
\text { recognition } \\
\text { examinations (IPERE) b } \\
\mathrm{n} ; \% ; 95 \% \mathrm{Cl}\end{array}$ & $\begin{array}{l}\text { Incomplete } \\
\text { immunisation uptake } \\
\text { (IIU)c } \\
\mathrm{n} ; \% ; 95 \% \mathrm{Cl}\end{array}$ & $\begin{array}{l}\text { referrale } \\
\text { n; \%; } 95 \% \text { Cl }\end{array}$ & Total \\
\hline kindergarten & 15465 & 29065 & 7400 & 13394 \\
\hline visit ${ }^{h}$ & $31.2(30.8-31.6)$ & $58.6(58.2-59.0)$ & $55.2(54.4-56.0)$ & \\
\hline \multicolumn{5}{|l|}{$N=49635$} \\
\hline \multirow[t]{2}{*}{ Yes } & 14128 & 27616 & 6904 & \\
\hline & $29.7(29.3-30.1)$ & $58.1(57.7-58.5)$ & $54.2(53.3-55.1)$ & \\
\hline \multirow[t]{2}{*}{ no } & 1337 & 1449 & 496 & \\
\hline & $64.5(62,4-66,6)$ & $69.9(67.9-71.9)$ & $74.6(71.3-77.9)$ & \\
\hline single parent & & & & 11532 \\
\hline household & 13251 & 26027 & 6310 & \\
\hline \multirow[t]{2}{*}{$N=44592$} & $29.7(29,3-30,1)$ & $58.4(57.9-58.9)$ & $54.7(53.8-55.6)$ & \\
\hline & 2369 & 3437 & 959 & \\
\hline \multirow[t]{2}{*}{ Yes } & $43.5(42.2-44.8)$ & $63.1(61.8-64.4)$ & $62.0(59.6-64.4)$ & \\
\hline & 10882 & 22590 & 5351 & \\
\hline no & $27.8(27.4-28.2)$ & $57.7(57.2-58.2)$ & $53.6(52.3-54.9)$ & \\
\hline area type ${ }^{i}$ & 16510 & 30638 & 7636 & 13806 \\
\hline$N=52171$ & $31.6(31.2-32.0)$ & $58.7(58.3-59.1)$ & $55.3(54.5-56.1)$ & \\
\hline \multirow[t]{2}{*}{ Rural } & 7066 & 15247 & 3538 & \\
\hline & $27.6(27.1-28.1)$ & $59.7(59.1-60.3)$ & $52.3(51.1-53.5)$ & \\
\hline \multirow[t]{2}{*}{ Urban } & 9444 & 15391 & 4098 & \\
\hline & $35.4(34.8-36.0)$ & $57.8(57.2-58.4)$ & $58.2(57.0-59.4)$ & \\
\hline \multicolumn{2}{|c|}{ participation in all U-examinations } & 30638 & 7636 & 13806 \\
\hline$N=52171$ & & $58.7(58.3-59.1)$ & $55.3(54.5-56.1)$ & \\
\hline \multirow[t]{2}{*}{ complete } & & 19033 & 4377 & \\
\hline & & $53.4(52.9-53.9)$ & $48.6(47.6-49.6)$ & \\
\hline \multirow[t]{2}{*}{ incomplete } & & 11605 & 3259 & \\
\hline & & $70.3(69.6-71.0)$ & $68.0(66.7-69.3)$ & \\
\hline
\end{tabular}

a children from the NRW districts Aachen, Bielefeld, Coesfeld, Dortmund, Essen, Euskirchen, Gelsenkirchen, Herne, Heinsberg, Hochsauerland-Kreis, Höxter, Krefeld, Leverkusen, Mönchengladbach, Oelde, Paderborn, and Recklinghausen

${ }^{b}$ at least one out of nine $\mathrm{U}$-examinations missing

c at least one out of nine vaccinations missing

${ }^{d}$ children with at least one diagnosis on visual or hearing acuity or deficits in kinetic or cognitive

development

e occurrence of referral of a child due to a new diagnose during school-entry screening

${ }^{f}$ migratory background was assumed when it was mainly not spoken German with the child at home

g summary measure of the highest school grade and training qualification of child's mother or father

${ }^{h}$ at least one year of kindergarten visit

${ }^{i}$ the area type was determined by the district of living (rural district = rural, city district = urban)

jParticipation in all U-examinations was used as predictor variable for the outcomes incomplete immunisation uptake and occurrence of referral due to a new diagnose 
Table 1 shows the absolute frequencies and prevalence rates of the unfavourable outcomes, according to the levels of each determinant. The table indicates also the available sample sizes for each determinant. The highest amount of missing values was present for the primary independent variable parental education $(20.1 \%)$, followed by the secondary independent variables siblings (19.8\%) and single-parent households (14.5\%). All other variables had less than $10 \%$ missing values. These rates of missing values were slightly higher in the population subsample available for the analysis of determinants of the outcome referral due to a screendetected diagnosis.

Incomplete participation in early recognition examinations (IPERE) was less prevalent (31.6\%) than incomplete immunisation uptake (IIU) (58.7\%) or referral (55.3\%) (Table 1). Children of families with a migratory background or low parental education had substantially more often an incomplete history of early recognition examinations (53.5 and $45.5 \%$, respectively). These children were also more often referred to specialist health care ( $71.0 \%$ and $62.7 \%$, respectively). Compared with the reference groups the prevalence of IIU was only slightly increased in these subgroups, however (60.9\% and $61.7 \%$, respectively). Moreover, children from a single-parent household and children who did not visit kindergarten were clearly more often at risk for IPERE and IIU and were more often referred for a screen-detected diagnosis. Finally, IIU and referral occurred more frequently in children who did not complete the programme of early recognition examinations (Table 1).

Stratified cross-table analysis was conducted to assess the influence of the determinants of primary interest per stratum of each of the other independent variables. Complete participation in early recognition examinations, which was also evaluated as a determinant of the two other outcome measures, appeared to be the only independent variable responsible for a substantial shift $(>10 \%)$ of the adjusted $\mathrm{OR}_{\mathrm{MH}}$ compared with the crude OR estimate (Table 2 ). Stratification for participation in early recognition examinations caused a change of the strength of the summary association between migratory background and IIU from 1.13 (95\% Cl: $1.08-1.17$ ) to 0.91 (95\%Cl: 0.87-0.95), and between low parental education and IIU from 1.29 (95\%Cl: 1.22-1.36) to 1.09 (95\% Cl: 1.03-1.16). Likewise, stratification for the same variable reduced the strength of the summary association between migratory background and referral from 2.47 (95\% Cl: $2.27-2.68$ ) to 2.08 (95\% Cl: 1.91-2.26), and between low parental education and referral from 1.71 (95\%Cl: 1.53$1.91)$ to 1.44 (95\% Cl: $1.28-1.61)$. The independent variable single-parent household appeared as an interaction effect for the relationship between the determinants of primary interest and the outcome IPERE (Table 2). As part of the multivariable logistic regression analyses this was further investigated, the results are presented in Table 3. 
Table 2 Relevant results of the stratified analysis, school-entry screening NRW, 2007.

\begin{tabular}{|c|c|c|c|c|}
\hline & & $\begin{array}{l}\text { OR } \\
95 \% \mathrm{Cl}\end{array}$ & $\begin{array}{l}\mathrm{OR}_{\mathrm{MH}} \\
95 \% \mathrm{Cl}\end{array}$ & $\begin{array}{l}\text { Breslow \& Day } \\
\text { Heterogeneity } \\
\text { test (p) }\end{array}$ \\
\hline & & \multicolumn{3}{|c|}{ migratory background - IIU } \\
\hline \multirow[t]{2}{*}{ crude effect } & & 1.13 & & \\
\hline & & $1.08-1.17$ & & \\
\hline participation in & complete & 0.91 & 0.91 & 0.872 \\
\hline early recognition & & $0.86-0.96$ & $0.87-0.95$ & \\
\hline \multirow[t]{3}{*}{ examinations } & incomplete & 0.91 & & \\
\hline & & $0.85-0.98$ & & \\
\hline & & low paren & leducation & \\
\hline \multirow[t]{2}{*}{ crude effect } & & 1.29 & & \\
\hline & & $1.22-1.36$ & & \\
\hline \multirow{4}{*}{$\begin{array}{l}\text { participation in } \\
\text { early recognition } \\
\text { examinations }\end{array}$} & complete & 1.12 & 1.09 & 0.098 \\
\hline & & $1.05-1.20$ & $1.03-1.16$ & \\
\hline & incomplete & 1.01 & & \\
\hline & & $0.90-1.13$ & & \\
\hline & & migratory & ackground & ferral \\
\hline \multirow[t]{2}{*}{ crude effect } & & 2.47 & & \\
\hline & & $2.27-2.68$ & & \\
\hline \multirow{4}{*}{$\begin{array}{l}\text { participation in } \\
\text { early recognition } \\
\text { examinations }\end{array}$} & complete & 2.03 & 2.08 & 0.552 \\
\hline & & $1.82-2.27$ & $1.91-2.26$ & \\
\hline & incomplete & 2.14 & & \\
\hline & & $1.88-2.44$ & & \\
\hline & & low paren & leducation & eferral \\
\hline \multirow[t]{2}{*}{ crude effect } & & 1.71 & & \\
\hline & & $1.53-1.91$ & & \\
\hline participation in & complete & 1.40 & 1.44 & 0.438 \\
\hline early recognition & & $1.22-1.60$ & $1.28-1.61$ & \\
\hline \multirow[t]{3}{*}{ examinations } & incomplete & 1.55 & & \\
\hline & & $1.25-1.94$ & & \\
\hline & & migratory & ackground & ERE \\
\hline \multirow[t]{2}{*}{ crude effect } & & 3.71 & & \\
\hline & & $3.56-3.87$ & & \\
\hline single parent & No & 4.09 & 3.91 & \\
\hline \multirow[t]{3}{*}{ household } & & $3.89-4.30$ & $3.73-4.10$ & $<0.001$ \\
\hline & yes & 2.74 & & \\
\hline & & $2.36-3.17$ & & \\
\hline
\end{tabular}

IIU=incomplete immunisation uptake

IPERE=incomplete participation in early recognition examinations

All measured determinants were included in the model. The determinant 'siblings' appeared not to improve the model on IIU and referral and was therefore excluded. Remarkably, when taking the other independent variables into account the association between migratory background and IIU of the child changed from OR=1.13 (unadjusted; $95 \% \mathrm{Cl}: 1.08-1.17$ ) to $\mathrm{OR}=0.88$ (adjusted; $95 \% \mathrm{Cl}$ : 0.84-0.93), indicating a protective effect. Furthermore, child's visit of a kindergarten was quite 
strongly reversely associated with a history of IPERE (OR=3.43), and to a lesser degree with the other indicators of insufficient health care utilisation. In addition, living in an urban area slightly decreased the odds of being under vaccinated (OR=0.85; $95 \% \mathrm{Cl}: 0.81-0.88)$, but slightly increased the probability of the other unfavourable health care utilisation outcomes.

Table 3 Results multivariable analysis (logistic regression), school-entry screening NRW, 2007.

\begin{tabular}{|c|c|c|c|c|c|c|}
\hline & \multicolumn{2}{|c|}{$\begin{array}{l}\text { incomplete } \\
\text { participation in early } \\
\text { recognition } \\
\text { examinations (IPERE) a }\end{array}$} & \multicolumn{2}{|c|}{$\begin{array}{l}\text { incomplete } \\
\text { immunisation uptake } \\
(\text { IIU) }\end{array}$} & \multicolumn{2}{|c|}{ referral $^{c}$} \\
\hline & OR & $95 \% \mathrm{Cl}$ & OR & $95 \% \mathrm{Cl}$ & OR & $95 \% \mathrm{Cl}$ \\
\hline \multicolumn{7}{|l|}{ migratory background } \\
\hline Yes & - & - & 0.88 & $0.84-0.93$ & 1.85 & $1.66-2.06$ \\
\hline No & - & - & 1 & & 1 & \\
\hline \multicolumn{7}{|l|}{ parental education } \\
\hline Low & 2.04 & $1.89-2.20$ & 1.12 & $1.05-1,19$ & 1.26 & $1.12-1.42$ \\
\hline Medium & 1.05 & $0.98-1.13$ & 1.04 & $0.98-1.09$ & 0.95 & $0.86-1.06$ \\
\hline High & 1 & & 1 & & 1 & \\
\hline \multicolumn{7}{|l|}{ Siblings } \\
\hline Yes & 1.25 & $1.16-1.34$ & - & - & - & - \\
\hline No & 1 & & - & - & - & - \\
\hline \multicolumn{7}{|l|}{ kindergarten visit } \\
\hline No & 3.43 & $2.97-3.97$ & 1.27 & $1.11-1.44$ & 1.77 & $1.39-2.25$ \\
\hline Yes & 1 & & 1 & & 1 & \\
\hline \multicolumn{7}{|l|}{ single parent household } \\
\hline Yes & - & - & 1.09 & $1.02-1.17$ & 1.29 & $1.14-1.46$ \\
\hline No & - & - & 1 & & 1 & \\
\hline \multicolumn{7}{|l|}{ Area type } \\
\hline Urban & 1.21 & $1.15-1.28$ & 0.85 & $0.81-0.88$ & 1.15 & $1.06-1.25$ \\
\hline Rural & 1 & & 1 & & 1 & \\
\hline \multicolumn{7}{|l|}{ Participation in U-examinations } \\
\hline incomplete & - & - & 1.91 & $1.82-2.01$ & 1.64 & $1.49-1.81$ \\
\hline complete & - & - & 1 & & 1 & \\
\hline \multicolumn{7}{|l|}{ Interaction } \\
\hline \multicolumn{7}{|l|}{ migratory background } \\
\hline single parent household & 2.07 & $1.61-2.68$ & & & & \\
\hline non single parent household & 3.10 & $2.91-3.95$ & & & & \\
\hline
\end{tabular}

\footnotetext{
a adjusted for kindergarten visit, area type, siblings, migratory background, or parental education respectively. Interaction term for migratory background and single parent household was included in the final model.

b adjusted for single parent household, kindergarten visit, area type, participation in early recognition examinations, migratory background, or parental education respectively

c adjusted for single parent household, kindergarten visit, area type, participation in early recognition examinations, migratory background, or parental education respectively
}

As already indicated in the stratified analysis, the preferred model describing the association between social determinants and participation in early recognition examinations appeared to 
include a term reflecting the interactive effect of migratory background and growing up in a single-parent household. Therefore, the association between migratory background and participation in early recognition examinations was assessed separately for single-parent households (OR=2.07; 95\% Cl: 1.61-2.68) and non-single-parent households (OR=3.10, 95\%Cl: 2.913.95).

\section{Discussion}

Our study results showed an increased likelihood of IPERE for children of families with a low educational index and with a migratory background. After adjustment for other risk factors, not visiting the kindergarten showed the strongest association in children with IPERE. Children with a migratory background were more likely to be sufficiently vaccinated compared to children without such a background. Moreover, an increased likelihood of referrals was observed for these children and children with low parental education, even after adjustment for participation in early recognition examinations. Again, kindergarten visit seems to have a positive influence on the timely and adequate identification and treatment of complaints like visual or hearing acuity and kinetic or cognitive development.

Generally, our study results on IPERE and IIU by children from the included districts in NRW are in line with previous findings from the national KiGGS study [5,12] and with outcomes of the analyses of Koller and Mielck on school district level [6]. The prevalence rate of IPERE in children with migratory background in the current study was comparable with the prevalence rate observed in the KiGGS study for children with parents having both a migratory background [13]. This observation is compatible, since our definition of migratory background was based on the parents' report not to speak German with their child at home, which is more likely when both parents have a migratory background.

Another often described observation is the increased likelihood of IIU in children of families with high socio-economic status $[11,12,19]$, which was not found in our analysis. Only a descriptive analysis of the participation in separate vaccinations showed that the prevalence of IIU in these children was often as high or even higher than for children of families with low parental education (results were not shown). However, when analysing the completeness of the combination of all nine vaccinations children of families with high parental education seemed to have more often all vaccinations complete than children of families with low parental education.

The interactive effect of migratory background and single-parent household on the participation in early recognition examinations seems to be misleading since this interaction resulted unexpectedly in a smaller effect for children with migratory background living in single-parent households $(\mathrm{OR}=2.07)$ compared to children with migratory background living in non-singleparent households $(\mathrm{OR}=3.10)$. This observation originates from the fact that unless the respective 
prevalence of IPERE is higher in children from single-parent households (migratory background: $63.8 \%$, non-migratory background: $39.2 \%$ ) compared to children from non-single-parent households (migratory background: $50.5 \%$, non-migratory background: $19.9 \%$ ) the difference in prevalence between children with migratory background and non-migratory background is larger in children from non-single-parent households (difference: $30.6 \%$ points) compared to $24.6 \%$ points in children from single-parent households.

Due to the cross-sectional design and the use of secondary data, our study has several limitations which might have led probably to an overestimation of the strength of the associations. We were not able to determine, for instance, if the screen-detected complaints, resulting in the referral of the child, originated months or years ago and thus could have been detected earlier, or if they arose recently. In addition, there was neither information on the severity of the complaints available, nor if the diagnosis of the school-entry screening was subsequently confirmed by a practitioner or specialist. Moreover, due to migration during the life course of the child, the documentation booklets could have been incomplete. It was not possible to adjust the results accordingly.

Furthermore, we were not able to analyse if insufficient health care utilisation was related to large distances to the next health care provider. This influence was only roughly taken into account by the inclusion of the type of the living area as one determinant for health service use.

The high proportion of missing values for the variable parental education could have affected the results as well. Therefore, we performed a sensitivity analysis using two scenarios, in which all missing values for this variable were imputed by the highest (best case), and the lowest value (worst case), respectively. It turned out that the worst case scenario, which was probably the most realistic one since missing values for other variables occurred mostly in children with a low parental education, hardly led to any changes in the observed associations (results not shown).

In this study we focussed on the health care utilisation of preventive services (early recognition examinations, immunisation). Also the outcome measure 'referral' concentrated just on deficits of visual or hearing acuity or kinetic or cognitive development, and not on any acute disorders. Therefore, it was not possible to make general assumptions on health care utilisation of children of families with migratory background or low parental education. National results on the use of ambulant health care services of pre-scholars showed for example no differences in the use of paediatricians and GPs between migrants and non-migrants and children from different social status. Only the use of specialist services, as it is required after referral due to a school-screen detected diagnose in the current study was different nationally. A less frequent use of specialists, especially ophthalmologists, in migrants and children of low social status was observed [5].

Another interesting observation was the fact that not visiting the kindergarten was strongly associated with a lack of health care utilisation, as it was measured in this study. This underlines 
the importance of kindergartens not only for the individual development of the child [2] but also as an assisting institution for families with regard to the use of preventive and health care services.

In conclusion we could show that health care service use of children is influenced by social determinants. Regional data from the NRW school-entry screening programme proved to be a useful, yearly available data source for research on health service use. In order to gain a deeper understanding on barriers that hinder equal health care utilisation and to be able to improve health services accordingly, this data could be an appropriate source for extended analyses.

\section{Acknowledgements}

Some results of this study were presented during the annual joint conference of the German Society for Epidemiology and the German Society for Social Medicine and Prevention in Berlin, Germany (22.9.2010). 


\section{References}

1. Berra S, Tebe C, Erhart M, Ravens-Sieberer U, Auquier P, Detmar S, Herdman M, Alonso J, Rajmil $L$ (2009) Correlates of use of health care services by children and adolescents from 11 European countries. Med Care 47 (2):161-167. doi:10.1097/MLR.0b013e3181844e09

2. Caniato RN, Alvarenga ME, Stich HL, Jansen H, Baune BT (2010) Kindergarten attendance may reduce developmental impairments in children: results from the Bavarian Pre-School Morbidity Survey. Scand J Public Health 38 (6):580-586. doi:1403494810376558

3. Dahlgren G, Whitehead M (1992) Policies and strategies to promote equity in health. WHO Regional Office for Europe, Copenhagen

4. Jöckel KH, Babitsch B, Bellach BM, Bloomfield K, Hoffmeyer-Zlotnik J, Winkler J, Wolf C (1998) Messung und Quantifizierung soziographischer Merkmale in epidemiologischen Studien. Available at:

http://www.rki.de/cln_100/nn_205212/DE/Content/GBE/EpidemiologischeMethoden/Em pfehlungen/empfehlungen__pdf2,templateld=raw, property=publicationFile.pdf/empfehl ungen_pdf2.pdf

5. Kamtsiuris P, Bergmann E, Rattay P, Schlaud M (2007) Inanspruchnahme medizinischer Leistungen. Ergebnisse des Kinder- und Jugendgesundheitssurveys (KIGGS). Bundesgesundheitsblatt Gesundheitsforschung Gesundheitsschutz 50 (5-6):836-850. doi:10.1007/s00103-007-0247-1

6. Koller D, Mielck A (2009) Regional and social differences concerning overweight, participation in health check-ups and vaccination. Analysis of data from a whole birth cohort of 6-year old children in a prosperous German city. BMC Public Health 9:43. doi:1471-2458-9-43

7. Landesinstitut für Gesundheit und Arbeit NRW LIGA.NRW (2008) Das Bielefelder Modell. http://www.liga.nrw.de/themen/gesundheit_berichte_daten/schulgesundheit/bielefeld er-modell/index.html?PISESSION=ea7f086d95ef85a8a4ad502ce34f9f7f. Accessed 2010

8. Majeed M, Williams C, Northstone K, Ben-Shlomo Y (2008) Are there inequities in the utilisation of childhood eye-care services in relation to socio-economic status? Evidence from the ALSPAC cohort. Br J Ophthalmol 92 (7):965-969. doi:bjo.2007.134841

9. Meyer C, Reiter S (2004) Impfgegner und Impfskeptiker. Geschichte, Hintergründe, Thesen, Umgang. Bundesgesundheitsblatt Gesundheitsforschung Gesundheitsschutz 47 (12):11821188.

10. Oberwöhrmann S, Bettge S (2007) Basisdaten zur gesundheitlichen und sozialen Lage von Kindern in Berlin - Ergebnisse auf der Basis der Einschulungsuntersuchungen 2005. Gesundheitsberichterstattung Berlin, Spezialbericht 2007 - 1. Senatsverwaltung für Gesundheit, Umwelt und Verbraucherschutz, Berlin

11. Poethko-Muller C, Ellert U, Kuhnert R, Neuhauser H, Schlaud M, Schenk L (2009) Vaccination coverage against measles in German-born and foreign-born children and identification of unvaccinated subgroups in Germany. Vaccine 27 (19):2563-2569 
12. Poethko-Muller C, Kuhnert R, Schlaud M (2007) Durchimpfung und Determinanten des Impfstatus in Deutschland. Ergebnisse des Kinder- und Jugendgesundheitssurveys (KIGGS). Bundesgesundheitsblatt Gesundheitsforschung Gesundheitsschutz 50 (5-6):851862

13. Schenk L, Neuheuser H, Ellert U, Poethko-Müller C, Kleiser C, G. M (2008) Kinder- und Jugendgesundheitssurvey (KiGGS) 2003-2006: Kinder und Jugendliche mit Migrationshintergrund in Deutschland. Gesundheitsberichterstattung des Bundes. Berlin

14. Schenk L, Bau AM, Borde T, Butler J, Lampert T, Neuhauser H, Razum O, Weilandt C (2006) Mindestindikatorensatz zur Erfassung des Migrationsstatus. Empfehlungen für die epidemiologische Praxis. Bundesgesundheitsblatt Gesundheitsforschung Gesundheitsschutz 49 (9):853-860. doi:10.1007/s00103-006-0018-4

15. Schirm H (1989) Untersuchungen und Untersuchungsmodelle zur Feststellung der Einschulungsfähigkeit. Sozial Pädagogik:7-11

16. Schultz A (2011) Aktualisierung der Clusteranalyse mit Sozialstruktur-indikatoren für Kreise und kreisfreie Städte in NRW - Gesundheitsberichterstattung Nordrhein-Westfalen - 2005 und 2008. Faktor Familie GmbH, Bochum

17. Strohmeier KP, Schultz A, Bardehle D, Annuss R, Lenz A (2007) Health indicator-based cluster analysis of districts and urban districts in North Rhine-Westphalia. Gesundheitswesen 69 (1):26-33. doi:10.1055/s-2007-960491

18. von Rueden U, Gosch A, Rajmil L, Bisegger C, Ravens-Sieberer U (2006) Socioeconomic determinants of health related quality of life in childhood and adolescence: results from a European study. J Epidemiol Community Health 60 (2):130-135.

doi:60/2/13010.1136/jech.2005.039792

19. Wei F, Mullooly JP, Goodman M, McCarty MC, Hanson AM, Crane B, Nordin JD (2009) Identification and characteristics of vaccine refusers. BMC Pediatr 9:18. doi:1471-2431-91810.1186/1471-2431-9-18

20. Wichmann O, Hellenbrand W, Sagebiel D, Santibanez S, Ahlemeyer G, Vogt G, Siedler A, van Treeck U (2007) Large measles outbreak at a German public school, 2006. Pediatr Infect Dis J 26 (9):782-786. doi:10.1097/INF.0b013e318060aca1

21. World Health Organisation The determinants of health.

http://www.who.int/hia/evidence/doh/en/print.html. Accessed July 2010 



\section{Part 3 I Developing infrastructure}





\section{Chapter 5 I Key features of an EU health information system}

Key features of an EU health information system - a concept mapping study

Rosenkötter N, Achterberg PW, van Bon-Martens $\mathrm{MJH}$, Michelsen $\mathrm{K}$, van Oers HAM, Brand $\mathrm{H}$

European Journal of Public Health 2015; 26(1): 65-70. 


\begin{abstract}
Background

Despite the acknowledged value of an EU health information system (EU-HISys) and the many achievements in this field, the landscape is still heavily fragmented and incomplete. Through a systematic analysis of the opinions and valuations of public health stakeholders, this study aims to conceptualize key features of an EU-HISys.
\end{abstract}

\title{
Methods
}

Public health professionals and policy makers were invited to participate in a concept mapping procedure. First, participants $(\mathrm{N}=34)$ formulated statements that reflected their vision of an EUHISys. Second, participants $(\mathrm{N}=28)$ rated the relative importance of each statement and grouped conceptually similar ones. Principal Component and cluster analyses were used to condense these results to EU-HISys key features in a concept map. The number of key features and the labelling of the concept map were determined by expert consensus.

\section{Results}

The concept map contains ten key features that summarize 93 statements. The map consists of a horizontal axis that represents the relevance of an 'organizational strategy', which deals with the 'efforts' to design and develop an EU-HISys and the 'achievements' gained by a functioning EUHISys. The vertical axis represents the 'professional orientation' of the EU-HISys, ranging from the 'scientific' through to the 'policy' perspective. The top ranking statement expressed the need to establish a system that is permanent and sustainable. The top ranking key feature focuses on data and information quality.

\section{Conclusions}

This study provides insights into key features of an EU-HISys. The results can be used to guide future planning and to support the development of a health information system for Europe.

\section{Introduction}

The use of sound data and information for the routinely assessment of populations' health and health system performance is a prerequisite for the development of relevant public health strategies and policies and the assurance of adequate health service provision., ${ }^{1,2}$ Public health surveillance is considered as an essential governmental capacity. ${ }^{1,3}$ On European Union (EU) level public health surveillance is legitimated by the Treaty on the functioning of the $\mathrm{EU}^{4,5}$ and is required for EU policy preparation, for enhancing cooperation and mutual learning between member states ${ }^{6-8}$ and to focus policymakers' attention to relevant problems in public health.., 10 
The political discourse pertaining to the development of an EU public health surveillance capacity, realized in a health information system (EU-HISys) has a long history..$^{911-13}$ This discourse and its continuing relevance is demonstrated by the following chronicle of major developments. Thereby we omit actions on the development of infectious disease surveillance which took a different, and with regard to infrastructure development, more successful course.

During the past decades the European Commission (EC) has established working parties and expressed its intention for information development in all public health programmes. ${ }^{14-16}$ The EC has also expressed a need for an EU-HISys in the EC health strategy 'Together for Health"17, and in the EC draft 'European health information - objectives and organisation'18. The Council of the EU recognized the value of a health information system for evidence-based decision making ${ }^{19}$ and invited the EC and the member states to 'cooperate with a view to establishing a sustainable and integrated EU health information system' ${ }^{20}$

Some of the most important practical work in this area has been the development of the European Core Health Indicators (ECHI). ${ }^{21-24}$ The ECHI-list has become a central feature of EC data directives and information policy. ${ }^{25,}{ }^{26}$ Eurostat and the national statistical offices have also worked to increase both, the amount, and quality, of data collected in certain areas such as 'European Union Statistics on Income and Living Conditions', 'European Health Information Survey', 'System of Health Accounts', mortality-, and demographic statistics. Finally, increased collaboration in the area of data collection between Eurostat, the Organization for Economic Cooperation and Development (OECD), the World Health Organization Regional Office for Europe (WHO-EUR) and European member states has improved the European health data situation to a certain extent.

But still, large differences can be found between member states in both the quality, and availability, of health data. Consequently, the level of comparability between EU member states is limited for many public health relevant policy areas. Moreover, EC co-funded actions, and the Directorate General for Health and Consumers (DG SANCO) itself, have attempted to develop a health information system. ${ }^{6,27}$ However, neither were able to be transferred into lasting structures. Yet, despite the obvious value of an EU-HISys and the reached progress, its development and the discussion about its realization is still not finalized.

This study aims to support the development of an EU-HISys by identifying the necessary key features relevant to build up a comprehensive system that supports health policy making. Since views on the key features of an EU-HISys might differ, this study attempts to conceptualize the opinions and valuations of potential user groups like public health professionals and policy makers. 


\section{Methods}

A concept mapping approach was used to collect, integrate and conceptualize the opinions and valuations of public health professionals and policy makers about the key features of an EUHISys. ${ }^{28,29}$ This approach was selected based upon its proven applicability in a previous study on quality criteria of regional public health reporting in the Netherlands. ${ }^{30}$ Concept mapping supports structured conceptualization of group ideas and consist of the stages: (i) study preparation, (ii) idea generation, (iii) statement structuring, (iv) concept mapping analysis, (v) concept map interpretation, and (vi) utilisation (e.g. by determining action items for a planning process). ${ }^{28}$ Concept mapping can be performed on-site, e.g. in focus groups, or by following a remote approach via internet or e-mail. In this study, we followed the remote approach and carried out stage 1 to 5 .

\section{Participants}

Individual invitations, including detailed information on the study purpose and procedure, and assurance of anonymized data processing, were sent via email to public health professionals or policy makers during February 2013.

The following criteria were applied for the selection of potential participants: The invited participant had recently worked (or currently works) at EU level, at international institutions, national ministries, public health authorities or public health departments of universities, and, worked (or currently works) on issues relevant to public health, for relevant EU co-funded projects or on comparative European analyses.

Invitations were sent directly to 261 potential participants. One general invitation was sent to the Public Health Monitoring and Reporting Section of the European Public Health Association. Participation in the study was voluntary. Informed consent was assumed with subjects' participation.

\section{Definition of an EU health information system}

An EU-HISys was defined as a system that aims to enable the development of policy relevant information and to create knowledge and awareness of important national and European public health problems and their determinants, among policymakers and others involved in organizations that can influence the health of the European population. ${ }^{31}$

\section{Study design}

Participants were invited to take part in stages 2 and 3 of the concept mapping. Stage 2 (idea generation) was achieved using a brainstorming exercise organized through the project website (www.healthinfo-concept.info). Stage 2 was conducted over a fixed period of 2.5 weeks. During the stage 2 brainstorming process, participants were asked to complete the following sentence: 'An EU health information system that supports health policy making should (provide)...'. Completed sentences were entered via a data collection interface on the project website. No 122 Part 3 I Developing infrastructure 
limitations were applied to how often participants participated and to how many statements participants could enter. To facilitate the exchange of ideas like in focus groups, all statement entries were published and updated daily onto the project website. At the end of stage 2 the statement set was reduced and edited independently by two researchers of the research group in order to obtain a list that is clear, understandable, not redundant and suitable to handle in stage $3 .^{28}$ The synthesis of ideas/statements was done by removing similar ones, shorting statements that provide a lot of examples and splitting multiple sentence statements into single sentence statements. This process was documented and afterwards reviewed by the other members of the research group. The final compilation of statements was then used as the input for stage 3 .

Statement structuring (stage 3) was performed by sending a prepared spreadsheet with the statement compilation of stage 2 to each participant via e-mail. Participants were asked to rate each statement according to its (relative) importance for the development of an EU-HISys. For statement ratings, a five-point Likert Scale was employed, ranging from (1) least importance to (5) very high importance. The participants were encouraged to equally divide statements over all points on the scale when assigning relative importance to statements. Participants were also asked to sort the statements into groups that they considered conceptually similar. The statement sorting task was performed independently from the previous rating task. Participants were only allowed to sort each statement into one of twelve groups at maximum. A time period of 4.5 weeks was assigned to this task.

\section{Analysis}

The individual results of stage 3 were entered into a software package [Ariadne Version 8 (NcGv /Talcott Bv.)] for the concept mapping analysis in stage $4 .{ }^{32} \mathrm{~A}$ matrix was generated for each participant based on how they sorted statements. Each matrix included as many rows and columns as the total number of statements. Statements that were grouped together were assigned the value ' 1 ', whereas statements that were not grouped together were assigned value ' 0 '. Afterwards, all matrices were aggregated into a group matrix. The larger the values of two statements in the group matrix, the conceptually closer the statements were considered to be. A principle component analysis was then performed using this information. The resulting coordinates of each statement were then plotted on to a $2 \mathrm{D}$ map in order to visualize the conceptual distance between each statement. In a second analytical step, the ' $x$ ' and ' $y$ ' coordinates of each point were used as input for a cluster analysis. In a final step, the average relative importance per statement and per cluster was calculated using the individual Likert Scale ratings. Statements and clusters were then ranked using a dense ranking strategy.

The members of the research group participated in stage 5 (concept map interpretation) where judgements concerning the number of clusters, their respective labelling, and the labelling of the 
horizontal and vertical axes and their dimensions was decided. It was decided that the clusters represent the key features of the EU-HISys.

Table 1 Participant characteristics in the structuring phase (stage 3).

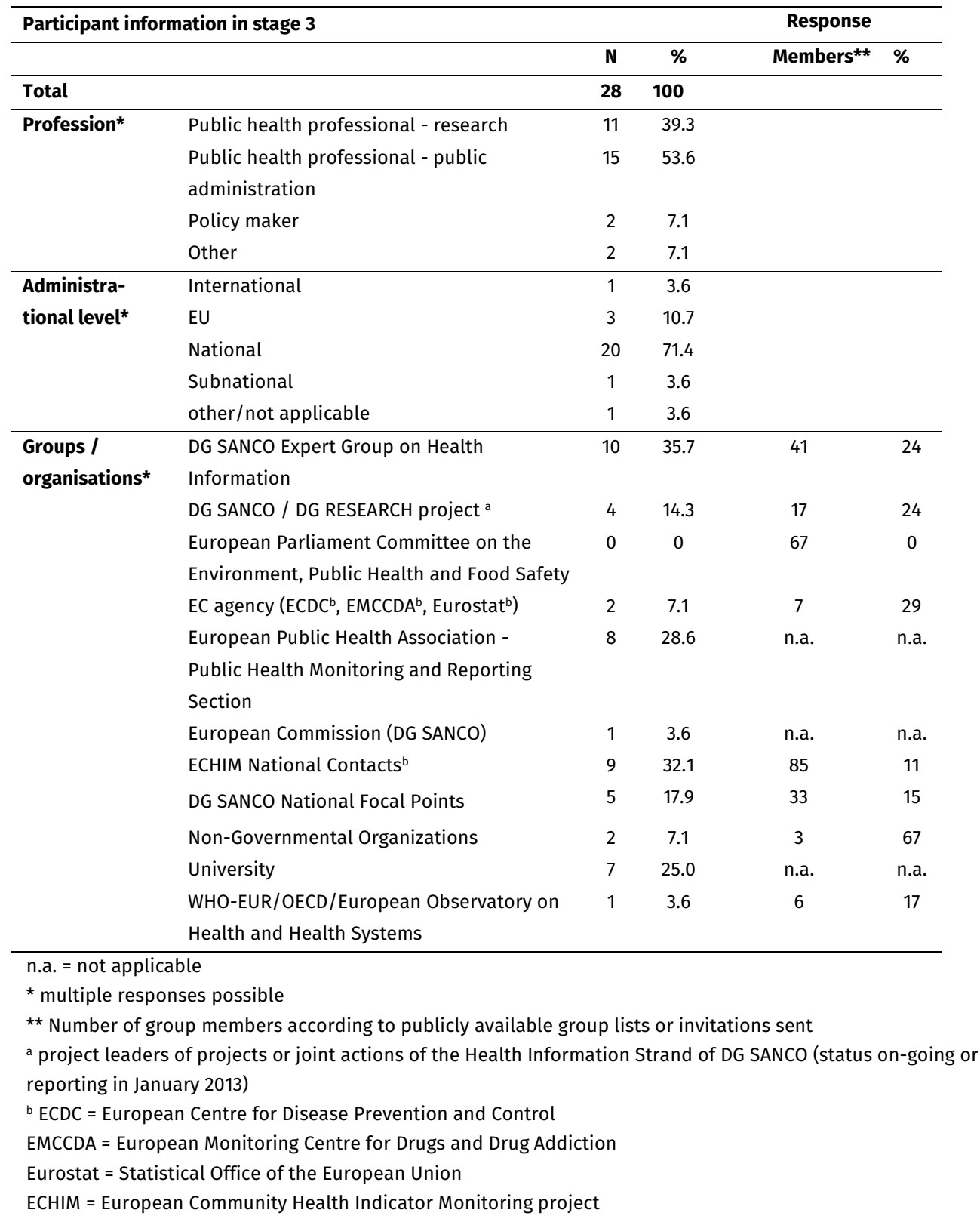




\section{Results}

During stage 2, 34 participants formulated 217 statements and during stage 3, we received responses from 28 public health professionals or policy makers who rated and/or sorted the final compilation of 93 statements. The response rate in stage 3 was at maximum $67 \%$, depending upon group membership (Table 1).

The scores on the relative importance of the top 10 statements are summarized in Table 2 . The highest relative importance was assigned to the development of a 'permanent and sustainable [system] in terms of content, infrastructure and resources'. Of next most importance (ranked 2 to 4) were statements that referred to the quality of data and information. More specifically, it was considered important that the system is 'reliable and based on reliable and comparable data and information', is 'based on a common, standardised and scientifically agreed health indicator system (e.g. ECHI shortlist)' and follows high quality standards for data collection, information compilation and reporting.

Other statements ranked in the top 10 were focused on the system's ability to identify policy needs by 'having a clear added value for member states (...)' and by being 'realised in consultation with EU policy makers and relevant stakeholders'. With regard to the development of an EU-HISys, it was emphasised that it is important to build 'on a long-term health information strategy', 'support and encourage harmonisation of data collection (...) to minimise the workload of Member States'. To facilitate policy development, the EU-HISys is expected to '(...) set(ting) priorities in the field of public health (...)'. The EU-HISys should also 'serve as a basis for developing and monitoring the EU Health Strategy (...)' and should 'be based on a conceptual model or framework that includes all relevant public health areas'.

The clustering of statements in the 2D concept map (Figure 1) represents the key features of an EU-HISys. A detailed description of each key feature can be gained from its component statements, which are provided in the supplementary material to this paper.

The horizontal axis of the concept map is labelled as 'organizational strategy' of the EU-HISys, a dimension that ranges from the organizational and strategic efforts that are required to design and develop an EU-HISys (far right), to the achievements that can be expected if the system is running and following a strategic approach (far left). On the right side of this range, are the necessary efforts regarding 'data collection', 'user orientation', 'system development', 'sustainability', and 'developing policy preparation'. All conceptual statements, mentioned in this study are positioned in this area, namely developing the system 'based on a conceptual model...' (statement \#10, key feature \#5), 'be(ing) based on a long-term health information strategy' (statement \#11, key feature \#6) and 'hav(ing) a formal position in the EU policy making cycle...' (statement \#36, key feature \#9). On the left side of the axis, clusters are positioned based upon 
the need to achieve, or generate, informative output that can provide knowledge, 'identify policy needs' and 'assist policy implementation'.

Table 2 Relative importance of statements on an EU health information system, top 10 ranking, 2013.

\begin{tabular}{|c|c|c|c|c|}
\hline Rank & $\begin{array}{l}\text { Statement } \\
\text { No. / key } \\
\text { feature No. }\end{array}$ & $\begin{array}{l}\text { "An EU health information system that supports health policy making } \\
\text { should..." }\end{array}$ & mean & SD* \\
\hline 1 & $19 / 7$ & $\begin{array}{l}\text {...be permanent and sustainable in terms of content, infrastructure, } \\
\text { resources. }\end{array}$ & 4.58 & 0.40 \\
\hline 2 & $21 / 1$ & ...be reliable and be based on reliable data and information. & 4.44 & 0.49 \\
\hline 3 & $59 / 1$ & $\begin{array}{l}\text {...provide comparable information (e.g. between countries, over time, } \\
\text { based on standard methodology). }\end{array}$ & 4.40 & 1.12 \\
\hline \multirow[t]{3}{*}{4} & $37 / 1$ & $\begin{array}{l}\text {...have high quality standards for data collection and connect data } \\
\text { collection and data quality control seamlessly. }\end{array}$ & 4.38 & 0.39 \\
\hline & $12 / 1$ & $\begin{array}{l}\text {...be based on high quality standards for information compilation and } \\
\text { reporting. }\end{array}$ & 4.38 & 0.47 \\
\hline & $9 / 1$ & $\begin{array}{l}\text {...be based on a common, standardised and scientifically agreed } \\
\text { health indicator system (e.g. ECHI shortlist) with information on health } \\
\text { status, health determinants/risk factors, health services/system incl. } \\
\text { health care utilisation, and prevention. }\end{array}$ & 4.38 & 0.54 \\
\hline \multirow[t]{2}{*}{5} & $35 / 3$ & $\begin{array}{l}\text {...have a clear added value for Member States and should support } \\
\text { their needs. }\end{array}$ & 4.35 & 0.69 \\
\hline & $88 / 6$ & $\begin{array}{l}\text {...support and encourage harmonisation of data collection, definitions, } \\
\text { and indicator development between Eurostat, WHO and OECD to } \\
\text { minimise the workload of Member States. }\end{array}$ & 4.35 & 1.30 \\
\hline 6 & $6 / 4$ & $\begin{array}{l}\text {...assist policymakers in setting priorities in the field of public health } \\
\text { and in defining policies and programmes that tackle health problems. }\end{array}$ & 4.31 & 0.98 \\
\hline 7 & $69 / 1$ & $\begin{array}{l}\text {...provide metadata (indicator definitions, link or contact information } \\
\text { to data holder, rationale of indicator, assessment of comparability). }\end{array}$ & 4.12 & 0.99 \\
\hline \multirow[t]{2}{*}{8} & $22 / 6$ & ...be stable enough to provide robust and objective information. & 4.08 & 0.76 \\
\hline & $11 / 6$ & ...be based on a long-term health information strategy. & 4.08 & 0.84 \\
\hline \multirow[t]{3}{*}{9} & $10 / 5$ & $\begin{array}{l}\text {...be based on a conceptual model or framework that includes all } \\
\text { relevant public health areas. }\end{array}$ & 4.00 & 1.46 \\
\hline & $81 / 4$ & ...serve as a basis for developing and monitoring the EU Health & 4.00 & 1.69 \\
\hline & $85 / 5$ & $\begin{array}{l}\text { Strategy and ensure transparency on progress towards health targets. } \\
\text {...should be the "go to" place for health statistics in Europe that } \\
\text { provides information that is undoubtedly state of the art. }\end{array}$ & 4.00 & 1.69 \\
\hline 10 & $20 / 3$ & $\begin{array}{l}\text {...be realised in consultation with European policy makers and relevant } \\
\text { stakeholders. }\end{array}$ & 3.96 & 0.68 \\
\hline
\end{tabular}

*SD= standard deviation

The vertical axis represents the "professional orientation" of an EU-HISys, which ranges from a scientific orientation to a policy orientation. The upper half of the map represents the technical and scientific work that is required to operate an EU-HISys. The lower half of the map contains clusters that illustrate the political support, and acceptance, necessary to develop and run an EU-HISys. 
The average score for key features on relative importance are given in Table 3. The majority of key features with higher ranks in terms of relative importance (ranks 1 and ranks 3-6) are located on the right side of the map and fall within the scientific and policy efforts to design and develop the system.

Table 3 Relative importance of the key features of an EU health information system, 2013.

\begin{tabular}{crlll}
\hline Rank & \multicolumn{2}{l}{$\begin{array}{l}\text { Key } \\
\text { feature } \\
\text { number }\end{array}$} & Key feature & Mean \\
\hline 1 & 1 & Quality of data and information & 3.53 \\
2 & 3 & Identify policy needs & 3.51 \\
3 & 6 & System development & 3.35 \\
4 & 4 & Assist policy implementation & 3.33 \\
& 7 & Sustainability & 3.33 \\
5 & 5 & User orientation & 3.20 \\
6 & 9 & Develop policy preparation & 3.12 \\
7 & 10 & Information improvement & 2.94 \\
8 & 8 & Knowledge provision & 2.70 \\
9 & 2 & Information coverage & 2.69 \\
\hline
\end{tabular}

\section{Discussion}

This study conceptualized key features of an EU-HISys through the systematic analysis of the opinions and valuations of public health practitioners and some policy makers in Europe. The key features of highest relative importance accentuate the need to realize the scientific and policy efforts to develop an EU-HISys. This demonstrates a strong desire for successful planning and implementation of an EU-HISys. It also demonstrates the importance of greater sustainability in funding inherent to institutionalized structures, as opposed to that of temporary projects or joint action funding mechanisms.

The definition of public health surveillance ${ }^{33}$ can be used as a reference to compare the key features shown in the concept map with elements of this definition. The following key features are part of this definition, 'ongoing systematic collection, analysis (key feature \#1; \#2; and \#10) and interpretation (key feature \#8 and \#4) of health data essential to the planning, implementation and evaluation of public health practice, closely integrated with the timely dissemination (key feature \#5) of these data to those who need to know'. It becomes apparent that our concept map also delineates additional key features that focus on the set-up requirements of an EU-HISys and its procedures (key feature \#6; \#; \#9; \#3; and partly \#4 and \#8). These elements indicate the participants' aspirations for (i) an EU-HISys to be developed, and, (ii) for the EU-HISys to be developed as an integrated system that aligns national data reporting required to the EU, OECD and WHO-EUR and that aligns the output of the EU-HISys with the development and evaluation of the EU health strategy and the EU policy cycle. 


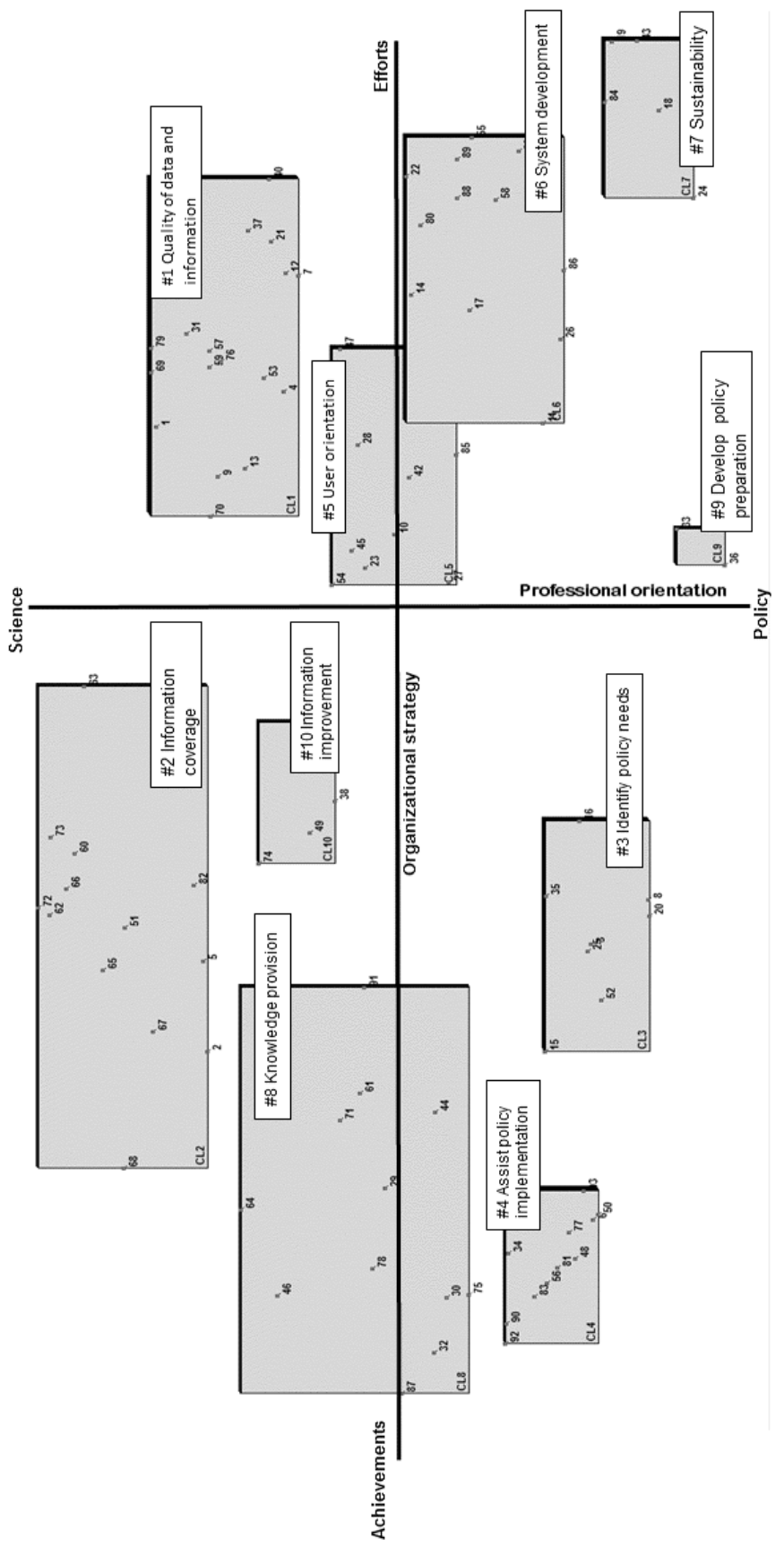

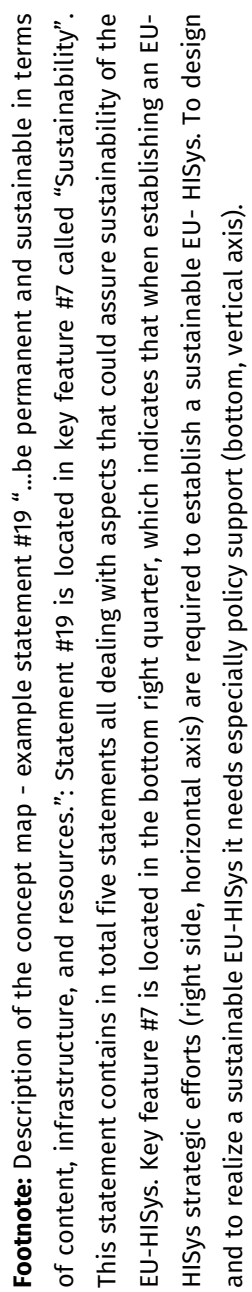

Figure 1 Concept map of key features of an EU health information system, 2013.

128 Part 3 I Developing infrastructure 
A definitional role for the design of information systems is also assigned to the data, information, knowledge and wisdom hierarchy. ${ }^{34}$ Our concept map misses the wisdom level of the hierarchy, which represents the development of sound evidence-based decisions built on the knowledge provided. But, practitioners' aspirations that the system should be able to 'identify policy needs' (\#3) and to 'assist policy implementation' (\#4) point towards this level.

Despite the acknowledged relevance of public health surveillance in general, the continuous formulation of intentions for system development, and numerous requests for a comprehensive EU-HISys as demonstrated and confirmed in our study, there seem to be considerable barriers that hinder its realization: In contrast to infectious diseases and other health threats that have the potential to spread without respecting national borders and that can evolve to an international public health issue, the relevance to invest in a wider health information infrastructure is politically less obvious. Thus, legislation, available infrastructure, and budgets devoted to the development of EU-HISys elements never reached comparable powers or levels as invested in the organization of EU infectious disease surveillance. ${ }^{9}$ But to increase availability and harmonization of the EU-HISys data base, health indicators that are collected through different and fragmented national health information systems require continuous coordination and support (legislative, financial) on member state- as well as on EU-level. ${ }^{21}$ Moreover, the standardized collection of health information could be politically charged given the concern that the information could lead to oversimplified rankings. ${ }^{9}$

However, at the time of writing there seems to be a new momentum for the development of an EU-HISys. ${ }^{35}$ Amongst others the Council of the European Union called upon its member states to cooperate when establishing an EU-HISys. ${ }^{20}$ In response to this request, a call to analyze the potential of a European Research Infrastructure Consortium (ERIC) for an EU-HISys was part of the 2014 call for proposals under the third EU public health programme (2014-2020). An ERIC is a legal entity developed to advance research activities with a clear European dimension, a tool that offers new perspectives in the discussion about the realization of an EU-HISys.

Even though the concept mapping procedure is highly applicable to the process of systematically summarizing group ideas, this study still experienced some limitations. The most important one was the lack of EU policy makers and politicians among the participants which might indicate a low interest of politics on health information system development. Accordingly, it was impossible to analyse differences between participant groups in the ranking or in the defined key features. Whilst individual invitations, and reminder emails, were sent directly to a large population of potential participants, and several weeks were allowed for online data collection, potential participant groups like policy makers might be more approachable through other means. However, the participants that took part in the study were all considered appropriate to provide insights from the perspective of a potential user, yet, since most of them are involved in the EUHISys discussions, uninfluenced user or policy maker perspectives could have been more strongly 
represented. Whilst the participation rate (in general) was lower than that of other concept mapping studies, the number of statements generated within this study was comparable. ${ }^{36}$ Additionally, the rating and sorting of statements might have been influenced by language differences between the participants.

In this study we organized the collective thinking of experts in the field of public health and provided an overview of key features of an EU health information system like data and information quality and sustainability. This concept map can be used to guide future planning at EU level, or of any other initiative that aims to develop an integrated health information system for Europe.

\section{Key points}

- This study highlights the aspirations of public health professionals and policy makers for an EU health information system that includes required key features of a public health surveillance system as well as their expectations regarding set-up requirements and procedures.

- As a cross-cutting issue, the study reproduced the demand for a permanent and sustainable EU health information system in terms of content, infrastructure and resources.

- The planning and development of an EU health information system should assure that the system has an organizational strategy and follows both a scientific and policy orientation.

- The key features identified in this study could be used by initiatives that aim to develop an integrated health information system for Europe.

\section{Acknowledgements}

We would like to express our sincere thanks to the experts who contributed to the study. We appreciated the support of Paula Marmann during her internship at the Department of International Health at Maastricht University in spring 2013. We would also like to thank Talcott B.V. for providing access to the Ariadne software and for the technical support offered throughout the study. The paper was partly presented at the European Public Health Conference on 14. November 2013 in Brussels. 


\section{References}

1. National Research Council. The Future of Public Health. Washington DC: The National Academies Press;1988.

2. Institute of Medicine. The Future of the Public's Health in the 21st Century. Washington DC: The National Academies Press;2003.

3. World Health Organization - Regional Office for Europe, Regional Committee for Europe. European Action Plan for Strengthening Public Health Capacities and Services. Copenhagen: World Health Organization, Regional Office for Europe;2012.

4. European Union. Treaty on the Functioning of the European Union. Lisbon; 2007.

5. Rosenkotter N, Brand H, McKee M, Riley N, Verma A, Verschuuren M. The realisation of a European health information system--time to get the politicians involved. Eur J Public Health 2014; 24(2): 184-5.

6. Aromaa A. Health observation and health reporting in Europe. Revue d'epidemiologie et de sante publique 1998;46(6): 481-90.

7. McKee M, Ryan J. Monitoring health in Europe: opportunities, challenges and progress. Eur J Public Health 2003;13(3 Suppl): 1-4.

8. Brand H, Rosenkötter N, Clemens T, Michelsen K. Austerity Policies in Europe - bad for health. Health protection within the EU mandate is more relevant than ever. BMJ 2013;346: f3716.

9. Elliott H. European Union health information infrastructure and policy. In: Greer SL, Kurzer P, editors. European Union Public Health Policy. Regional and global trends. Abingdon, UK: Routledge, 2013:36-50.

10. Greer S, Fahy N, Elliott HA, Wismar M, Jarman H, Palm W. Everything you always wanted to know about European Union health policies but were afraid to ask. Copenhagen: World Health Organization, 2014:59-61.

11. European Commission. Commission communication on the framework for action in the field of public health (COM(93) 559 final). Brussels: Commission of the European Communities;1993.

12. European Union. The Maastricht Treaty. The Treaty on the European Union (TEU). Maastricht;1992.

13. Nielsen TM, Jorgensen HD. Factors to consider when establishing a Europe-wide Network for exchange of health information. In: Brender J, Scherer JR, Pihlkjar J, McNair P, editors. Medical Informatics Europe 1996 - Human Facets in Information technology. Amsterdam: IOS Press;1996:8-12.

14. European Parliament, Council of the European Union. Decision on adopting a programme of Community action on health monitoring within the framework of action in the field of public health (1997-2001) (1400/97/EC). Off J Eur Communities 1997;40(L193):1-10. 
15. European Parliament, Council of the European Union. Decision on adopting a programme of Community action in the field of public health (2003-2008) (1786/2002/EC). Off J Eur Union 2002;45(L271):1-11 .

16. European Parliament, Council of the European Union. Decision on establishing a second programme of Community action in the field of health (2008-13) (1350/2007/EC). Off J Eur Union 2007;50(L301):3-13.

17. European Commission. White paper. Together for Health: A strategic Approach for the EU 2008-2013 (COM(2007) 630 final). Brussels: Commission of the European Communities;2007.

18. DG SANCO, Public Health and Risk Assessment, Health Information. Discussion Paper. European health information - objectives and organisation. European Commission; 2009: http://ec.europa.eu/health/strategy/docs/ev_20090428_rd01_en.pdf

Accessed [15.07.2014].

19. Council of the European Union. Council conclusions: towards modern, responsive and sustainable health systems (2011/C 202/04). Off J Eur Union 2011;54(C202):10-12.

20. Council of the European Union. Council Conclusions on the "Reflection process on modern, responsive and sustainable health systems". Brussels: Council of the European Union;2013.

21. Kilpeläinen K, Tuomi-Nikula A, Thelen J, et al. Health indicators in Europe: availability and data needs. Eur J Public Health 2012;22(5): 716-21.

22. Verschuuren M, Kramers P, Gudfinnsdottir GK, Aromaa A. Providing a solid evidence base for policy makers: ECHI initiative. Eurohealth 2011;16(3): 4-7.

23. Verschuuren M, Gissler M, Kilpelainen K, et al. Public health indicators for the EU: the joint action for ECHIM (European Community Health Indicators \& Monitoring). Archives of public health 2013;71(1): 12.

24. Aromaa A. Implementation of joint health indicators in Europe - Joint Action for ECHIM. Arpo Aromaa on behalf of the ECHIM core group. Archives of public health 2012;70(1):22.

25. European Parliament, Council of the European Union. Commission Regulation on implementing Regulation (EC) No 1338/2008 of the European Parliament and of the Council on Community statistics on public health and health and safety at work, as regards statistics based on the European Health Interview Survey (EHIS) (141/2013). Off J Eur Union 2013;56(L47):20-21.

26. European Parliament and the Council. Regulation on Community statistics on public health and health and safety at work ((EC) No 1338/2008). Off J Eur Union 2008; 51(L354):70-75.

27. Achterberg PW, Kramers PG, van Oers HA. European community health monitoring: the EUPHIX-model. Scandinavian Journal of Public Health 2008;36(7):676-84.

28. Kane M, Trochim WMK. Concept Mapping for Planning and Evaluation. Thousand Oaks, London, New Dehli: SAGE Publications, 2007.

29. Trochim WMK. An introduction to concept mapping for planning and evaluation. Evaluation and Programme Planning 1989;12: 1-16.

30. van Bon-Martens MJ, Achterberg PW, van de Goor IA, van Oers HA. Towards quality criteria for regional public health reporting: concept mapping with Dutch experts. Eur J Public Health 2012;22(3): 337-42. 
31. Rosén M. Critical factors for effective health reporting. In: Achterberg PW Kramers P, editors. Health Reporting in the European Union. Bilthoven: National Institute for Public Health and the Environment (rivm); 1998.

32. Severens P. Handbook concept mapping using Ariadne. In: National Centre for Mental Health (NcGv), Talcott BV, editors. Utrecht; 1995.

33. Thacker SB, Berkelman RL. Public health surveillance in the United States. Epidemiologic reviews 1988;10: 164-90.

34. Rowley J. The wisdom hierarchy: representations of the DIKW hierarchy. Journal of Information Science 2007;33(2): 163-80.

35. Rosenkötter N, van Bon-Martens M. Public health monitoring and reporting: maintaining and improving the evidence base. Eurohealth 2015; 21(1): 17-20.

36. Rosas SR, Kane M. Quality and rigor of the concept mapping methodology: a pooled study analysis. Evaluation and Programme Planning 2012;35(2): 236-45. 


\section{Supplementary material to this paper}

Statements per key feature, including mean rating and standard deviation (SD)

\begin{tabular}{|c|c|c|c|}
\hline \multirow{2}{*}{$\begin{array}{l}1 \\
\text { No. }\end{array}$} & \multicolumn{3}{|c|}{ Quality of data and information } \\
\hline & mean & SD & "An EU health information system that supports health policy making should..." \\
\hline 21 & 4.44 & 0.49 & be reliable and be based on reliable data and information. \\
\hline 59 & 4.40 & 1.12 & $\begin{array}{l}\text { provide comparable information (e.g. between countries, over time, based on } \\
\text { standard methodology). }\end{array}$ \\
\hline 9 & 4.38 & 0.54 & $\begin{array}{l}\text { be based on a common, standardised and scientifically agreed health indicator } \\
\text { system (e.g. ECHI shortlist) with information on health status, health } \\
\text { determinants/risk factors, health services/system incl. health care utilisation, } \\
\text { prevention }\end{array}$ \\
\hline 12 & 4.38 & 0.47 & be based on high quality standards for information compilation and reporting. \\
\hline 37 & 4.38 & 0.39 & $\begin{array}{l}\text { have high quality standards for data collection and connect data collection and } \\
\text { data quality control seamlessly. }\end{array}$ \\
\hline 69 & 4.12 & 0.99 & $\begin{array}{l}\text { provide metadata (indicator definitions, link or contact information to data holder, } \\
\text { rationale of indicator, assessment of comparability). }\end{array}$ \\
\hline 31 & 3.85 & 1.05 & $\begin{array}{l}\text { deliver data and information based on common guidelines for surveys, registries, } \\
\text { and data reporting. }\end{array}$ \\
\hline 7 & 3.77 & 2.02 & $\begin{array}{l}\text { be able to exploit data that are already digitally collected through the healthcare } \\
\text { systems. }\end{array}$ \\
\hline 53 & 3.69 & 1.29 & provide a central indicator database. \\
\hline 57 & 3.40 & 1.44 & provide alerts for indicating the limitations in indicator (data) comparability. \\
\hline 40 & 3.31 & 1.75 & identify mechanisms to collect up-to date and reliable data. \\
\hline 76 & 3.23 & 1.79 & provide unambiguous data. \\
\hline 79 & 3.23 & 1.25 & $\begin{array}{l}\text { report statistical significance (e.g. confidence limits) to avoid invalid comparisons } \\
\text { and rankings }\end{array}$ \\
\hline 4 & 3.15 & 1.36 & $\begin{array}{l}\text { aim to identify solutions to enable the collection of missing but relevant health } \\
\text { indicators for public health issues. }\end{array}$ \\
\hline 1 & 2.46 & 1.48 & $\begin{array}{l}\text { consider issues of rates based on small numbers (which is particularly relevant for } \\
\text { small countries) carefully. }\end{array}$ \\
\hline 70 & 2.24 & 1.46 & $\begin{array}{l}\text { provide multilingual content and reports, e.g. indicator definitions should be } \\
\text { translated in all European languages. }\end{array}$ \\
\hline 13 & 1.62 & 0.54 & $\begin{array}{l}\text { be based on two types of indicators for each topic or public health issue: } \\
\text { 'mandatory' and 'nice to have'. }\end{array}$ \\
\hline Mean & 3.53 & & \\
\hline
\end{tabular}




\begin{tabular}{|c|c|c|c|}
\hline & \multicolumn{3}{|c|}{ Information coverage } \\
\hline & Mean & SD & "An EU health information system that supports health policy making should..." \\
\hline 68 & 3.73 & 1.35 & provide information to assess socio-economic health inequalities. \\
\hline 67 & 3.44 & 1.53 & provide information on the EU level and the EU/EEA member states. \\
\hline 51 & 3.42 & 1.24 & $\begin{array}{l}\text { make use of summary indicators, such as life expectancy, disease burden, and } \\
\text { avoidable death. }\end{array}$ \\
\hline 72 & 3.23 & 1.33 & provide retrospective and prospective (trend) information. \\
\hline 5 & 2.77 & 1.25 & analyse care (e.g. demand for care) as a determinant of public health. \\
\hline 62 & 2.76 & 1.14 & provide economic/financial information. \\
\hline 65 & 2.62 & 1.7 & $\begin{array}{l}\text { provide information on other countries than official EU Member States: EFTA } \\
\text { countries, EU candidate countries, EU acceding countries, other interested } \\
\text { countries. }\end{array}$ \\
\hline 82 & 2.62 & 1.85 & $\begin{array}{l}\text { serve as a repository of country profiles (e.g. the Health System in Transition from } \\
\text { the Observatory) updated dynamically with the latest available data. }\end{array}$ \\
\hline 2 & 2.58 & 1.78 & where possible, state cause and effect. \\
\hline 66 & 2.23 & 1.49 & provide information on subnational level. \\
\hline 73 & 2.00 & 0.77 & $\begin{array}{l}\text { provide specific and comprehensive information on perinatal and neonatal } \\
\text { health. }\end{array}$ \\
\hline 63 & 1.96 & 0.88 & $\begin{array}{l}\text { provide information by country groups (e.g. Baltic states, Nordic countries and } \\
\text { suchlike). }\end{array}$ \\
\hline 60 & 1.58 & 0.71 & provide data related to prematurity. \\
\hline Mean & 2.69 & & \\
\hline
\end{tabular}

\begin{tabular}{|c|c|c|c|}
\hline & \multicolumn{3}{|c|}{ Identify policy needs } \\
\hline & Mean & SD & "An EU health information system that supports health policy making should..." \\
\hline 35 & 4.35 & 0.69 & have a clear added value for Member States and should support their needs. \\
\hline 20 & 3.96 & 0.68 & $\begin{array}{l}\text { be realised in consultation with European policy makers and relevant } \\
\text { stakeholders. }\end{array}$ \\
\hline 3 & 3.88 & 1.18 & $\begin{array}{l}\text { address people active in policymaking, science, healthcare, education and mass } \\
\text { media. }\end{array}$ \\
\hline 15 & 3.54 & 1.09 & be flexible enough to incorporate emerging policy needs and new expectations. \\
\hline 8 & 3.50 & 1.56 & be a-political. \\
\hline 16 & 3.31 & 1.29 & be linked to clear objectives. \\
\hline 25 & 2.96 & 1.27 & $\begin{array}{l}\text { be widely used to justify value for money, to ensure high standards, and to } \\
\text { increase the visibility of the system. }\end{array}$ \\
\hline 52 & 2.58 & 1.71 & position itself clearly as distinct from policy documents. \\
\hline Mean & 3.51 & & \\
\hline
\end{tabular}




\begin{tabular}{|c|c|c|c|}
\hline & \multicolumn{3}{|c|}{ Assist policy implementation } \\
\hline & Mean & SD & "An EU health information system that supports health policy making should..." \\
\hline 6 & 4.31 & 0.98 & $\begin{array}{l}\text { assist policy makers in setting priorities in the field of public health and in } \\
\text { defining policies and programmes that tackle health problems. }\end{array}$ \\
\hline 81 & 4.00 & 1.69 & $\begin{array}{l}\text { serve as a basis for developing and monitoring the EU Health Strategy and } \\
\text { ensure transparency on progress towards health targets. }\end{array}$ \\
\hline 56 & 3.81 & 1.46 & provide a means for planning and monitoring of EU health policy. \\
\hline 93 & 3.77 & 1.02 & take the needs of policy makers into account. \\
\hline 90 & 3.72 & 1.56 & $\begin{array}{l}\text { support evidence-based decision making and provide information on cost- } \\
\text { effective policies, programmes and interventions in public health. }\end{array}$ \\
\hline 83 & 3.54 & 0.94 & $\begin{array}{l}\text { should allow decision makers to assess the responsiveness, accessibility, equity, } \\
\text { sustainability, etc. of their health systems. }\end{array}$ \\
\hline 50 & 3.19 & 2.08 & lead to real policy statements or actual policy. \\
\hline 48 & 2.77 & 1.49 & $\begin{array}{l}\text { influence policy by being innovative and placing new policy possibilities on the } \\
\text { health agenda. }\end{array}$ \\
\hline 92 & 2.62 & 0.93 & $\begin{array}{l}\text { support integrated health policy by providing recommendations for integrated } \\
\text { policy actions (e.g. Health in all Policy approach). }\end{array}$ \\
\hline 34 & 2.46 & 1.79 & $\begin{array}{l}\text { give advice for recommended international collaboration in relation to a health } \\
\text { problem. }\end{array}$ \\
\hline 77 & 2.42 & 1.86 & put policy relevance above scientific relevance. \\
\hline Mean & 3.33 & & \\
\hline
\end{tabular}

\begin{tabular}{|c|c|c|c|}
\hline & \multicolumn{2}{|c|}{ User orientation } & \multirow[b]{2}{*}{ "An EU health information system that supports health policy making should..." } \\
\hline & Mean & SD & \\
\hline 10 & 4.00 & 1.46 & $\begin{array}{l}\text { be based on a conceptual model or framework that includes all relevant public } \\
\text { health areas. }\end{array}$ \\
\hline 85 & 4.00 & 1.69 & $\begin{array}{l}\text { should be the "go to" place for health statistics in Europe that provides } \\
\text { information that is undoubtedly state of the art. }\end{array}$ \\
\hline 47 & 3.62 & 1.39 & $\begin{array}{l}\text { include user-friendly online tools for data set disaggregation (e.g. per disease, } \\
\text { sex, social class,...), analysis/visualisation (comparisons, maps, graphs, trends) } \\
\text { and download/export of data or generated figures. }\end{array}$ \\
\hline 23 & 3.50 & 0.87 & $\begin{array}{l}\text { be sufficiently specific and applicable for the reader/user within different } \\
\text { countries and settings and give an convenient overview on health information. }\end{array}$ \\
\hline 28 & 3.38 & 1.62 & $\begin{array}{l}\text { contain easy accessible (e.g. web-based) interpretation of indicator-based } \\
\text { information that is published in an attractive way, e.g. in the form of policy } \\
\text { briefs, fact sheets, short reports, short info-sheets with info-graphics, short info- } \\
\text { videos }\end{array}$ \\
\hline 27 & 3.23 & 1.25 & communicate health information on a regular basis to the broader public. \\
\hline 54 & 3.00 & 1.60 & $\begin{array}{l}\text { provide a graphic summary for particular areas of health (e.g. dashboard) } \\
\text { accompanied by policy-relevant commentary which regularly reports highlights } \\
\text { from the data. }\end{array}$ \\
\hline 45 & 2.62 & 1.08 & $\begin{array}{l}\text { include regularly updated data and information and should inform all } \\
\text { stakeholders when the next update is due. }\end{array}$ \\
\hline 42 & 1.46 & 0.40 & include community participation tools. \\
\hline Mean & 3.2 & & \\
\hline
\end{tabular}




\begin{tabular}{|c|c|c|c|}
\hline \multirow{2}{*}{$\begin{array}{l}6 \\
\text { No }\end{array}$} & \multicolumn{3}{|c|}{ System development } \\
\hline & Mean & SD & "An EU health information system that supports health policy making should..." \\
\hline 88 & 4.35 & 1.30 & $\begin{array}{l}\text { support and encourage harmonisation of data collection, definitions, and } \\
\text { indicator development between Eurostat, WHO and OECD to minimise the } \\
\text { workload of Member States. }\end{array}$ \\
\hline 11 & 4.08 & 0.84 & be based on a long-term health information strategy. \\
\hline 22 & 4.08 & 0.76 & be stable enough to provide robust and objective information. \\
\hline 26 & 3.58 & 1.09 & $\begin{array}{l}\text { build on current and previous efforts made by EU Member States and the } \\
\text { European Commission (e.g. in EC co-funded projects and actions). }\end{array}$ \\
\hline 14 & 3.46 & 1.48 & $\begin{array}{l}\text { be easy accessible by internet, smartphone, tablet etc. and flexible to adapt to } \\
\text { new technologies. }\end{array}$ \\
\hline 89 & 3.31 & 1.21 & $\begin{array}{l}\text { support countries which have difficulties to collect relevant information (data, } \\
\text { indicators). }\end{array}$ \\
\hline 17 & 3.27 & 1.27 & be linked with other EU information systems. \\
\hline 39 & 3.19 & 1.23 & $\begin{array}{l}\text { identify means of engaging with Member States to enable timely information } \\
\text { exchange and to offer feedback on the data collection process. }\end{array}$ \\
\hline 86 & 3.04 & 1.42 & should be widely introduced to different stakeholders. \\
\hline 80 & 2.77 & 1.79 & securely store and manage health policy data. \\
\hline 55 & 2.69 & 0.98 & provide a help desk that provides timely response to user issues. \\
\hline 58 & 2.35 & 0.84 & provide an interactive collaboration environment for all the users. \\
\hline Mean & 3.35 & & \\
\hline
\end{tabular}

\begin{tabular}{|c|c|c|c|}
\hline & \multicolumn{2}{|c|}{ Sustainability } & \multirow[b]{2}{*}{ "An EU health information system that supports health policy making should..." } \\
\hline & Mean & SD & \\
\hline 19 & 4.58 & 0.40 & be permanent and sustainable in terms of content, infrastructure, resources. \\
\hline 18 & 3.64 & 1.67 & $\begin{array}{l}\text { be maintained and run by an institution with an official mandate for that task } \\
\text { and personnel. }\end{array}$ \\
\hline 84 & 3.15 & 1.36 & $\begin{array}{l}\text { should assure the participation of acknowledged experts for active and on-going } \\
\text { advice and evaluation. }\end{array}$ \\
\hline 43 & 2.92 & 1.46 & $\begin{array}{l}\text { include National Implementation Teams which get an official status and } \\
\text { necessary resources. }\end{array}$ \\
\hline 24 & 2.35 & 1.92 & be under the command, coordination and steering of EC/DG SANCO. \\
\hline Mean & 3.33 & & \\
\hline
\end{tabular}




\begin{tabular}{|c|c|c|c|}
\hline & \multicolumn{3}{|c|}{ Knowledge provision } \\
\hline & Mean & SD & "An EU health information system that supports health policy making should..." \\
\hline 91 & 3.24 & 1.46 & $\begin{array}{l}\text { support the effective use of health data by enabling data linkage in the future } \\
\text { and resolving data protection issues at EU level. }\end{array}$ \\
\hline 46 & 3.04 & 1.88 & $\begin{array}{l}\text { include the EU dimension of health: e.g. patient migration and health workforce } \\
\text { migration, health security (care, food, environment), innovation including } \\
\text { (pharmaceutical) industry (e.g. investment in R\&D), EU internal } \\
\text { market/globalisation }\end{array}$ \\
\hline 30 & 3.00 & 1.46 & $\begin{array}{l}\text { contain recommendations based on the analyses of policy relevant health } \\
\text { indicators. }\end{array}$ \\
\hline 64 & 3.00 & 1.15 & $\begin{array}{l}\text { provide information in coherence and close collaboration with social policy on } \\
\text { the social determinants of health. }\end{array}$ \\
\hline 71 & 3.00 & 1.62 & $\begin{array}{l}\text { provide public health reports that are linked with up-to date scientific } \\
\text { knowledge. }\end{array}$ \\
\hline 78 & 3.00 & 1.46 & quantify the potential health benefits. \\
\hline 44 & 2.65 & 1.92 & include only key indicators linked to relevant policies and strategies. \\
\hline 75 & 2.62 & 1.93 & $\begin{array}{l}\text { provide tools for simulations enabling policy makers to "know" the impact of } \\
\text { their policy before adopting them. }\end{array}$ \\
\hline 61 & 2.42 & 1.47 & $\begin{array}{l}\text { provide easy access to important reports and policy documents by the major } \\
\text { international players in the field of health and healthcare. }\end{array}$ \\
\hline 32 & 2.31 & 1.21 & $\begin{array}{l}\text { deliver information on needs to decide how to assign people, resources, and } \\
\text { finances. }\end{array}$ \\
\hline 87 & 2.12 & 1.03 & summarise present policy and interventions. \\
\hline 29 & 2.08 & 1.46 & $\begin{array}{l}\text { contain information on leaders in EU health policy and other relevant players } \\
\text { (expert groups, networks projects). }\end{array}$ \\
\hline Mean & 2.7 & & \\
\hline
\end{tabular}

\begin{tabular}{llll}
\hline 9 & \multicolumn{3}{l}{ Develop policy preparation } \\
No. & Mean & SD & "An EU health information system that supports health policy making should..." \\
\hline 36 & 3.19 & 1.77 & $\begin{array}{l}\text { have a formal position in the EU policy making cycle (or at least the main results } \\
\text { of the system) and be timely and transparently connected to it. } \\
\text { engage with different stakeholders to ensure a high degree of acceptability. }\end{array}$ \\
\hline 33 & 3.04 & 1.73 & \\
\hline Mean & 3.12 & & \\
\hline
\end{tabular}

\begin{tabular}{|c|c|c|c|}
\hline \multirow{2}{*}{$\begin{array}{l}10 \\
\text { No. }\end{array}$} & \multicolumn{3}{|c|}{ Information improvement } \\
\hline & Mean & SD & "An EU health information system that supports health policy making should..." \\
\hline 49 & 3.27 & 1.35 & $\begin{array}{l}\text { inform on the development of health indicators (e.g. for benchmarking, } \\
\text { comparisons across countries and over time) among relevant groups (age, sex, } \\
\text { other). }\end{array}$ \\
\hline 38 & 3.00 & 1.23 & highlight information gaps. \\
\hline 74 & 2.77 & 1.33 & $\begin{array}{l}\text { provide the possibility to link health data with indicators from other fields, e.g. } \\
\text { finance, economic situation, climate, environment factors. }\end{array}$ \\
\hline 41 & 2.73 & 1.81 & $\begin{array}{l}\text { include an almost in "real-time" available set of key indicators that enable } \\
\text { public health practitioners to identify public health effects (e.g. of the financial } \\
\text { crisis) timely. }\end{array}$ \\
\hline Mean & 2.94 & & \\
\hline
\end{tabular}





\section{General discussion}




\section{General Discussion}

This dissertation aimed to explore conditions relevant to advance public health surveillance capacities Europe. It is focussed on the three perspectives: European Union (EU) public health policy (Part 1), public health surveillance data and information (Part 2), and EU public health surveillance infrastructure requirements (Part 3). Within this dissertation the status quo of EU public health (surveillance) policy actions is explored; opportunities for advancing the stock of public health surveillance data for information and knowledge generation are analysed; and key features of an EU-level health information system are defined.

In the following, the key findings of the conducted research are summarised and the research questions are answered. A compilation of the main results of this thesis is given in Figure 1. The outline of the main research findings is followed by a discourse that aims to carve out the conditions that could support the development of advanced European public health surveillance capacities.

\section{Advancing public health surveillance in Europe}

\begin{tabular}{|c|c|c|c|c|}
\hline $\begin{array}{l}\text { POLICY } \\
\text { Assessing the } \\
\text { status quo }\end{array}$ & \multicolumn{3}{|c|}{$\begin{array}{l}\text { DATA and INFORMATION } \\
\text { "Off-label-use" of data for information and knowledge generation } \\
\text { in public health }\end{array}$} & $\begin{array}{l}\text { INFRASTRUCTURE } \\
\text { Developing } \\
\text { infrastructure }\end{array}$ \\
\hline $\begin{array}{l}\text { Among all EU-level } \\
\text { policy actions (1992- } \\
\text { 2012) the main focus of } \\
\text { attention of EU public } \\
\text { health experts is not } \\
\text { placed on actions } \\
\text { related to public } \\
\text { health surveillance. } \\
\text { Good practice } \\
\text { exchange is regarded } \\
\text { as influential EU } \\
\text { health policy output. }\end{array}$ & $\begin{array}{l}\text { European emergency } \\
\text { medical care data, } \\
\text { especially emergency } \\
\text { department data, are } \\
\text { supportive for the } \\
\text { timely detection of the } \\
\text { beginning of an } \\
\text { influenza season. }\end{array}$ & $\begin{array}{l}\text { The broad definition of } \\
\text { health threats under } \\
\text { the IHR (2005) calls for } \\
\text { the inclusion of less } \\
\text { specific, but routinely } \\
\text { available health } \\
\text { information and the } \\
\text { introduction of } \\
\text { syndromic surveillance } \\
\text { approaches in Europe. }\end{array}$ & $\begin{array}{l}\text { If regular school-entry } \\
\text { screening is available, } \\
\text { this data source can } \\
\text { provide valid } \\
\text { information on health } \\
\text { care utilisation of } \\
\text { children and existing } \\
\text { inequalities. }\end{array}$ & $\begin{array}{l}\text { A permanent, } \\
\text { sustainable and } \\
\text { comprehensive } \\
\text { health information } \\
\text { system on EU-level is } \\
\text { requested by public } \\
\text { health practitioners } \\
\text { and policy makers. }\end{array}$ \\
\hline
\end{tabular}

Figure 1 Main findings for this thesis: Advancing public health surveillance in Europe.

\section{Summary of main research findings}

\section{Part 1 - the policy perspective: Assessing the status quo}

\section{Research question}

How do key experts in EU health matters perceive EU health

policy actions from 1992 to 2012, reflected in terms of achievements, failures and missed opportunities?
For the research conducted in Part 1, Chapter $\mathbf{1}$ we made use of the momentum of the twentieth anniversary of the Maastricht Treaty wherein an EU health mandate was defined for the first time. In this study we assessed expert perceptions on achievements, failures and missed opportunities of EU health policy. This general assessment 
approach opened up the chance to evaluate the status quo of actions on EU public health surveillance amongst the whole breath of EU health policy actions.

The interviewed experts perceived infrastructures like a Directorate on health issues (DG SANCO, since 2015 DG SANTÉ), related public health programmes, and established EU agencies as achievements. These infrastructures improved the development of a European public health domain. The work on tobacco control was a prominent issue for positively perceived legislative actions. The Health in All Policies (HiAP) approach was generally assessed as an achievement, since it is stipulated within the European Treaties. It enables an intersectoral policy orientation and offers the possibility to address health determinants outside the health sector. However, the implementation status of the HiAP approach was perceived as a missed opportunity. The label failure was rarely assigned. The missing integration or link of EU health policy to social policies appeared in some interviews under this heading as well as the strength of the internal market, which annulled e.g. national protective alcohol legislations in some member states.

Regarding the status quo of public health surveillance, it can be concluded that Infectious diseases surveillance and the establishment of the European Centre for Disease Prevention and Control (ECDC) was perceived as an achievement. EU actions on general public health surveillance like a common indicator set (European Core Health Indicators (ECHI)), the European Health Information Survey (EHIS), or instruments like the HEIDI tool (now ECHI data tool) were rarely mentioned during the interviews.

Summary Part 1: Despite several EU funded projects, networks and actions that aimed to develop capacities for EU public health surveillance, respective elements seemed to be less prominent and influential in the perception of the interviewed experts. The status quo of EU public health surveillance is rather weak.

Part 2 - the data and information perspective: "Off-label-use" of data for information and knowledge generation in public health

Part 2 of this thesis focussed on secondary data sources for information and knowledge generation in public health. It was intended to identify the potential of these data sources for advancing EU public health surveillance activities.

The first study in Part 2 (Chapter 2) dealt with the assessment of a syndromic surveillance approach. We analysed retrospectively the timeliness and validity of syndromic surveillance with immediate and electronically available emergency medical care data. It was the first time that validity and timeliness of syndromic surveillance

\section{Research question}

What is the validity and timeliness of different European emergency medical care data sources for syndromic influenza surveillance during the autumn/winter wave of $A(H 1 N 1)$ influenza 2009? 
were compared for emergency medical dispatch, ambulance service and emergency department data in one study.

It turned out that emergency department data demonstrated the best timeliness and indicated the beginning of the influenza pandemic up to one week in advance. In addition, emergency department data showed a convincing potential to identify outbreak and non-outbreak periods correctly. The assessment of emergency department data was based on single emergency departments. Similar compelling results were found for ambulance service data, but here larger catchment areas seemed to be necessary. Thus, regional level data of ambulance services should be preferred to data from local services.

The results underline the utility of the syndromic surveillance approach in addition to traditional influenza surveillance and event-based surveillance approaches. The presented syndromic surveillance approach proved to be a supportive information source during an early season influenza pandemic, as it was the case in $2009 / 2010$. This is especially relevant, if influenza sentinel surveillance programmes are scheduled during the usual influenza periods and are not active throughout the year. Those systems would miss the beginning of an early influenza season like the one in 2009/2010.

\section{Research question}

What is the potential of indicatorbased syndromic surveillance approaches for the surveillance of non-infectious health threats under the International Health Regulations (2005)?
In Part 2, Chapter 3 the benefit of a syndromic surveillance approach for the detection of non-infectious health threats is discussed in a narrative review. Potential noninfectious health threats are described in the International Health Regulations (2005) (IHR 2005). Similar to infectious diseases, they can constitute a Public Health Emergency of International Concern (PHEIC).

Non-infectious health threats are very diverse in their nature. They can range from food or drug safety issues to the international distribution of hazardous goods, to chemical incidents with environmental dispersion, to natural disasters. The range of potential health effects is as diverse as the events. Traditional infectious disease surveillance systems are not suitable for the identification and monitoring of non-infectious threats. Event-based systems, that e.g. summarise news wires, might identify the emergency, but are often not able to monitor the presence and magnitude of health effects on population level. Therefore, less specific systems that make use of other, immediately available routine health data sources like emergency medical care data or data from medical telephone helplines can be used for syndromic surveillance to support situational awareness regarding the health impact of a given situation.

In this narrative review we presented syndromic surveillance systems that make use of routine health care data for the monitoring of non-infectious events. Syndromic surveillance systems support public health authorities e.g. to gain situational awareness about the health impact of 
heat waves or of smoke exposure during a peat bog wildfire. The review provided also insights into theoretical and real-life health threats of non-infectious origin that have the potential to constitute a PHEIC. We argue that routine health data can be applied within a syndromic surveillance approach and thus, can contribute to an improved awareness about the health impact of the potential PHEIC. Examples of respective health threats are internationally traded contaminated foods, drugs, or hazardous goods or environmental threats like the volcanic eruption in Iceland in April 2010 that led to a dispersion of volcanic ash across Europe. Emergency medical care data, telephone helpline calls for general practitioner services or advice of poison control centres are potentially useful data sources for such a syndromic surveillance approach.

It is concluded that public health authorities that want to be able to identify health threats or monitor health effects related to non-infectious events under the IHR (2005) do not need to invest in additional data collections. Less specific routine health information can be used within a syndromic surveillance approach to improve and expand indicator-based surveillance. To strengthen public health surveillance under the IHR (2005) and to establish more comprehensive surveillance systems an investment in development of syndromic surveillance capacities that augment infectious disease surveillance systems would be necessary.

For the research conducted in Part 2, Chapter 4 routine population-based school-entry screening data from North Rhine-Westphalia, Germany were used for assessing social determined inequalities in health care utilisation of children at the age of five to seven years. In addition, it was aimed to assess whether school-entry screening data are suitable for assessing the delivery and utilisation of child health services in general, e.g. as one aspect of health system performance.

\section{Research question}

What is the potential of school-entry screening data for assessing the relationship of parents' educational level and families' migrant background to pre-school children's health care utilisation?

The study revealed an increased likelihood of incomplete participation in national recommended early recognition examinations in children of families with a low educational level and with a migrant background. In contrast, children with a migrant background were more likely to be sufficiently vaccinated compared to non-migrants. An increased likelihood of referrals due to findings made during the school-entry screening was observed for children with migrant background and children with low parental education, even after adjustment for participation in early recognition examinations. Interestingly, visiting the kindergarten revealed to be supportive for improved health care utilisation indicated as complete participation in screening and vaccination programmes and timely and adequate identification and treatment of complaints like visual or hearing acuity and kinetic or cognitive development. 
Since a discussion about the potential of this data source for public health surveillance in a European context (e.g. for specific aspects of health systems performance and inequalities in health care utilisation) is not included in the paper presented in Part 2, Chapter 4, a brief discussion of this aspects is presented in the following. In North Rhine-Westphalia, the data turned out to be a suitable data source for assessing child health care utilisation and related inequalities on population level. The relative high proportion of not adequately treated children that need to be referred for further examination to a paediatrician or another specialist reveals potential for quality improvements in paediatric health care. Since this data are yearly available for a full cohort of children, they tend to be especially useful for small-scale public health surveillance on local level. According to the experiences made in North Rhine-Westphalia, this data support local public health authorities in identifying local health inequalities and enabling target-oriented distribution of resources, like support programmes for young families, structural prevention programmes, or public dental care programmes..$^{1-3}$ Moreover, public health authorities use this routine examination for additional data collection depending on local information needs (e.g. media consumption of kids, rate of kids with a swimming badge). On regional and national level these data are used for assessing child health (e.g. proportion of overweight and obese children) and the utilisation of health services. Its utilisation for public health surveillance is widely established in Germany.

On European level, the collection of data at school-entry seems to differ. An overview provided by Rimpelä et al. suggests that school health services that examine child health exist in various European countries. ${ }^{4}$ However, the availability, the timing and the extent of school (entry) screening programmes vary due to different organisational and cultural structures in the respective member states or even across the regional entities in the EU. Therefore, this data source might not be suitable for comparable assessments of child health care utilisation across Europe.

Summary Part 2: Public health surveillance can make use of various data sources for information and knowledge generation. The emergence of novel data sources and monitoring approaches for public health surveillance is triggered by technological advances in data retrieval and data analysis, and by learning from examples in other countries or settings. The conducted case studies in Part 2 underline that continuous monitoring of potential novel data sources and monitoring approaches for public health surveillance as well as the assessment of their relevance is one key component of public health surveillance systems. 
Part 3 - the infrastructure perspective: Developing infrastructure

In Part 3, Chapter 5 it was aimed to respond to the demand of an EU health information system as indicated by different project consortia, expert groups and recently by the Council of Ministers of the European Union..$^{5-8}$ It was intended to identify necessary key features for a comprehensive EU health information system.

\section{Research question}

What features do public health experts expect to be part of a European health information system and how do they rate and organise them?

The key features were identified by conceptualising the opinions and valuations of public health professionals and policy makers active on European level. In general, the key features were comparable with the elements inherent in the general definition of public health surveillance and the core aspects provided by the Data-Information-Knowledge-Wisdom-hierarchy (DIKW) (Figure 2) that was introduced in the Introduction of this thesis. The analysis revealed the importance of realising scientific and policy efforts to develop an EU health information system. This result demonstrates a strong desire for successful planning and implementation of a useroriented EU health information system. It also demonstrates the importance of greater sustainability in funding inherent to institutionalised structures, as opposed to that of temporary projects or joint action funding mechanisms.

With regard to data and information - the basis of the DIKW-hierarchy - it is expected that high quality data and information are provided on EU- and national level, that cover all areas of public health interest. The system should deliver improved information that timely informs about health inequalities and current patterns and trends of diseases and health determinants.

The knowledge provided by the information system should e.g. cover the EU dimension of health, support close collaboration with the social policy sector, and include recommendations based on the monitoring results. It is expected that the system support policy preparation by having a formal position in the EU policy-making cycle.

The knowledge derived within the EU health information system should be able to strengthen decision-making (wisdom). This should be achieved by having the capacity to respond (identify) to policy needs on EU- and on national level and by assisting policy makers in setting priorities and by acting as a mean for planning and monitoring of EU health policy.

Summary Part 3: This study made a case for the development of a sustainable and comprehensive EU health information system that covers all aspects of information systems as indicated in the DIKW-hierarchy. 
Wisdom

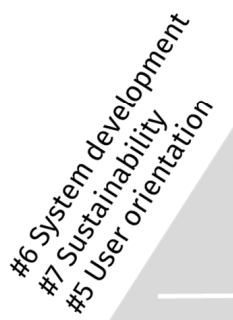

\#4 Assist policy implementation

\#3 Identify policy needs

\#9 Support policy preparation

\#8 Knowledge provision

\#2 Information coverage \#10 Information improvement

\#1 Quality of data and information

Data

Figure 2 Assignment of the identified key features to the DIKW-hierarchy

\section{Discourse: How to advance public health surveillance in Europe}

The research conducted in this thesis revealed some structural weaknesses of public health surveillance, especially the results of Part 1 and Part 2 point directly towards weaknesses of EU level public health surveillance:

- past actions on public health surveillance were not remembered as achievements in the 20 years history of EU public health actions (Part 1).

- regular assessment of (newly) available data sources and surveillance approaches is key for modern health information systems (Part 2).

- public health experts await the development of a comprehensive and sustainable EU health information system (Part 3).

The following discourse aims to carve out the conditions that could support the further development and routine implementation of European public health surveillance. The development of routine EU capacities in infectious disease surveillance and the measurement of Healthy Life Years were selected as good practice examples. They were chosen since they evolved, like general public health surveillance, out of project-funded structures. Moreover, EU-level investment was made with the intention to ensure the development of a common European-wide approach and a capacity in measurement and monitoring - a development that is also awaited in general public health surveillance (Part 3 of this thesis).

A short description of the conditions that supported the development of the chosen good practice examples is followed by a discourse about the extent to which comparable supporting conditions are also present in general public health surveillance on EU-level. 


\section{Infectious disease surveillance in the EU}

The free movement of people and goods within the European Union came along with increased cross-border travel and trade activities. Both pose a commonly understandable legitimation for EU-level health security actions, like integrated EU-level actions on infectious disease control and control efforts on other cross-border health threats.

Already in the 1980 s research centres in the EU member states received European Commission (EC) funding to set up networks to discuss EU-level infectious disease surveillance. By this work, a lot of variation in diagnostic criteria and classification systems of infectious diseases in the member states were identified. The national surveillance centres and the EC established an informal advisory body to identify routes for tackling these differences. In 1998, the European Parliament and the Council of the European Union approved to set-up a network for epidemiological surveillance and control.9.10 These developments paved the way for the establishment of more centralised EU-level surveillance structures in form of the European Centre for Disease Prevention and Control (ECDC). ${ }^{10}$ Moreover, and perhaps more importantly, the development of ECDC was triggered by the growing mobility of people and goods and in particular by the emergence of public health crises in the beginning of the century (SARS, bioattacks in the US). ${ }^{10-12}$ These crises made insufficiencies of existing infrastructures and lacking powers to improve commitment for infrastructure development in the member states tangible and supported the development of ECDC.

In close collaboration with health protection agencies in the member states ECDC started to work towards the aim to "identify, assess and communicate current and emerging threats to human health posed by infectious diseases ${ }^{\text {133, }}$. To reach this goal, they focussed on the development of harmonised case definitions, improved early warning systems, common data collection, and enhanced information exchange. ${ }^{9}$ Through the development of ECDC it was possible to integrate various EU-level surveillance networks under a single body, which resulted in the development of a common platform for data management and analysis and improved coherence and sustainability of actions in this field. ${ }^{10}$

In a nutshell, EU-level infectious disease surveillance became more formalised and supportive by pre-established network structures, crises, convincing narratives, and increasing needs to work towards security.

\section{The development of a Healthy Life Years indicator}

The Lisbon Strategy was launched in 2000 with a focus on growth, jobs, and a green and innovative economy. Within the Lisbon Strategy, structural indicators were defined to measure economic and structural progress of EU member states. The indicators were developed to monitor progress within the five Lisbon objectives: (1) employment, (2) innovation, (3) economic reform, (4) social cohesion, (5) environment. To ensure up to date monitoring and benchmarking a necessary 
infrastructure was developed: the indicators were presented within a publicly accessible database and website managed by Eurostat and a regular mechanism for further improvement and adjustment of the selected indicators was installed. ${ }^{15}$

Among these structural indicators, one indicator on health was included. The indicator Healthy Life Years (HLY) - was first part of the development section of the structural indicators and later one of the core structural indicators. ${ }^{15,16}$ With this indicator it was aimed to monitor health trends and health gaps in Europe, ${ }^{15,17}$ but also to monitor health as an economic factor. ${ }^{16}$ Thus, the indicator and its applicability to monitor aspects of quality of life, healthy ageing, employability of older workers, and the functioning of the health care system was directly linked to the Lisbon goal of the EU to further sustainable economic growth.

Pushed by these powerful aims and the already existing groundwork by prior EC co-financed project networks, the further development and routine measurement of this indicator was made possible. To ensure harmonised measurement of HLY across the EU the Minimum European Health Module was included in the yearly survey on European Union Statistics on Income and Living Conditions (EU-SILC) as well as in the Health Information Survey template. Thereby, the indicator was measurable for all EU member states even though the member states do not measure the indicator by themselves.

This example illustrates that by intertwined bottom-up (e.g. groundwork by prior networks) and top-down processes (aim to monitoring central structural indicators) improved European integration of surveillance mechanisms as well as infrastructural development can occur. ${ }^{18,19}$ And even though the inclusion of HLY as one of the central EU indicators was discontinued in 2010 when the European Council displaced the Lisbon Strategy with the Europe 2020 growth strategy, the indicator is still a relevant outcome indicator of the Innovation Union, one of the Europe 2020 flagship initiatives. Under the European Innovation Partnership on Active and Healthy Ageing, a headline target is set to increase the EU average of HLY at birth by two years by 2020. Moreover, the indicator is one of the overarching indicators in the monitoring framework of the EC Social Protection Committee. ${ }^{20}$

\section{Advancing conditions for EU public health surveillance}

The brief description of EU-level infectious disease surveillance and EU-wide measurement of HLY illustrate the conditions relevant for the development of EU surveillance infrastructures and measurement routines. Their development was triggered by certain conditions in the area of (1) infrastructure, (2) data and (3) policy (Figure 3):

- starting by the preparation of infrastructure through networks,

- improved formalisation that lead to increased data harmonisation, the implementation of routine data collection mechanisms and means for maintaining the information base, 
- and finally the occurrence crises (epi-/pandemics), the establishment of convincing narratives, and influences from other policy sectors that triggered necessary actions.

In the following, these conditions are transferred to general public health surveillance including a discussion of current developments in this area.

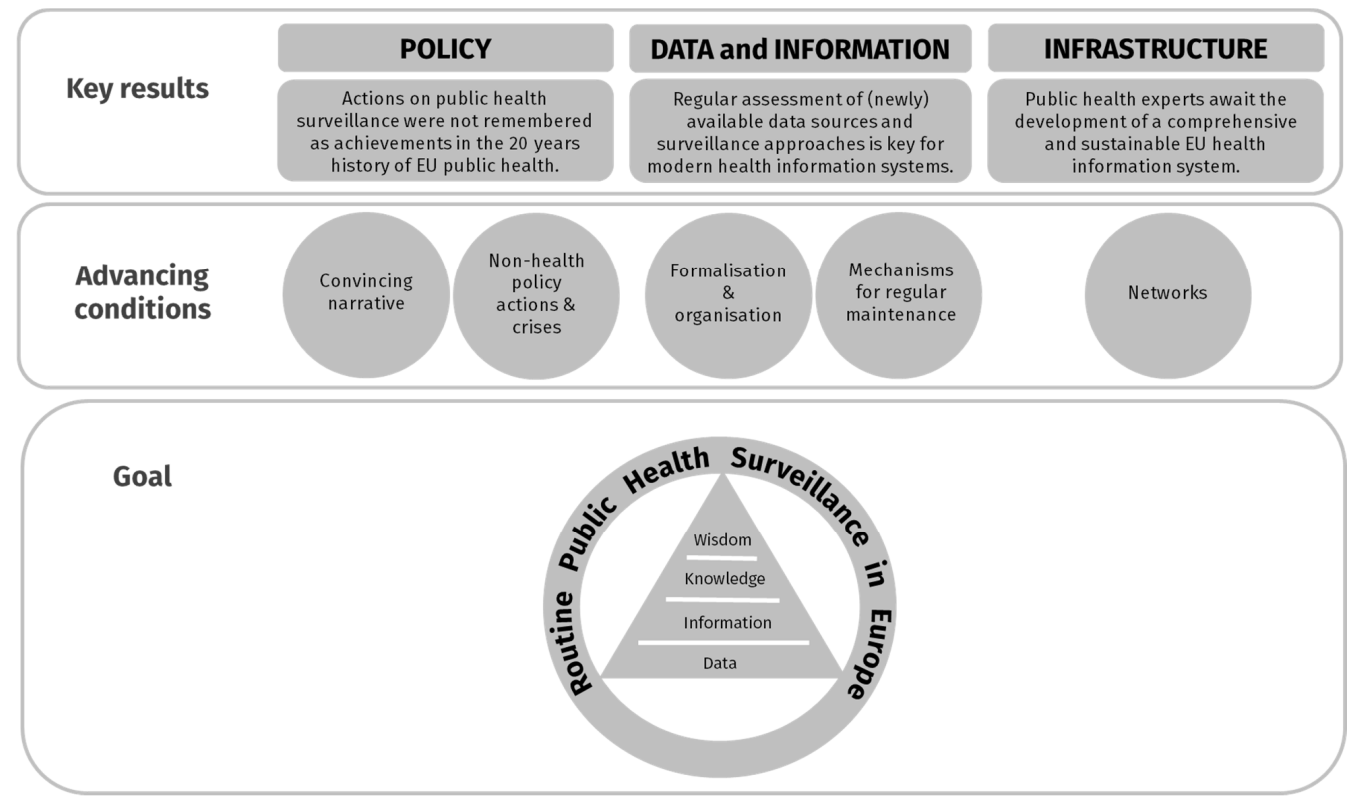

Figure 3 Summary of thesis results and advancing conditions for the development of a comprehensive and sustainable routine public health surveillance system in Europe

\section{Advancing condition: preparation of infrastructure by networks}

EU support and funding lead in case of infectious disease surveillance and the development of HLY measurement to the establishment of EU-wide networks and working groups that prepared and cultivated the field to reach sustainable infrastructures.

This precondition is also fulfilled for general public health surveillance measures. Since the introduction of the EU health mandate it was worked on public health surveillance issues. EU support lead to the development of networks working on public health surveillance indicators, the definition of a relevant and comprehensive indicator set, measurement tools, health information portals, and cooperation mechanisms with international actors like the Organisation for Economic Co-operation and Development (OECD) and the World Health Organization Regional Office for Europe (WHO/EURO). This "gradual expansion"21 of EU public health surveillance seems to be further pursued by keep sticking to the work in networks, expert groups, EC co-funded projects and cooperation with other stakeholders.

Recently, EC'S DG SANTÉ has co-funded BRIDGE Health - a project with the aim "to prepare the transition towards a sustainable and integrated European health information system for both 
public health and research purposes"22. The project comprises all relevant EU health information initiatives from the past and aims to jointly develop an overview on available structures and recommendations for a sustainable EU health information system. This project could mark the next to last step before sustainable EU health information structures are finally established.

Moreover, one can observe advanced cooperation between the various supranational and international public health surveillance actors. Examples are the joint publication of EU public health reports (Health at a Glance series), common data collections (e.g. System of Health Accounts), and joint networks and discussion fora (EU Expert Group on Health Information, WHOEUR European Health Information Initiative). These initiatives have the potential to lead to more harmonised and improved data collections in the future, common public health messages, reduced data-reporting burden for member states, and increased knowledge exchange and capacity-building efforts.

Advancing condition: formalising the organisation of data collection and maintenance of the information base

To further develop and maintain infectious disease surveillance and the measurement of HLY, investments in the organisation of the data collection and data quality played an important role. The ECDC triggered the work on harmonising case definitions, improving early warning systems, developing a common data collection, and enhancing information exchange. ${ }^{9,}{ }^{14}$ By including questions on health in the EU survey on Statistics on Income and Living Conditions (EU-SILC) ${ }^{23}$ the quality and regular measurement of HLY was ensured.

Also general public health surveillance experienced in the past to some extend improvements by formalising data collection aproaches. During a multiphase project, a common public health surveillance indicator set called European Core Heath Indicators (ECHI) and extensive metadata that specified the definition of each indicator, its rationale as well as its measurement and calculation was developed. ${ }^{24}$ With this indicator set and the related metadata it is aimed to support harmonisation of health information, cross-national comparisons and assistance of policy-making across and within the EU. ${ }^{25}$

Legislative formalisation of the data and information base occurred in 2008. A framework regulation on Community Statistics on Public Health and Health and Safety at Work ${ }^{26}$ was adopted which covers the areas: health status and health determinants, health care, causes of death, accidents at work, and occupational diseases and other work-related health problems and illnesses. It is further specified by the implementing regulations on Statistics on Causes of Death ${ }^{27}$ and on Statistics on Accidents at Work ${ }^{28}$ in 2011, by a regulation on the Implementation of the European Health Interview Survey in $2013,{ }^{29}$ and by a regulation on the Implementation of Statistics on Healthcare Expenditure and Financing. ${ }^{30}$ With regard to the availability of the ECHI it 
is expected that the framework regulation offers at least some kind of stability to the ECHI system. ${ }^{31}$

However, an evaluation study on the use and impact of ECHI concluded that improved formalisation and organisation is still needed to cultivate, maintain, and make use of an EU health indicator set like ECHI. According to the evaluation, a governance model that supports the organisation and maintenance of health information should comprise a permanent, institutional mechanism, involvement of public health authorities in the member states, a leading role of the EC, and collaboration with OECD and WHO-EUR. ${ }^{31}$

Such a governance model should also support the monitoring of newly emerging secondary data and monitoring approaches like the ones studied in Part 2 of this thesis. Such a mechanism is especially relevant since the information age will lead to an increase of available data. Computerisation as well as information and communication technologies improve the storability, exchange and processability of information. The term "big data" is closely linked to the information age. Big data can be generated from social networks (human-sourced information), from traditional business systems (process-mediated data), and the internet of things (machinegenerated data). ${ }^{32}$ Already now, several applications of these data sources for public health surveillance are discussed in the literature. ${ }^{33-37}$ Research on its applicability for public health surveillance and its value and utility for EU-wide surveillance needs to be closely monitored. A respective governance model would ensure that regular assessments of new emerging data sources are conducted to adjust and maintain a modern data and information base for EU public health surveillance.

Advancing condition: crises, convincing narratives and pushes by other policy sectors

European public health policy was in history often been shaped by "exogenous shocks that have opened a policy window for public health advocates to extend European powers to new areas of public health concern"21.38 Moreover, an easy understandable narrative, which has the potential to convince a wider audience, can support the development of EU-level surveillance actions. Infectious disease surveillance is an appropriate example to illustrate how crises (anthrax attacks in 2001 in the United States, the international spread of SARS) and pithy phrases like "microbes without borders"11, 39 can boost European integration. With regard to the measurement of HLY, it was shown that interests from other policy sectors respectively, the impact of an EU-wide strategy could support continuous measurement and harmonisation.

At a first sight, comparable supporting conditions like convincing narratives or pushes from other policy sectors seem to be missing in the area of general public health surveillance.

The narrative that summarises the necessity of investments in coordinated and continuous EU public health surveillance is presumably very clear within the public health community and the health division of the EC, but probably less convincing outside of the public health arena and in 
the member states. The narrative embraces the fact that in order to tackle common trends in Europe like

- the tremendous impact of non-communicable diseases and other disabling conditions on population health, ${ }^{40}$

- the persistence of significant (social) health inequalities between EU member states, ${ }^{41,42}$ and

- major health policy differences across Europe ${ }^{43}$

a sustainable EU public health surveillance system is needed. Such a public health surveillance system would support

1. the regular analysis of health inequalities between EU member states.

2. cross-country learning and effective evidence-informed policy making in the member states.

3. priority setting of EU actions.

This narrative might have remained without effect since actions that potentially affect health system organisation are in principal not subject of the EU. Member states probably fear oversimplified benchmarks and rankings conducted by a common public health surveillance system which might open the floodgates to the EU to influence national competencies in health system organisation. ${ }^{21}$ These circumstances might be a reason for the reluctance of EU as well as national policy makers to invest in common public health surveillance measures and indicator harmonisation across member states.

On the contrary, small member states, that usually experience the various international data collection requirements as a relatively high burden, embrace the support of supranational institutions and international organisations. ${ }^{44,45}$ There the narrative for investing in EU public health surveillance structures seems to be more convincing than in the rest of the EU. ${ }^{46}$

Pushes for improved public health surveillance by other (more powerful) EU policy areas than health were rather rare in the past. ${ }^{47}$ However, there are indications for change: ${ }^{48}$

- In 2009, the Commissioner for Health and the Commissioner for Employment, Social Affairs and Equal Opportunities published a joint Commission Communication on reducing health inequalities in the EU. Amongst others a need to improve the data and knowledge base and mechanism for measuring, monitoring and reporting health inequalities was identified. ${ }^{49}$

- A related resolution on reducing health inequalities in the EU was adopted by the European Parliament in 2011 calling of the EC to develop guidelines and to improve public health surveillance measures. ${ }^{50}$

- The Council of the European Union, consisting of representatives from each member state, documented in the Council Conclusions the joint responsibility of member states and the Commission in developing a sustainable public health surveillance infrastructure. ${ }^{8}$ 
Moreover, country-specific recommendations for economic reforms, that are formulated by the EC within the European Semester cycle, have expanded their social scope and are increasingly targeting health care systems of EU member states..51, ${ }^{52}$ For the development of effective, accessible and resilient health systems and the formulation of respective recommendations factual knowledge on the status of population health and health system performance should be the basis..$^{53}$ To support the recognition of factual knowledge on health and long-term care a set of indicators are part of the Indicator Portfolio of the Social Protection Committee (an EU advisory committee for the Employment and Social Affairs Council (EPSCO)) for monitoring social protection and inclusion. ${ }^{20}$ Additionally, the Social Protection Committee's Indicator subgroup is reviewing the quality and availability of various health indicators in order to strengthen the use of the evidence-base of the Social Protection Committee in its activities related to health policy. These efforts and the work Towards a Joint Assessment Framework in the Area of Health have the potential to strengthen the recognition of health information within the European Semester process in particular ${ }^{54}$ and the further development of EU public health surveillance in general.

\section{Recommendations and concluding remarks}

In the past, many investments in terms of project funds and networks have been made by the EC and the member states to advance public health surveillance on EU and member state level. As research has shown in this thesis, these efforts seem to be less recognised compared to other areas where sustainable infrastructure development like the formation of ECDC has taken place (Part 1, Chapter 1).

However, slow advancements appeared to occur in 2015. Eurostat started for instance to exploit the provision of health information within their series Statistics Explained, to work on improved morbidity statistics, ${ }^{55}$ to provide information on health by social determinants (e.g. life expectancy by educational attainment), or to improve the inclusion of health in regular EU surveys like EU-SILC. Moreover, DG SANTÉ improved the former HEIDI tool (now ECHI Data Tool) for presenting data on the European Core Health Indicators.

Nevertheless, the discourse in this thesis showed that the work on EU public health surveillance is still heavily scattered and fragmented - a circumstance that does not promote wide recognition by the interested audience. Therefore, the expectations regarding the outcome of the BRIDGEHealth project, that has the task to prepare the transition towards a sustainable EU health information system, are high. If the project team is successful in formulating a blue print for a sustainable EU health information system that is implemented in a later step, the project could mark the next to last step before sustainable EU health information structures are finally established. In this thesis, we already examined key features of such an EU public health surveillance system. Based on the results it is recommended to design a comprehensive EU 
health information system that covers all core aspects of a health information system (Introduction and Part 3, Chapter 5 of this thesis). Such a system would support the regular analysis of health inequalities between EU member states, cross-country learning and good practice exchange as well as priority setting of EU actions in health.

Carinci expanded the work presented in Part 3 of this thesis with regard to the technical construction of such a system. ${ }^{56}$ To succeed in a final EU public health surveillance system the support and participation of member states as well as a commonly agreed concept for system development of DG SANTÉ, Eurostat and the member states is required. Moreover, a permanent contact point for member states with regard to technical, methodological and organisational questions on data and information requirements is necessary. ${ }^{56}$

A comparison of the current status quo of EU public health surveillance with the conditions that could advance infrastructure development reveals that the investment in project groups and networks seems finally to have a positive influence on EU public health surveillance, even though the time required was long. Their influence supported the progress of EU public health surveillance. However, improved formalisation is required to organise and maintain the data and information base.

Moreover, it is recommended to develop convincing narratives for decision makers on EU as well as on national level to support advancing of EU public health surveillance and to combat the fear of ignoring member states responsibility in health. The importance of cross-country learning for evidence-informed policy-making with regard to health problems that are widely shared across the EU as well as steering of EU actions that support strengthening of EU member states should be the main arguments for joint public health surveillance actions. Such a narrative should be augmented by an EU health information strategy that clearly outlines the processes, objectives, outcomes and cooperation mechanisms of the surveillance approach.

Additionally, the uptake of health information by other non-health policy sectors is beginning to establish on EU-level and seems to become stronger. By linking health information to the formulation of country-specific EU recommendations on health policy and health systems strengthening within the European Semester process, the availability, quality and use of health indicators might experience a new seriousness that demonstrates the need for comprehensive and sustainable EU public health surveillance structures. To assure that the application of health information and the formulation of recommendations on health are based on valid and comparable indicators and newest available evidence, these developments should be organised, steered and channelled by strong EU public health surveillance actors.

It is also recommended that a common EU public health surveillance infrastructure acts as a platform that supports public health surveillance research on newly emerging data and information sources and surveillance approaches as studied in Part 2 of this thesis. The 
opportunities and threats linked to the use of big data streams in official statistics needs to be discussed on EU-level since coordination and cooperation of member states is required to handle these international challenges. Such a conclusion was also drawn by national statistics offices when agreeing on the European Statistical Systems Big Data Roadmap and Action Plan 1.0 in $2014 .{ }^{57}$ So far, this roadmap does not explicitly include a statistical health domain, which might be a symptom of missing public health surveillance infrastructures.

The focus of this thesis was on public health surveillance structures on EU-level. However, for successful development cooperation between EC, OECD and WHO-EUR is required to make use of the respective expertise of each stakeholder and to avoid doubling or tripling of work. Mutual recognition in expert networks like the EU Expert Group on Health Information or the WHO-EUR European Health Information Initiative has the potential to assure cooperation and the development of joint procedures.

The research done in this thesis as well as the discourse provided in the General Discussion illustrate that the time is right for a comprehensive and sustainable public health surveillance infrastructure in Europe - the conditions for advancing public health surveillance in Europe have never been more favourable than now. 


\section{References}

1. Bourguignon U, Groos T, Jaque-Rodney J, Jehles N, Kersting V. Familienhebammen in Mülheim an der Ruhr. Evaluation 2013. Mülheim an der Ruhr: Mülheimer Gesellschaft für soziale Stadtentwicklung mbH Familienhebammen und Netzwerk Frühe Hilfen; 2014.

2. Ostermann E. Zahngesundheit bei Kindern in Köln. Gesundheitsbericht 2012. Köln: Stadt Köln. Gesundheitsamt; 2012.

3. Koch T. Erprobung des Konzeptes "Lokaler Fachplan Gesundheit" in der StädteRegion Aachen. 2015.

http:/ / www.gesunde-staedte-

netzwerk.de/fileadmin/user_upload/Beitrag_3_Thilo_Koch_GSN_HH_160315.pdf (accessed 21.7.2015).

4. Rimpelä A, Caan W, Bremberg S, Wiegersma PW, Wolfe I. Schools and health of children and young people. In: Wolfe I, McKee M, eds. European Child Health Services and Systems Lessons without borders. Berkshire: Open University Press; 2013: 145-82.

5. Verschuuren M, Kramers P, Gudfinnsdottir GK, Aromaa A. Providing a solid evidence base for policy makers: ECHI initiative. Eurohealth 2011; 16(3): 4-7.

6. Aromaa A. Implementation of joint health indicators in Europe - Joint Action for ECHIM. Arpo Aromaa on behalf of the ECHIM core group. Archives of public health 2012; 70(1): 22.

7. Kilpeläinen K, Tuomi-Nikula A, Thelen J, Gissler M, Sihvonen AP, Kramers P, Aromaa A. Health indicators in Europe: availability and data needs. Eur J Public Health 2012; 22(5): 716-21.

8. Council of the European Union. Council Conclusions on the "Reflection process on modern, responsive and sustainable health systems". Brussels: Council of the European Union; 2013.

9. Greer S, Fahy N, Elliott HA, Wismar M, Jarman H, W. P. Everything you always wanted to know about European Union health policies but were afraid to ask. Copenhagen: World Health Organization Regional Office for Europe; 2014.

10. Liverani M, Coker R. Protecting Europe from diseases: from the international sanitary conferences to the ECDC. J Health Polit Policy Law 2012; 37(6): 915-34.

11. Greer SL, Matzke M. Bacteria without Borders: Communicable Disease Politics in Europe. J Health Polit Policy Law 2012; 37(6): 887-914.

12. Elliott H. European Union health information infrastructure and policy. In: Greer SL, Kurzer $\mathrm{P}$, eds. European Union Public Health Policy Regional and global trends. Abingdon, UK: Routledge; 2013.

13. European Centre for Disease Prevention and Control. About us. http:/ / ecdc.europa.eu/en/aboutus/Pages/aboutus.aspx (accessed July 2015). 
14. European Parliament, Council of the European Union. Regulation (EC) No 851/2004 of the European Parliament and the Council on establishing European centre for disease prevention and control. Official Journal of the European Union 2004; L142: 1-11.

15. Commission of the European Communities. Communication from the Commission: structural indicators (COM(2003) 585 final). Brussels: European Commission; 2003.

16. European Commission, DG Health and Food Safety. Healthy Life Years. www.ec.europa.eu/health/indicators/healthy_life_years/index_en.htm_accessed 20.08.2015).

17. Robine JM, Cambois E, Nusselder W, Jeune B, Oyen HV, Jagger C, team JE. The joint action on healthy life years (JA: EHLEIS). Archives of public health 2013; 71(1): 2.

18. Lamping W, Steffen M. European Union and Health Policy: The "Chaordic" Dynamics of Integration. Soc Sci Quart 2009; 90(5): 1361-79.

19. Princen $S$, Rhinard M. Crashing and creeping: agenda-setting dynamics in the European Union. Journal of European Public Policy 2006; 13(7): 1119-32.

20. Social Protection Committee Indicators Subgroup. Portfolio of EU Social Indicators for the Monitoring of Progress Towards the EU Objectives for Social Protection and Social Inclusion. Luxembourg: Publications Office of the European Union; 2015.

21. Briatte F. The politics of European public health data. In: Greer SL, Kurzer P, eds. European Union Public Health Policy Regional and global trends. Abingdon, UK: Routledge; 2013: 5163.

22. BRIDGE Health. BRIDGE Health Leafelet. Belgium; 2015.

23. European Parliament, Council of the European Union. Regulation (EC) No 1177/2003 of the European Parliament and of the Council of 16 June 2003 concerning Community statistics on income and living conditions (EU-SILC). Official Journal of the European Union 2003; L 165: 1-9.

24. Joint Action for ECHIM. ECHI Indicator Development and Documentation. Joint Action for ECHIM Final Report Part II. Bilthoven: National Institute for Public Health and the Environmetn (RIVM); 2012.

25. Verschuuren M, Gissler M, Kilpelainen K, Tuomi-Nikula A, Sihvonen AP, Thelen J, et al. Public health indicators for the EU: the joint action for ECHIM (European Community Health Indicators \& Monitoring). Archives of public health 2013; 71(1): 12.

26. European Parliament and the Council. Regulation (EC) No 1338/2008 on community statistics on public health and health and safety at work. Official Journal of the European Union 2008; L354: 70-81.

27. European Parliament, Council of the European Union. COMMISSION REGULATION (EU) No 328/2011 of 5 April 2011 implementing Regulation (EC) No 1338/2008 of the European Parliament and of the Council on Community statistics on public health and health and 
safety at work, as regards statistics on causes of death. Official Journal of the European Union 2011; L 90: 22-4.

28. European Parliament, Council of the European Union. COMMISSION REGULATION (EU) No 349/2011 of 11 April 2011 implementing Regulation (EC) No 1338/2008 of the European Parliament and of the Council on Community statistics on public health and health and safety at work, as regards statistics on accidents at work. Official Journal of the European Union 2011; L 97: 3-8.

29. European Parliament, Council of the European Union. Commission Regulation on implementing Regulation (EC) No 1338/2008 of the European Parliament and of the Council on Community statistics on public health and health and safety at work, as regards statistics based on the European Health Interview Survey (EHIS). In: European Union, editor. 141/2013. Official Journal of the European Union; 2013.

30. European Parliament, Council of the European Union. COMMISSION REGULATION (EU) 2015/359 of 4 March 2015 implementing Regulation (EC) No 1338/2008 of the European Parliament and of the Council as regards statistics on healthcare expenditure and financing. Official Journal of the European Union 2015; L 62: 6-15.

31. Public Health Evaluation and Impact Assessment Consortium (PHEIAC). Evaluation of the use and Impact of the European Community Health Indicators ECHI by Member States. Brussels: European Commission; 2013.

32. United Nations Economic Commission for Europe (UNECE). Big data in official statistics. Classification of types of big data. 2013.

http://www1.unece.org/stat/platform/display/bigdata/Big+Data+in+Official+Statistics (accessed February 2016).

33. Paul MM, Greene CM, Newton-Dame R, Thorpe LE, Perlman SE, McVeigh KH, Gourevitch MN. The state of population health surveillance using electronic health records: a narrative review. Population health management 2015; 18(3): 209-16.

34. Bartlett C, Wurtz R. Twitter and public health. Journal of public health management and practice 2015; 21(4): 375-83.

35. Denecke K, Krieck M, Otrusina L, Smrz P, Dolog P, Nejdl W, Velasco E. How to exploit twitter for public health monitoring? Methods of information in medicine 2013; 52(4): 326-39.

36. Adler AJ, Eames KT, Funk S, Edmunds WJ. Incidence and risk factors for influenza-likeillness in the UK: online surveillance using Flusurvey. BMC Infectious Diseases 2014; 14(1): 1-8.

37. Paul MJ, Sarker A, Brownstein JS, Nikfarjam A, Scotch M, Smith KL, Gonzalez G. Social Media Mining for Public Health Monitoring and Surveillance. Pacific Symposium on Biocomputing Pacific Symposium on Biocomputing 2016; 21: 468-79. 
38. McKee M, Hervey T, Gilmore A. Public health policies. In: Mossialos E, Permanand G, Baeten $\mathrm{R}$, Hervey TK, eds. Health Systems Governance in Europe. Cambridge: Cambridge University Press; 2010: 231-81.

39. European Centre for Disease Prevention and Control. Microbes without borders: Key facts on infectious diseases in Europe. Highlights from ECDC's annual report on infectious diseases in Europe. Stockholm: European Centre for Disease Prevention and Control; 2007.

40. Institute for Health Metrics and Evaluation. The Global Burden of Disease: Generating Evidence, Guiding Policy - European Union and European Free Trade Association Regional Edition. Seattle, WA: IHME; 2013.

41. Mackenbach JP. Health Inequalities: Europe in Profile. London: Department of Health; 2006.

42. European Commission Directorate-General for Health and Consumers. Health inequalities in the EU - Final report of a consortium. Consortium lead: Sir Michael Marmot: European Union; 2013.

43. Mackenbach JP, McKee M. A comparative analysis of health policy performance in 43 European countries. Eur J Public Health 2013; 23(2): 195-201.

44. World Health Organization Regional Office for Europe. Meeting report of the first highlevel meeting of small countries. Implementing the health 2020 vision in countries with small populations. San Marino, 3-4 July 2014. Copenhagen: World Health Organization Regional Office for Europe; 2014.

45. Azzopardi-Muscat N, Thyssen SG, Stoner D, Calleja N. Factors affecting data availability in the European region - does population size matter. 8th European Public Health Conference. Milan: European Journal of Public Health; 2015. p. 225.

46. Azzopardi-Muscat N, Sorensen K, Aluttis C, Pace R, Brand H. Europeanisation of health systems: a qualitative study of domestic actors in a small state. BMC public health 2016; 16(1): 334.

47. Rosenkotter N, Brand H, McKee M, Riley N, Verma A, Verschuuren M. The realisation of a European health information system--time to get the politicians involved. Eur J Public Health 2014; 24(2): 184-5.

48. Rosenkötter N, van Bon-Martens M. Public health monitoring and reporting: maintaining and improving the evidence base. Eurohealth 2015; 21(1): 17-20.

49. Commission of the European Communities. Solidarity in Health: Reducing Health Inequalities in the EU. COM(2009)567 Brussles: Commission of the European Communities; 2009.

50. European Parliament. European Parliament Resolution of 8 March 2011 on Reducing Health Inequalities in the EU (2010/2089/(INI)). Strasbourg: European Parliament; 2011. 
51. Azzopardi-Muscat N, Clemens T, Stoner D, Brand H. EU Country Specific Recommendations for health systems in the European Semester process: Trends, discourse and predictors. Health Policy 2015; 119(3): 375-83.

52. Zeitlin J, Vanhercke B. Economic governance in Europe 2020: socialising the European Semester against the odds? In: Natali D, Vanhercke B, eds. Social Policy in the European Union: State of Play 2015. Brussels: European Trade Union Institute,European Social Observatory; 2015: 65-95.

53. European Commission. Communication from the Commission on effective, accessible and resilient health systems COM(2015) 215 final. Brussels: European Commission; 2014.

54. Social Protection Committee Indicators Subgroup. Towards a Joint Assessment Framework in the Area of Health. Work in progress: 2014 update. Brussels: Social Protection Committee Indicators Subgroup; 2015.

55. European Commission. Morbidity Statistics in the EU - report on pilot studies. Luxembourg: Publications Office of the European Union; 2014.

56. Carinci F. Essential levels of health information in Europe: an action plan for a coherent and sustainable infrastructure. Health Policy 2015; 119(4): 530-8.

57. Zwick M. Big data in der amtlichen Statistik. Bundesgesundheitsblatt, Gesundheitsforschung, Gesundheitsschutz 2015; 58: 838-43. 


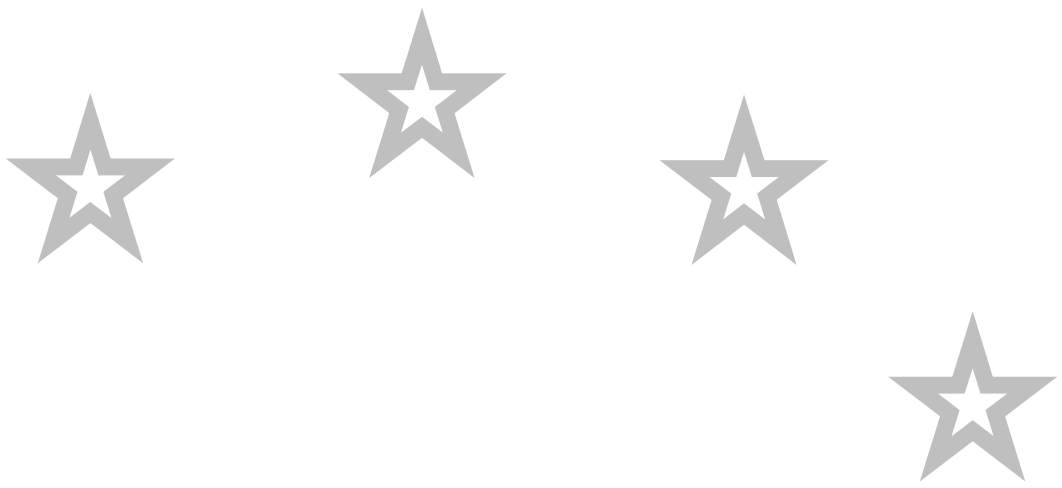

\section{Valorisation}
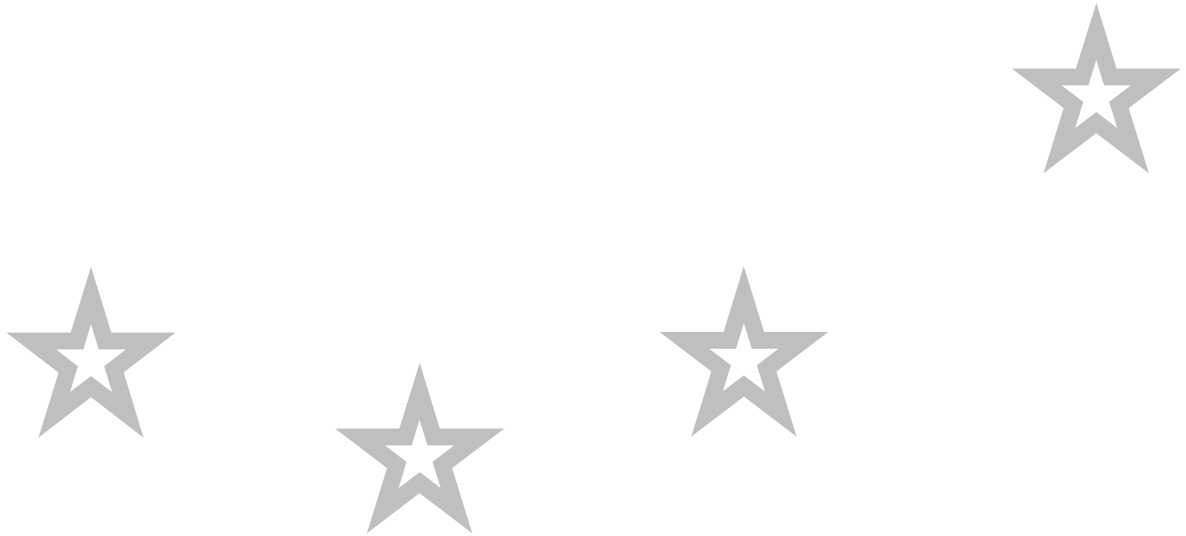


\section{Valorisation}

Public health surveillance is considered as an Essential Public Health Operation ${ }^{1}$ since it enables governments and other stakeholders to act in an evidence-informed manner when identifying health needs, adjusting (health) policy actions and allocating resources, when reacting on certain health threats, or when assessing progress with regard to certain health targets. This dissertation, by providing evidence on conditions to advance public health surveillance, proposes insights for the development of modern and resilient public health surveillance systems in general and on European Union (EU) level in particular. The valorisation activities applied to the results in this dissertation, intended to make the knowledge suitable and available for social use and the translation into further developmental processes.

The valorisation chapter follows the same structure as the dissertation:

- Assessing the status quo of EU health policy and EU public health surveillance (Part 1)

- "Off-label-use" of data for information and knowledge generation (Part 2)

- Developing an EU public health surveillance infrastructure (Part 3)

\section{Part 1 - Assessing the status quo of EU health policy and EU public health surveillance}

The results of the study on the "Twentieth anniversary of the European Union health mandate: taking stock of perceived achievements, failures and missed opportunities" were discussed in a broader policy perspective during a distinct conference on "European Public Health. 20 years of the Maastricht Treaty - Turning past experiences into visions" (Maastricht, The Netherlands, May 2013) ${ }^{a}$. During this conference international academics, representatives from the European institutions as well as national and regional decision makers took stock of past EU actions related to health and discussed how recent and future challenges should be tackled in Europe. Nearly one hundred participants from 28 countries took part in the conference discussions.

Moreover, the authors of the research presented in Chapter 1 were invited to write a viewpoint paper in the European Journal of Public Health. The journals' viewpoint papers consist of contrasting pieces of general interest to stimulate discussion among public health researchers and policy makers. The authors of the research provided in this dissertation took a positive perspective. They valued the achievements made in EU health policy so far, but also called “... to increase the political power of the health dossier even further to make health a central component within the European Commission. (...) Moreover, EU policies continuously need to be informed by science and evidence building on relevant, timely and comparable data as the monitoring systems

\footnotetext{
${ }^{a}$ More information: https://inthealth.mumc.maastrichtuniversity.nl/conference-european-public-health

166 Valorisation
} 
help to push European institutions as well as Member States to improve health for all."2 The paper made a case for strengthening public health surveillance as well as for including health in a new EU narrative to reach out to the European citizens. ${ }^{2}$ Scott Greer, who argued that the Eurozone and the internal market overshadowed the health effects of the Maastricht Treaty, provided the contrasting piece. ${ }^{3}$ He concluded that public health advocates should "(...) bring public health expertise and values into the detailed mechanisms of [EU] fiscal governance and policy-especially by making a serious evidence-based case for investment in health." ${ }^{3}$

\section{Brief summary of the conference on "European Public Health. 20 years of the Maastricht Treaty - Turning past experiences into visions"}

The first part of the conference was dedicated to review past developments. The reflection and discussion was triggered by the results of the research presented in Part 1 of this dissertation and by presentations on European Commission (EC) health activities, European integration and EU health policy, the convergence in European health systems and their common needs as well as the role of EU agencies in public health. The verdict of the participants was clear: the glass is half-full, and if filling it up further; more could be achieved at EU-level to ensure a high level of health protection across Europe and to retain the set of shared values of European health systems: universality, access to good quality care, equity, and solidarity on health systems.

The contributions in the second part of the conference addressed the future of EU health policies. During the discussion, several aspects were recurrently emphasised. One of them, and most important in the context of this dissertation: EU policies influencing health should be better informed by science and evidence. To safeguard health interests, it was deemed relevant, that those accountable for health at the EU and national level are part in the debate on EU health policy.

The conference results were disseminated in a press release "Experts' verdict on 20 year EU health mandate: success so far, expansion needed". (http://www.ehfg.org/maastrich-event.html)

\section{Part 2 - "Off-label-use" of data for information and knowledge generation}

The research conducted in Part 2 of this dissertation had the intention to provide insights regarding the applicability and potential of non-traditional data sources for public health surveillance. The scholarly work on syndromic surveillance - conducted in Chapter 2 and Chapter 3 - was part of an EU Health programme action called SIDARTHa (European Emergency Data-based Syndromic Surveillance System) and made use of emergency medical care data for ad-hoc surveillance purposes. The research informed the SIDARTHa project partners when establishing and fine-tuning their routine syndromic surveillance system, as it was the case in the Autonomous Region of Cantabria in Spain. ${ }^{4}$ Moreover, the research supported the development of a concept 
for syndromic surveillance based on routine emergency data sources. ${ }^{5}$ The results were also taken up in another EU Health programme action called TRIPLE S-AGE (Syndromic Surveillance Survey - Assessment towards Guidelines for Europe), which used amongst others the results of SIDARTHa for the development of European Guidelines for Syndromic Surveillance Systems. ${ }^{6}$

The results of the research conducted in Chapter 4 delivered a more detailed analysis of schoolentry screening data and the utilisation of health services by children in North-Rhine Westphalia, Germany. These results were also applied in a North-Rhine Westphalian public health report to explain patterns and social-determined differences in child health care utilisation to the public and representatives of the regional parliament.

\section{Part 3 - Developing an EU public health surveillance infrastructure}

To make the results of the research conducted in Chapter 5 suitable and available for social use and translation into further developmental processes we developed an infographic (see Figure 1). This infographic summarises the desired key features of an EU health information system in a comprehensible way. Information on the conducted research, the 93 individual statements on the wanted characteristics of an EU health information system as well as the infographic are publicly accessible via www.healthinfo-concept.info. Moreover, the results were disseminated at the European Public Health Conference in 2013. They provided input for a round table discussion on a "European Health Information System: Steps from idea to reality". In this session representatives of the European Commission, the World Health Organization Regional Office for Europe, the Organisation for Economic Co-operation and Development and the European Public Health Association explored how the diverse European health information initiatives could be integrated to create an infrastructure that is comprehensive, functional and sustainable. The results of this round table discussion were shared with the research, policy and practice community in a Letter to the Editor of the European Journal of Public Health. ${ }^{8}$ Finally, it will be reflected on the results of this scholarly work within a book on population health monitoring (expected date of publication: 2017/2018), which makes the knowledge accessible for education and practice. 


\section{TOP Key Features of an EU Health Information System}

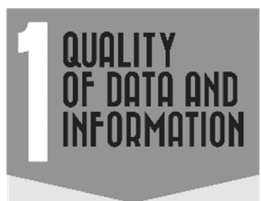

"An EU Health Information System should be reliable and be based on reliable data and information."

"An EU Health Information System should provide comparable information (e.g. between countries, over time, based on standard methodology)."

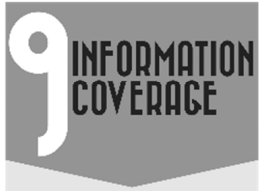

"An EU Health Information System should provide information to assess socio-economic health inequalities."

"An EU Health Information System should provide information on the EU level and the EU/EEA member states."

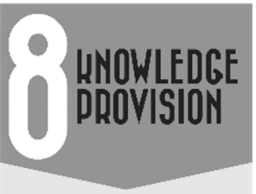

"An EU Health Information System should include the EU dimension of health $(\ldots)^{\prime \prime}$

"An EU Health Information System should contain recommendations based on the analyses of policy relevant health indicators."

This info sheet is based on a concept mapping study that summarises opinions and valuations of public health practitioners an policy makers in Europe.

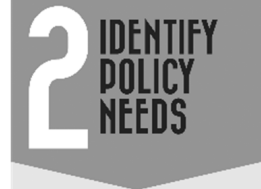

"An EU Health Information System should have a clear added value for Member States and should support their needs."

"An EU Health Information System should be realized in consultation with European policy makers and relevant stakeholders."

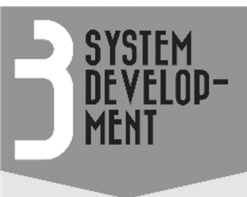

"An EU Health Information System should be based on a long-term health information strategy.

"An EU Health Information System should support and encourage harmonisation of data collection, definitions and indicator development between Eurostat, WHO, and OECD (...)."

An EU Health Information System
is relevant because ...
EU countries have similar
health problems.
there is a growing interest in
cross-national learning to tackle
health problems and develop
effectiv policies.
it enhances co-operation across
Member States.
it supports EU policy preparation.
(e.g. within the European Semester)
It is a prerequisite for good and
transparent governance.

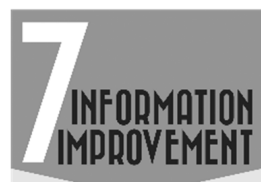

"An EU Health Information System should highlight information gaps."

“An EU Health Information System should provide the possibility to link health data with indica-

tors from other fields, e.g. finance, economic situation, climate, environment factors."

More information on www.healthinfo-concept.info and in Rosenkötter N, Achterberg PW, van Bon-Martens $\mathrm{MJ} \mathrm{H}$, Michelsen $K$, van Oers HAM, Brand $\mathrm{H}$ :

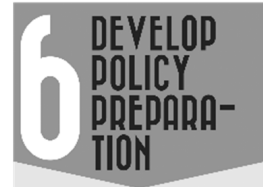

"An EU Health Information System should have a formal position in the EU policy making cycle (at least results of the system) and be timely and transparently connected to it."

"An EU Health Information System should engage with different stakeholders to ensure a high degree of acceptability."

Key features of an EU health information system: a concept mapping study. European Journal of Public Health 2015. doi: 10.1093/ eurpub/ckv075

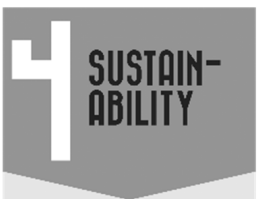

"An EU Health Information System should be permanent and sustainable in terms of content, infrastructure and resources."

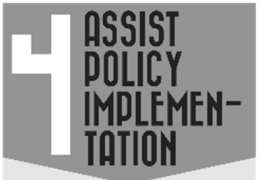

"An EU Health Information System should assist policy makers in setting priorities in the field of public health and defining policies and programmes (...)."

"An EU Health Information System should serve as a basis for developing and monitoring the EU Health Strategy and ensure transparency on progress towards health targets."

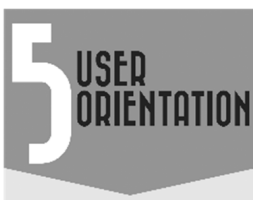

"An EU Health Information System should be based on a conceptual model or framework that includes all relevant public health areas."

"An EU Health Information System should be the "go to" place for health statistics in Europe that provides information that is undoubtedly state of the art."

Contact: Nicole.Rosenkoetter@ maastrichtuniversity.nl

Figure 1 Infographic on the key features of an EU health information system (Chapter 5 of this dissertation) 


\section{Conclusion}

This chapter describes how various channels have been used to share and discuss the results of this dissertation with public health actors and decision makers. We conducted specific conferences and conference sessions, transferred the results into further projects, guidelines and public health reports, and translated them into easy accessible formats like infographics or brief contributions in public health journals.

The General Discussion of this dissertation provided - based on the results of this dissertation a discourse on the conditions that advance public health surveillance in Europe. Joint networks, further formalisation of the data collection on EU-level, and pushes by non-health policy actions were regarded relevant and a supportive atmosphere for advancing public health surveillance in Europe was identified at the time of writing. The results of this dissertation have - through the wide dissemination activities - provided a useful contribution to this development and have the potential to inform the future development of routine European public health surveillance capacities. 


\section{References}

1. World Health Organization - Regional Office for Europe, Regional Committee for Europe. European Action Plan for Strengthening Public Health Capacities and Services. Copenhagen: World Health Organization, Regional Office for Europe; 2012.

2. Sørensen K, Clemens T, Rosenkötter N. The EU's health mandate after 20 years: the glass is half full. European Journal of Public Health 2013. 23(6):906-907.

3. Greer S. Glass half empty: the Eurozone and internal market overshadow the health effects of Maastricht. European Journal of Public Health 2013. 23(6):907-908.

4. Schrell S, Ziemann A, Garcia-Castrillo Riesgo L, Rosenkötter N, Llorca J, Popa D, Krafft T,. Local implementation of a syndromic influenza surveillance system using emergency department data in Santander, Spain. Journal of Public Health 2013. 35(3):397-403.

5. Ziemann A, Rosenkötter N, Garcia-Riesgo L, Schrell S, Kauhl B, Vergeiner G, Fischer M, Lippert FK, Krämer A, Brand H, Krafft T. A concept for routine emergency-care data-based syndromic surveillance in Europe. Epidemiology \& Infection 2014. 142:2433-2446.

6. Hulth A. First European Guidelines on syndromic surveillance in human and animal health published. Eurosurveillance 2014. 19(41):pii20927.

7. Ministerium für Gesundheit, Emanzipation, Pflege und Alter (MGEPA). Landesgesundheitsbericht 2015. Informationen zur Entwicklung von Gesundheit und Krankheit in Nordrhein-Westfalen. Düsseldorf: MGEPA, 2016.

8. Rosenkötter R, Brand H, McKee M, Riley N, Verma A, Verschuuren M. The realisation of a European health information system - time to get the politicians involved. European Journal of Public Health 2014. 24(2):184-185. 



\section{Summary \\ Zusammenfassung}




\section{Summary}

The research conducted in this dissertation aimed to identify conditions relevant to advance public health surveillance in Europe. This was done within three research perspectives and by applying qualitative as well as quantitative research approaches. In Part 1 of this dissertation the status quo of European Union (EU) public health policy and EU public health surveillance efforts is explored. Part 2 is focussed on data and information sources that are not commonly used for general public health surveillance. Part 3 is focussed on the necessary key features of a potential EU health information system. A General Discussion about the conditions that could support the development of advanced European public health surveillance capacities closes this dissertation.

The research revealed some structural weaknesses of European public health surveillance:

- part 1: despite several EU funded projects, networks and actions that aimed to develop capacities for EU public health surveillance, respective elements seemed to be less prominent and influential. The status quo of EU public health surveillance is rather weak.

- part 2: public health surveillance can make use of various data sources for information and knowledge generation. The emergence of novel data sources and monitoring approaches for public health surveillance is triggered by technological advances in data retrieval and data analysis, and by learning from examples in other countries or settings. Continuous monitoring of potential novel data sources and monitoring approaches for public health surveillance as well as the assessment of their relevance is a key component of public health surveillance systems.

- part 3: public health experts await the development of a comprehensive and sustainable EU health information system that covers all aspects of information systems as indicated in the Data-Information-Knowledge-Wisdom-hierarchy.

Based on these results, the General Discussion of this dissertation aimed to carve out the conditions that could support the further development and implementation of EU public health surveillance. The history of the implementation of routine EU capacities in infectious disease surveillance and the measurement of Healthy Life Years were selected as good practice examples. Their development was triggered by certain conditions in the area of (1) infrastructure, (2) data and (3) policy actions:

1. starting by the preparation of infrastructure through networks,

2. improved formalisation of the data collection, the implementation of routine data collection mechanisms and means for maintaining the information base,

3. and finally the occurrence of crises, the establishment of convincing narratives, and influences from other policy sectors that triggered necessary actions. 
To what extent are these supporting conditions present in general EU public health surveillance?

EU public health surveillance experienced to a large extent preparatory work through networks. EU support led to the development of networks working for example on the definition of a comprehensive health indicator set or - lately - a project to prepare the transition towards a sustainable and integrated European health information system for both public health and research purposes. This project comprises many past EU health information initiatives and can mark the next to last step before a sustainable EU health information system is finally established.

General EU public health surveillance experienced also to some extent improvements by formalised data collection approaches. The definition of a common public health surveillance indicator set called European Core Heath Indicators (ECHI) and the adoption of a framework regulation on Community Statistics on Public Health and Health and Safety at Work are two examples. However, to assure the availability of high quality data and health indicators further formalisation efforts and an improved organisation of the data collection are needed. This could be achieved by a permanent, institutional mechanism for EU public health surveillance, involvement of public health authorities in the member states, a leading role of the European Commission (EC), and collaboration with the OECD and the World Health Organization Regional Office for Europe. Such a governance model should also support the assessment of newly emerging secondary data and information sources and monitoring approaches.

At a first sight, the third condition that comprises convincing narratives or pushes from other policy sectors seems to be missing in the area of general EU public health surveillance. The narrative that summarises the necessity for the development of and investment in coordinated and routine EU public health surveillance activities is presumably very clear within the public health community and the health division of the EC, but this narrative was in the past less convincing outside the public health arena and in the member states. However, with regard to pushes by other policy sectors indications for change become visible. These can be derived from joint communication papers of different EC directorates and statements from the European Parliament and the Council of the European Union as well as the uptake of health information within the European Semester process. These developments have the potential to strengthen the need for and the relevance of EU public health surveillance.

The research done in this thesis as well as the discourse provided in the General Discussion illustrate that the time is right for a comprehensive and sustainable public health surveillance infrastructure in Europe - the conditions for advancing public health surveillance in Europe have never been more favourable than now. 


\section{Zusammenfassung}

Die Arbeiten, die im Rahmen dieser Dissertation durchgeführt wurden, sollten Bedingungen für eine Weiterentwicklung der Gesundheitsberichterstattung auf europäischer Ebene identifizieren. Dazu wurden drei Forschungsperspektiven eingenommen und sowohl qualitative als auch quantitativen Forschungsmethoden angewandt. Im Teil 1 wurde der Status quo von Public Health Maßnahmen der Europäischen Union (EU) und der europäischen Gesundheitsberichterstattung untersucht. Im Teil 2 standen verschiedene Datenquellen und Monitoringansätze, die nicht routinemäßig für die europäische Gesundheitsberichterstattung genutzt werden, im Fokus der Analysen. Im dritten Teil der Dissertation wurden die Schlüsselfunktionen eines potentiellen EU Gesundheitsinformationssystems ermittelt. Die Dissertation endet mit einer allgemeinen Diskussion notwendiger Bedingungen für die Weiterentwicklung der EU Gesundheitsberichterstattung.

Die durchgeführten Studien machten strukturelle Schwächen der Gesundheitsberichterstattung auf europäischer Ebene sichtbar:

- Teil 1: Trotz einer Vielzahl von EU geförderten Maßnahmen, Projekten und Netzwerken zur Entwicklung von infrastrukturellen Elementen der Gesundheitsberichterstattung auf EUEbene, scheint deren Bekanntheit und Einfluss eher gering. Der Status quo einer europäischen Gesundheitsberichterstattung ist eher schwach ausgeprägt.

- Teil 2: Die Gesundheitsberichterstattung kann verschiedenen Datenquellen für die Generierung von Informationen und Wissen nutzen. Die Verfügbarkeit neuer Datenquellen und neuer Monitoringansätze für die Gesundheitsberichterstattung verändert sich durch verbesserte technologische Möglichkeiten und durch den Erfahrungsaustausch mit anderen Ländern oder anderen Settings. Eine regelmäßige Bewertung von (neuen) Datenquellen und Monitoringansätzen für die Gesundheitsberichterstattung sollte eine Kernaufgabe von Gesundheitsinformationssystemen darstellen.

- Teil 3: Public Health Experten erwarten, dass ein umfassendes und nachhaltiges EU Gesundheitsinformationssystem entwickelt wird, welches alle Elemente von Informationssystemen entsprechend der Data-Information-Knowledge-WisdomHierarchie beinhaltet.

Auf Grundlage dieser Ergebnisse wurden im Rahmen der allgemeinen Diskussion Bedingungen identifiziert, die die weitere Entwicklung und Implementierung einer Gesundheitsberichterstattung auf EU-Ebene fördern könnten. Die Entwicklung einer EU-weiten Surveillance von Infektionserkrankungen sowie einer regelmäßigen Erfassung und Analyse der Gesunden Lebensjahre wurden als Good-Practice Beispiele ausgewählt. Ihre Entwicklung wurde durch bestimmte Bedingungen in den Bereichen (1) Infrastruktur, (2) Daten und (3) durch politische Maßnahmen gefördert: 
1. Die Entwicklung begann mit der Vorbereitung von geeigneten Infrastrukturen im Rahmen von Netzwerken,

2. einer Formalisierung der Datensammlung, der Implementierung von Routinen zur Datenerhebung und Mitteln für die Instandhaltung und Weiterentwicklung der Daten- und Informationsbasis,

3. und letztlich dem Auftreten von Krisen, der Entwicklung überzeugender Erklärungen für die Notwendigkeit von europäischen Surveillancestrukturen sowie Anstöße zur Entwicklung entsprechender Strukturen durch andere Ressorts.

In welchem Ausmaß sind diese fördernden Bedingungen auch im Bereich der allgemeinen europäischen Gesundheitsberichterstattung vorhanden?

Elemente der allgemeinen europäischen Gesundheitsberichterstattung wurden in der Vergangenheit ebenfalls im Rahmen von Netzwerken entwickelt. Finanzielle Förderungen der EU führten beispielsweise zu der Entwicklung eines umfassenden europäischen Indikatorensatzes (Europäische Gesundheitsindikatoren (ECHI)). In jüngerer Vergangenheit wurde zudem ein Projekt bewilligt, dass die Entwicklung eines nachhaltigen und integrierten EU Gesundheitsinformationssystems für Public Health und Forschungszwecke vorbereiten soll. In diesem Projekt wurden frühere europäische Projekte und Maßnahmen zur Entwicklung einer europäischen Gesundheitsberichterstattung einbezogen. Dieses Projekt könnte ein vorletzter Schritt sein, bevor ein nachhaltiges europäisches Gesundheitsinformationssystem Realität wird.

Die allgemeine europäische Gesundheitsberichterstattung wurde zu einem gewissen Grad auch durch eine Formalisierung der Datensammlung und Datenerhebung gestärkt. Die Definition Europäischer Gesundheitsindikatoren und die Verabschiedung einer Rahmenverordnung zu Gemeinschaftsstatistiken über öffentliche Gesundheit und über Gesundheitsschutz und Sicherheit am Arbeitsplatz sind zwei Beispiele. Um jedoch in einem größeren Umfang qualitativ hochwertige Daten und Gesundheitsindikatoren auf europäischer Ebene verfügbar zu machen, sind weitergehende Maßnahmen der Formalisierung und der Organisation der Datensammlung und Datenerhebung notwendig. Diese Maßnahmen könnten durch eine Institutionalisierung der europäischen Gesundheitsberichterstattung, die Einbeziehung von Public Health Instituten in den Mitgliedsstaaten, eine führende Rolle der Europäischen Kommission sowie Kooperationen mit der OECD und dem Regionalbüro Europa der Weltgesundheitsorganisation unterstützt werden. Hierbei sollte auch die regelmäßige Bewertung neuer Datenquellen und Monitoringansätze für die Gesundheitsberichterstattung einbezogen werden.

Elemente der dritten Bedingung, die die Entwicklung überzeugender Erklärungsansätze oder Anstöße durch andere politische Ressorts umfasst, scheinen auf den ersten Blick im Bereich der allgemeinen europäischen Gesundheitsberichterstattung zu fehlen. Die Erklärungsansätze für die Entwicklung und Finanzierung einer europäischen Gesundheitsberichterstattung sind unter den 
Public Health Akteuren und innerhalb der Gesundheitsabteilung der Europäischen Kommission vermutlich offensichtlich, waren aber in der Vergangenheit weniger überzeugend in Public Health fremden Ressorts und in den Mitgliedsstaaten. Es gibt jedoch Hinweise für ein zunehmendes Interesse anderer Ressorts an einer europäischen Gesundheitsberichterstattung. Diese Hinweise können aus gemeinsamen Mitteilungen verschiedener Direktorate der Europäischen Kommission und Stellungnahmen des Europäischen Parlaments und des Europäischen Rats sowie der Nutzung von Gesundheitsinformationen im Rahmen des Europäischen Semesters entnommen werden. Diese Entwicklungen haben das Potential das Bewusstsein für und die Relevanz der europäische Gesundheitsberichterstattung zu stärken.

Die Arbeiten, die im Rahmen dieser Dissertation durchgeführt wurden sowie der Diskurs der im Rahmen der allgemeinen Diskussion präsentiert wurde, unterstreichen, dass der Zeitpunkt für die Entwicklung einer umfassenden und nachhaltigen europäischen Gesundheitsberichterstattung erreicht ist - die Bedingungen für die Weiterentwicklung der europäischen Gesundheitsberichterstattung waren nie besser als heute. 



\section{Acknowledgements}




\section{Acknowledgements}

After my first vocational training and working experiences as medical laboratory assistant, I decided in 2000 to advance myself and to study Public Health. If someone had told me at that time, that I will defend my PhD thesis one day, I would not have believed this. However, here I am and this would not have been possible without the continuous and wholehearted support of Professor Dr. Helmut Brand.

After a voluntary internship at the public health institute in North Rhine-Westphalia in 2006, Helmut, as director of this institute, was the one who offered me my first job as public health graduate in one of my aspired working fields: public health surveillance. Due to his efforts, I got in touch with European public health in general and EU-level public health surveillance in particular - the topics, which are now also the very basis of my dissertation. After Helmut's change to Maastricht University, he gave me the opportunity to start a PhD trajectory. Helmut, I cannot express how thankful I am in terms of trust, tremendous support and freedom you gave me throughout the years. Thank you for helping me grow.

As long as I know Helmut, I also work together with Dr. Kai Michelsen, my co-supervisor. Kai, as political scientist, added new perspectives to my research and challenged me to rethink my work. Thank you Kai, for your support and your critical reading. It was a pleasure working with you.

My PhD trajectory was not dedicated to one single research project. I cooperated with many great people who receive my sincerest thanks. First, I would like to thank my supervisors of my first epidemiological study based: Professor Dr. Martien van Dongen, Dr. Wolfgang Hellmeier, Klaus Simon, and Professor Dr. Pieter Dagnelie. I definitely enjoyed and appreciated your supervision and support as well as your patience during the publication process.

I am pleased that I had the possibility to be part of the SIDARTHa group and to work on syndromic surveillance. I would like to thank the project coordinators Dr. Alexandra Ziemann and Professor Dr. Thomas Kraft as well as the project members. Special thanks go to Professor Dr. Luis GarciaCastrillo Riesgo, Gernot Vergeiner and Professor Dr. Jean-Bernard Gillet. Due to your support, I had the possibility to work with emergency medical care data and to understand the characteristics of this particular data source. You gave me a warm welcome and great support as rookie in this field - thank you for that.

The support of Helmut and all colleagues at the Department of International Health at Maastricht University enabled me to conduct the study on the achievements, missed opportunities and failures of EU public health actions. I would particular like to thank Dr. Kristine Sørensen and Timo Clemens for their cooperation. We invested a lot of time to discuss the study set-up and the analytical approach, to interview the identified experts and to make sense out of the interview results. Kristine and Timo, thank you very much for this great teamwork effort. 
Dr. Marja van Bon-Martens, Dr. Peter Achterberg and Professor Dr. Hans van Oers gave the inspiration for the study on the key features of an EU health information system. It was extremely inspiring to experience the sincere interest of the group in advancing public health surveillance in Europe. I am grateful that I had the chance to cooperate with you in this project.

I am also grateful for the more personal experiences that I made during my PhD trajectory and the process-related support that I experienced in Maastricht. Alexandra, Kristine, Bea Scholtens, Timo, and Christoph Aluttis receive a thunderous applause. It was wonderful having you as PhD fellows and being part of such a strong PhD group. Special thanks also go to Kristine and Daniela Popa with whom I shared the office in Maastricht. Thank you for the laughs we had and the tears we shared. It was brilliant and definitely important for my personal development to be amongst you. Finally again Alexandra: oh my God, I cannot imagine how this whole process would have been without you as colleague, roommate and friend. You are one of the best listener and advice giver I know. Talking to you on whatever topic always helped me to remove the fog in my brain. All of the research that I present in this dissertation became clearer by these discussions. You also provided me such a fantastic part-time home in Maastricht. I had the best what life could offer: Four times per week with my partner Michael at home in Bünde and three days per week together with you as close friend in Maastricht - I am really looking forward to the years to come with you as a friend.

I am also so thankful for the support that I experienced outside the research projects and the Maastricht environment. A big thank you goes to all my friends at home and my colleagues at the NRW Centre for Health in Bielefeld. The whole PhD process was longer than expected and all of you were always patient and supportive. This is especially true for Evi Buschlinger who supported me in creating the layout of this thesis. I would also particular like to thank my close friend Hille Kajüter who triggered me end of the 1990s to study public health. Thank you for being my forerunner, best friend and paranymph.

Of course, I would not be where I am today, without the foundations laid by my parents: deep trust in life, the conviction that everything is going to be alright, and a great openness for the various possibilities that life offers. Thank you for this basis and for always being there for me.

To my partner Michael I owe the most sincere thanks. Thank you for your love, patience and for being my pillar of strength - xoxo. 
184 Acknowledgements 


\section{A "Song" is Worth a Thousand Words}

A brief summary of my life during the PhD trajectory and a big thank you to my family and my fellows!

For Helmut

Jazzkantine Ode an die Freude

The joy and the difficulties in doing a PhD

The Black Eyed Peas Let's Get it Started

Placebo Devil in the Details

Janne Schra Carry on

Olli Schulz Wenn es gut ist

There is more to life than that...

The Overtones The Bare Necessities

For the possibility to continue as external PhD

Ásegeir Going Home [52 $\left.11^{\prime} 53.6^{\prime \prime} \mathrm{N} 8^{\circ} 34^{\prime} 59.64^{\prime \prime} \mathrm{E}\right]$

For my friends and colleagues, my parents, and my brother

Queen $\quad$ Friends will be friends

Boy Army

The Beatles All You Need is Love

Rosi Tanzen

For Michael

Bruce Springsteen If I Should Fall Behind

Done!

Frank Turner Four Simple Words

Smith \& Burrows Wonderful Life 



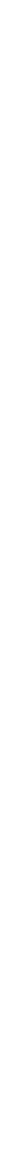




\section{Curriculum Vitae}

Nicole Rosenkötter was born in June 1975 in Germany. She grew up in the German town Bünde in North Rhine-Westphalia. After she finished secondary school in 1991 she started a vocational training in Osnabrück to become a medical laboratory assistant. In 1993 she started to work in a laboratory in Bremen and continued in different laboratories in Hamburg. In 1999 she decided to visit a specialized secondary school in Hamburg to qualify for studying Public Health at the Hamburg University of Applied Sciences. The study programme started in 2000 and she graduated in 2005 with a diploma in public health (Diplom Gesundheitswirtin (FH)). In her thesis Nicole focussed on the surveillance of Methicillin resistant Staphylococcus aureus (MRSA) in a German hospital.

Thereafter she moved from Hamburg back to Bünde and started to gather work experience at the Institute of Public Health in North Rhine-Westphalia, Germany (Bielefeld, lögd, now NRW Centre for Health (LZG.NRW)). She worked as a research assistant in several European Union co-funded projects. The projects were mainly focussed on national and regional level public health surveillance in European Union member states (ECHI, ECHIM, I2SARE). In addition to her work at the North Rhine-Westphalian Institute of Public Health, Nicole started in 2008 to study the Master programme Public Health (Epidemiology) at Maastricht University in the Netherlands. She graduated in 2010, with her Master's thesis on inequalities in health care utilisation of pre-school children in North Rhine-Westphalia.

In 2010, Nicole changed her job and moved from the Institute of Public Health in Bielefeld, Germany to the Department of International Health at Maastricht University to become a PhD fellow of the CAPHRI Research School. Her PhD research concentrated on policy, data and infrastructure aspects of public health surveillance, mainly with a European Union context. Furthermore, Nicole taught within the Bachelor and Master programme of European Public Health at Maastricht University. She gave lectures on public health surveillance, was tutor within several modules, and guided Bachelor and Master students during the writing process of their thesis. Since autumn 2013 Nicole continued her PhD research as external PhD fellow because she was appointed as research associate at the NRW Centre for Public Health, Bielefeld, Germany. At the NRW Centre for Public Health Nicole works on regional population health monitoring and reporting.

In 2014, Nicole was elected as president of the European Public Health Association (EUPHA) section on Public Health Monitoring and Reporting. In this context, Nicole also represents EUPHA at the European Health Information Initiative of the World Health Organization Regional Office for Europe. 


\section{List of publications related to this dissertation and to public health surveillance}

Borrmann B, Rosenkötter N. Integrierte Berichterstattung für ressortübergreifende kommunale Gesundheitspolitik. Public Health Forum 2016, 24(4):272-274.

Rosenkötter N, Annuß R, Borrmann B, Mekel O. Regional population health monitoring at the North Rhine-Westphalia Institute for Health, Germany. Public Health Panorama 2016, 2(3):388393.

Rosenkötter N, Achterberg PW, van4 Bon-Martens MJH, Michelsen K, van Oers HAM, Brand H. Key features of an EU health information system - a concept mapping study. European Journal of Public Health 2016, 26(1):65-70.

Rosenkötter N, van Bon-Martens MJH. Public Health Monitoring and Reporting: Maintaining and Improving the Evidence-Base. Eurohealth 2015. 21(1):17-20.

Ziemann A, Rosenkötter N, Garcia-Castrillo Riesgo L, Fischer M, Krämer A, Lippert FK, Vergeiner G, Brand H, Krafft T. Meeting the International Health Regulations (2005) surveillance core capacity requirements at the subnational level in Europe: the added value of syndromic surveillance. BMC Public Health 2015. 15(1):107.

Borrmann B, Rosenkötter N. Steuerungspotentiale des ÖGD - Gesundheitsberichterstattung. Public Health Forum 2014. 22(4):11-13.

Rosenkötter N, Ziemann A, Krafft T, Riesgo LG, Vergeiner G, Brand H. Non-infectious events under the International Health Regulations (2005) in Europe - a case for syndromic surveillance. J Public Health Policy 2014. 35(3):311-326.

Rosenkötter N, Brand H, McKee M, Riley N, Verma A, Verschuuren M. The realisation of a European health information system--time to get the politicians involved. Eur J Public Health 2014. 24(2):184-185.

Ziemann A, Rosenkötter N, Garcia-Castrillo Riesgo L, Schrell S, Kauhl B, Vergeiner G, Fischer M, Lippert FK, Krämer A, Brand H, Krafft T. A concept for routine emergency-care data-based syndromic surveillance in Europe. Epidemiol Infect. 2014. 24:1-14.

Sørensen K, Clemens T, Rosenkötter N. The EU's heath mandate after 20 years: the glass is half full. Eur J Public Health 2013.23(6):906-7.

Rosenkötter N, Clemens T, Sørensen K, Brand H. Twentieth anniversary of the European Union health mandate: taking stock of perceived achievements, failures and missed opportunities - a qualitative study. BMC Public Health 2013; 13(1):1074. 
Brand $\mathrm{H}$, Rosenkötter N, Clemens T, Michelsen K. Austerity policies in Europe - bad for health. Health protection within the EU mandate is more relevant than ever. BMJ 2013. 346:f3716.

Schrell S, Ziemann A, Garcia-Castrillo Riesgo L, Rosenkötter N, Llorca J, Popa D, Krafft T, on Behalf of the SIDARTHa Project Consortium. Local implementation of a syndromic influenza surveillance system using emergency department data in Santander, Spain. Journal of Public Health 2013. 35(3):397-403.

Rosenkötter N, van Dongen MCJM, Hellmeier W, Simon K, Dagnelie P. The influence of migratory background and parental education on health care utilisation of children. European Journal of Pediatrics 2012. 171(10):1533-1540.

Ziemann A, Krafft T, Rosenkötter N, Garcia-Castrillo Riesgo L, Vergeiner G, Fischer M, Lippert F, Krämer A, Pinheiro P, Brand H, Rosenberg M, Overton J. Syndromic Surveillance: Enhancing Public Health Responsiveness to Global Change - A European Perspective. IHDP Update 2011.1:12-18.

Rosenkötter N, Vondeling H, Blancquaert I, Kristensen FB, Mekel OCL, Brand A. The contribution of health technology assessment, health needs assessment, and health impact assessment to the assessment and translation of technologies in the field of public health genomics. Public Health Genomics Journal 2011.14(1):43-52.

Simon K, Rosenkötter N. Adipositas bei Einschülern in NRW- tatsächliche Stagnation des Anteils adipöser Kinder oder Fehlinterpretation? Bundesgesundheitsblatt, Gesundheitsforschung, Gesundheitsschutz 2010.53(2):258-264.

Schröter M, Alpers K, van Treeck U, Frank C, Rosenkötter N, Schaumann R. Outbreak of wound botulism among injecting drug users. Epidemiology and Infection 2009.137:1602-1608.

Mellmann A, Friedrich AW, Rosenkötter N, Rothgänger J, Karch H, Reintjes R, Harmsen D. Automated DNA sequence-based early warning system for the detection of methicillin-resistant Staphylococcus aureus outbreaks. PLoS Medicine 2006. 3(3):e33.

Book chapters

Rosenkötter N, Reintjes R. Frühwarnsysteme. In: Reintjes R, Klein S (Editors):

Gesundheitsberichterstattung und Surveillance. Messen, entscheiden und handeln. Huber 2006, Bern, page 124-132 



ISBN 978-3-00-055311-0
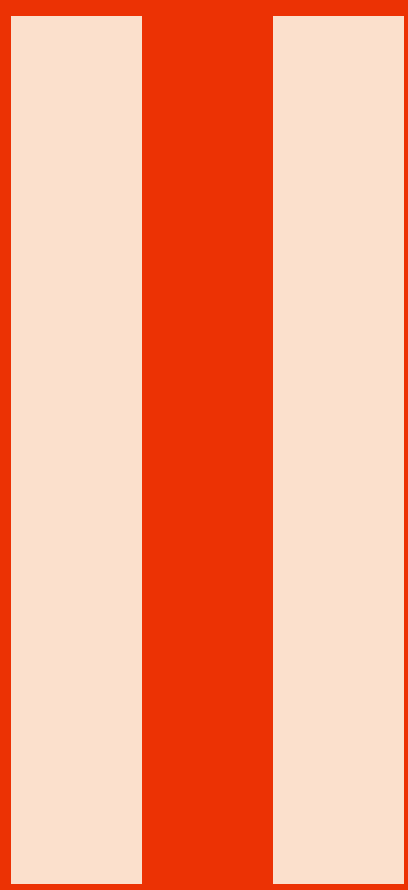